\title{
CFD SIMULATIONS TO IMPROVE AIR DISTRIBUTION INSIDE COLD CLIMATE BROILER HOUSES INVOLVING HEAT EXCHANGERS
}

by

Frédéric COULOMBE

\author{
MANUSCRIPT-BASED THESIS PRESENTED TO ÉCOLE DE \\ TECHNOLOGIE SUPÉRIEURE IN PARTIAL FULFILMENT FOR A \\ MASTER'S DEGREE WITH THESIS IN ENGINEERING, \\ CONCENTRATION IN RENEWABLE ENERGY AND ENERGY \\ EFFICIENCY \\ M.A.Sc.
}

MONTREAL, SEPTEMBER 20, 2018

ÉCOLE DE TECHNOLOGIE SUPÉRIEURE UNIVERSITÉ DU QUÉBEC 


\section{(9) $(\mathcal{Q} \Theta \Theta$}

This Creative Commons license allows readers to download this work and share it with others as long as the author is credited. The content of this work can't be modified in any way or used commercially. 


\section{BOARD OF EXAMINERS}

THIS THESIS HAS BEEN EVALUATED

BY THE FOLLOWING BOARD OF EXAMINERS

Mr. Daniel Rousse, Thesis Supervisor

Département de génie mécanique at École de technologie supérieure

Mr. Mathias Glaus, President of the Board of Examiners

Département de génie de la construction at École de technologie supérieure

Mr. Louis Lamarche, Member of the jury

Département de génie mécanique at École de technologie supérieure

THIS THESIS WAS PRESENTED AND DEFENDED

IN THE PRESENCE OF A BOARD OF EXAMINERS AND PUBLIC

AUGUST $22^{\mathrm{TH}} 2018$

AT ÉCOLE DE TECHNOLOGIE SUPÉRIEURE 



\section{ACKNOWLEDGMENT}

First, I would like to thank Daniel R. Rousse, my supervisor, who allowed me to work on this great project, with a high level of liberty. My desire to learn and work with OpenFOAM extended the duration of my master, and I am quite grateful for his patience to support me through the end. I would also like to thank M. Michel Trottier, for his generous financial support of the $\mathrm{t} 3 \mathrm{e}$ research group. Our activities would not be possible without him.

Thank you as well to Pierre-Luc Paradis, my fellow student and friend, who helped me throughout this project, with his many suggestions and infinite energy. Thank you also to all students of the $\mathrm{t} 3 \mathrm{e}$ research group, past and present, for the good times we shared. Thank you to Michel Drouin, Christian Masson and Jörn Nathan. Thank you to the jury members for their participation in the evaluation of my work. You all have busy schedules, and I appreciate you giving me some of your time. Also, I would like to give a hug to family and friends who maintained an interest in my project and asked for the latest news. It sustained the belief that my work was meaningful, worth my time and efforts.

Strangely enough, I would like to thank all the people involved in the open-source products that I used, namely: OpenFOAM, ParaView, Salome, Arduino, Linux Mint, Gnuplot, Eagle CAD, Processing IDE, LibreOffice, GNU Octave and gmsh. Those free tools empower us as a species, much like numbers and language. What would it be like if we had to pay each time we use the alphabet? I believe more knowledge and tools must be transferred to the public domain if we are to survive the challenges ahead.

Finally, a very special thanks to my mother, France Poisson. Although she took her life in the first month of this project, she remains the largest contributor. When I was a child, she gave

me the most nourishing environment, one of trust, curiosity and patience, a world full of books and wonders. Thank you for your love. Thank you for making me who I am. 



\title{
SIMULATIONS CFD POUR AMÉLIORER LA DISTRIUTION D'AIR DANS LES POULAILLERS EN CLIMAT FROID AVEC ÉCHANGEURS DE CHALEUR
}

\author{
Frédéric COULOMBE
}

\section{RÉSUMÉ}

Bien que la viande de poulet soit moins polluante que d'autres viandes, les émissions de GES associées à ce type d'élevage demeurent problématiques si l'on considère l'objectif 2050 qui est de 1 tonne $\mathrm{CO}_{2}$-eq par capita. Dans le cas du poulet de chair, la majorité des émissions sont associées à la production de la moulée, mais la production en climat froid requiert un apport énergétique additionnel pour le chauffage de l'espace. Cet apport est généralement fourni par du gaz propane. Depuis 2014, le secteur aviaire a un intérêt accru pour l'efficacité énergétique en raison des fluctuations du prix de l'énergie. La récupération de chaleur peut réduire significativement les besoins en chauffage, en préchauffant l'air frais avec le flux sortant d'air vicié.

De nombreuses études ont porté sur l'amélioration de la ventilation directe des poulaillers, en climat chaud ou froid. Peu d'attention cependant a été accordée aux échangeurs de chaleur en milieu avicole. La littérature actuelle ne permet pas de positionner efficacement cet équipement dans un parquet d'élevage de manière à assurer des conditions environnementales homogènes (température de l'air, humidité, contaminants).

Ce mémoire étudie l'intégration d'échangeurs de chaleur dans un poulailler commercial situé en climat nordique (Sainte-Mélanie, Canada). L'objectif est d'améliorer les conditions environnementales dans ce poulailler rectangulaire de $800 \mathrm{~m}^{2}$ équipé de deux échangeurs de chaleurs air-air, sans réseau de conduites pour la distribution de l'air frais. Le logiciel de mécanique des fluides OpenFOAM a permis de créer une simulation $3 \mathrm{D}$ en régime permanent utilisant le modèle de turbulence RNG et tenant compte des effets de flottabilité. Le modèle CFD fut validé par des données expérimentales collectées au poulailler du partenaire de projet.

Dans la configuration originale $(\mathrm{C} 0)$, les deux échangeurs sont positionnés parallèlement sur le même mur longitudinal du bâtiment. Trois configurations alternative $(\mathrm{C} 1, \mathrm{C} 2$, et $\mathrm{C} 3)$ furent étudiées pour tenter d'améliorer les conditions environnementales à la hauteur des poussins $(0.1 \mathrm{~m}): \mathrm{C} 1$ consiste à augmenter la distance entre les deux échangeurs, $\mathrm{C} 2$ consiste à pivoter chaque échangeur de $30^{\circ}, \mathrm{C} 3$ consiste à positionner un échangeur sur chaque mur de bout. La vitesse, la température et l'âge de l'air furent utilisées comme critères de performance. 
VIII

Chaque configuration se comporte et performe différemment. La configuration avec la meilleure performance globale est C2 . C2 montre une amélioration de 45\% de la distribution de l'âge de l'air et une amélioration de $24 \%$ de la distribution de la vitesse. La distribution de température à l'extérieur des zones de chauffage est elle aussi améliorée, mais cela n'est pas reflétée par le coefficient de variation globale pour la température.

Mots-clés : âge de 1'air, CFD, échangeur de chaleur, OpenFOAM, poulailler 


\title{
CFD SIMULATIONS TO IMPROVE AIR DISTRIBUTION INSIDE COLD CLIMATE BROILER HOUSES INVOLVING HEAT EXCHANGERS
}

\author{
Frédéric COULOMBE
}

\begin{abstract}
While chicken meat production is less polluting than other meats, it remains a problem, given a target of 1 ton $\mathrm{CO}_{2}$-eq per capita in 2050. Most of the emissions are associated with feed production, but cold climate requires an additional energy input for space heating. This input is usually provided by propane gas. Since 2014, energy efficiency has sparked in the world of broiler production. Heat recuperation through heat exchanger can reduce significantly the heating requirement, by preheating fresh air inlet with stale air outlet.

While there have been many studies on the improvement of direct ventilation in both hot and cold climate, little attention has been given to heat exchangers in broiler houses. It is therefore unknown how best to integrate this equipment in a broiler house to provide homogenous housing conditions (air temperature, humidity, contaminants).

This thesis studies the integration of heat exchangers (HX) in a commercial broiler house located in a cold climate (Sainte-Mélanie, Canada). The goal is to improve the housing conditions of a rectangular $1760 \mathrm{~m}^{3}$ broiler house equipped with two ductless air-to-air heat exchangers $\left(0.38 \mathrm{~m}^{3} \mathrm{~s}^{-1}\right)$. Computational fluid dynamics (CFD) software OpenFOAM was used to create a 3D steady-state buoyant simulation with RNG $k$ - $\varepsilon$ turbulence model. CFD model was validated with experimental data collected at the participating broiler house. In the original configuration $(\mathrm{C} 0)$, the two heat exchangers are parallel, on the same longitudinal wall. Three alternative configurations $(\mathrm{C} 1, \mathrm{C} 2$, and $\mathrm{C} 3)$ were studied to improve housing conditions at chick height $(0.1 \mathrm{~m})$ : $\mathrm{C} 1$ consists of increasing the distance between the $\mathrm{HX}, \mathrm{C} 1$ consists of a $30^{\circ}$ rotation of the $\mathrm{HX}$, and $\mathrm{C} 3$ consists of positioning one $\mathrm{HX}$ on each end wall. Air velocity, air temperature and age of air were used as performance criteria.
\end{abstract}

All configurations behaved and performed differently. The configuration with the best overall performance was C2. It showed a $45 \%$ improvement in age of air distribution and $24 \%$ in velocity distribution. Temperature distribution also improved, but it was not reflected in the coefficient of variation.

Keywords: age of air, broiler house, CFD, heat exchanger, OpenFOAM 



\section{TABLE OF CONTENTS}

INTRODUCTION

\section{.1}

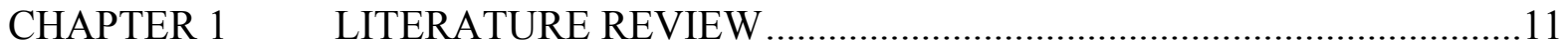

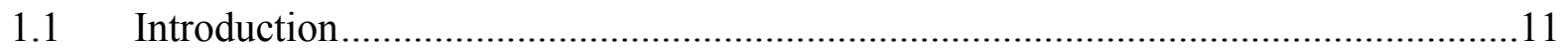

1.2 Overview of housing conditions for broiler production ........................................11

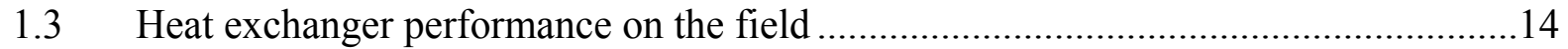

$1.4 \quad$ Overview of poultry ventilation numerical studies..............................................14

CHAPTER 2 CFD SIMULATION TO IMPROVE HEAT EXCHANGER PERFORMANCE INSIDE A COLD CLIMATE BROILER HOUSE ...19

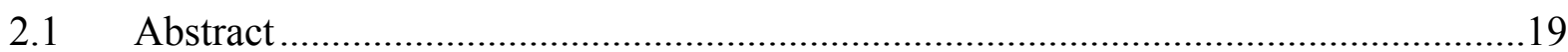

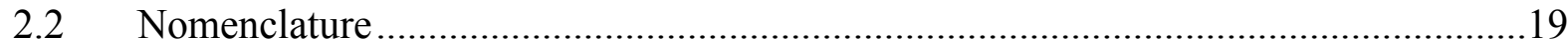

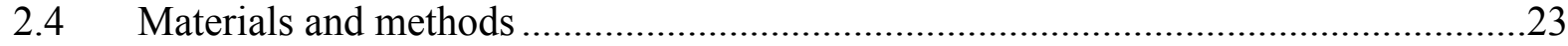

2.4.1 Description of the broiler house.......................................................... 23

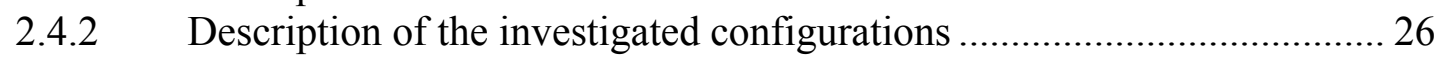

2.4.3 Numerical method............................................................................ 27

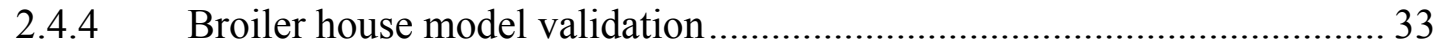

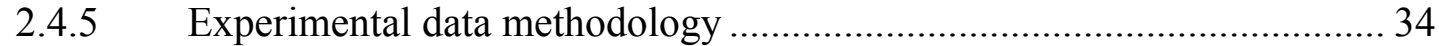

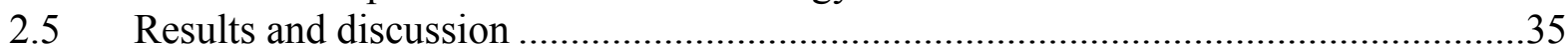

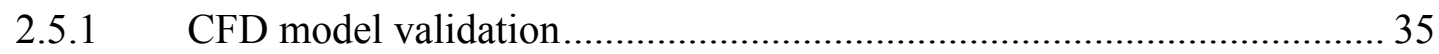

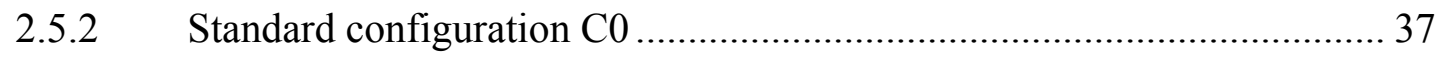

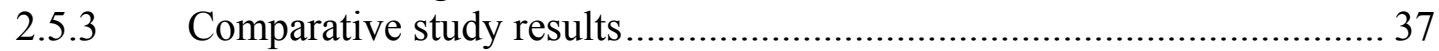

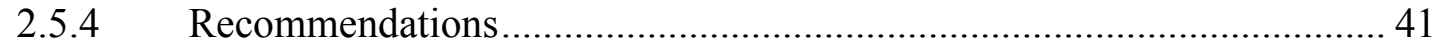

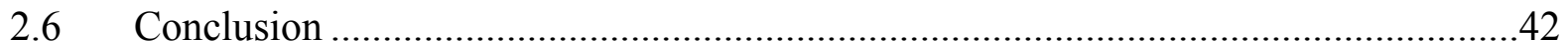

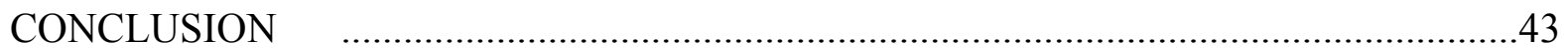

APPENDIX I OPENFOAM SOLVER VALIDATION CASE .................................45

APPENDIX II $\quad$ OPENFOAM BROILER ROOM SIMULATION DESIGN ..................53

APPENDIX III $\quad$ EXPERIMENTAL APPARATUS DESIGN .....................................69

APPENDIX IV TEMPERATURE MEASUREMENT ACCURACY ..........................85

APPENDIX V EXPERIMENTAL APPARATUS ARDUINO CODE.........................89

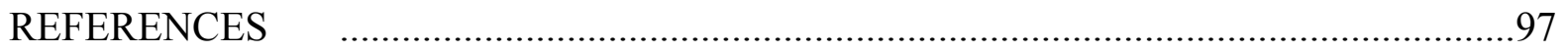





\section{LIST OF TABLES}

Page

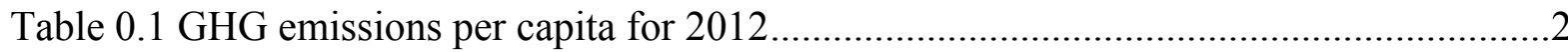

Table 0.2 Main GHG emissions sources in Quebec as a percentage of total emissions, 2014 data

Table 1.1 A selection of numerical studies dedicated to broiler house ventilation ................15

Table 2.1 A selection of numerical studies dedicated to broiler house ventilation ................22

Table 2.2 Main CFD inputs for all simulations .........................................................28

Table 2.3 Thermal conditions of the numerical model for standard configuration $\mathrm{C} 0$...........31

Table 2.4 Heat transfer distribution of a radiant propane heater operating at

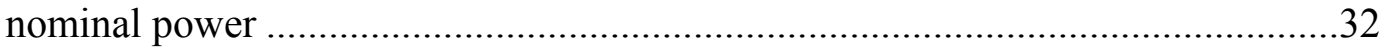

Table 2.5 Numerical model thermal conditions for validation simulation ...........................34

Table 2.6 Heaters parameter values for validation simulation .........................................34

Table 2.7 Performance data of ventilation configurations at bird height $(z=0.1 \mathrm{~m}) \ldots \ldots \ldots \ldots . . .38$ 



\section{LIST OF FIGURES}

Page

Figure 0.1 Breakdown of total global GHG emissions by category for chicken meat and egg layers. Source: (MacLeod et al., 2013) .... .5

Figure 2.1 Top view of the broiler house in standard configuration, with HX, heaters ..........24

Figure 2.2 a) View of the broiler house studied b) A typical radiant propane heater.............24

Figure 2.3 Counter-flow air-to-air HX unit installed in a broiler house ...............................25

Figure 2.4 Schematic representation of the HX unit....................................................25

Figure 2.5 Top view of the standard and alternative ventilation configurations, $\mathrm{C} 0$ to $\mathrm{C} 3$,

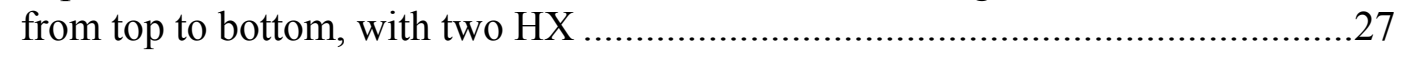

Figure 2.6 Room air inlet (blue) and outlet (brown) on HX (pink) against the exterior

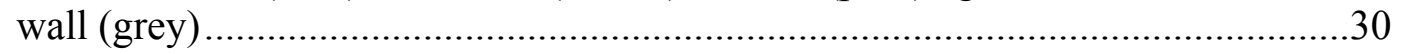

Figure 2.7 Cut view of the mesh for the standard configuration $\mathrm{C} 0$, vis-à-vis the

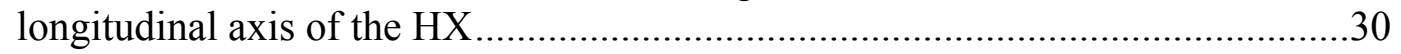

Figure 2.8 Schematic of propane heater modes of heat transfer..........................................32

Figure 2.9 Top view of the second broiler house with measurement locations and

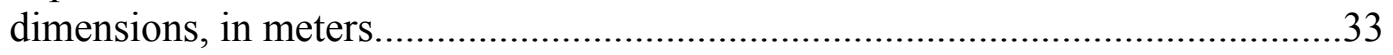

Figure 2.10 Air velocities at 44 positions inside the broiler house, experimental versus numerical results.

Figure 2.11 Air temperature at 77 positions inside the broiler house, experimental versus numerical results

Figure 2.12 Velocity magnitude $\left[\mathrm{m} \mathrm{s}^{-1}\right]$ distribution at $y z$ plane $x=25.4 \mathrm{~m}$ for the standard configuration $\mathrm{C} 0$.

Figure 2.13 Comparative study results with a top view of relevant fields at bird height $(z=0.1 \mathrm{~m})$ 



\section{LIST OF ABBREVIATIONS}

\begin{tabular}{|c|c|}
\hline AoA & age of air \\
\hline $\mathrm{ACH}$ & air changes per hour \\
\hline $\mathrm{ADC}$ & analog-to-digital converter \\
\hline ANOVA & analysis of variance \\
\hline $\mathrm{BC}$ & boundary condition \\
\hline BSF & buoyantSimpleFoam \\
\hline CFD & computational fluid dynamics \\
\hline $\mathrm{CH}_{4}$ & methane \\
\hline $\mathrm{CO}_{2}$ & carbon dioxide \\
\hline $\mathrm{CO}_{2}$-eq & equivalent to carbon dioxide \\
\hline $\mathrm{CoV}$ & coefficient of variation \\
\hline FCR & feed conversion ratio \\
\hline FVM & finite volume method \\
\hline GHG & greenhouse gas \\
\hline $\mathrm{HHV}$ & high heating value \\
\hline $\mathrm{HX}$ & heat exchanger \\
\hline $\mathrm{IC}$ & integrated circuit \\
\hline ITV & index of temperature and velocity \\
\hline LUC & land-use change \\
\hline MUX & multiplexer \\
\hline NDIR & non-dispersive infrared \\
\hline
\end{tabular}


XVIII

$\begin{array}{ll}\mathrm{NH}_{3} & \text { ammonia } \\ \mathrm{N}_{2} \mathrm{O} & \text { nitrous oxide } \\ \mathrm{NPN} & \text { negative-positive-negative transistor } \\ \mathrm{NPT} & \text { national pipe tapered } \\ \mathrm{PIV} & \text { particle image velocimetry } \\ \text { RANS } & \text { Reynolds-averaged Navier-Stokes } \\ \text { RH } & \text { relative humidity } \\ \text { RNG } & \text { re-normalization group } \\ \text { RTD } & \text { resistance temperature device } \\ \text { SIMPLE } & \text { semi-implicit method for pressure-linked equations } \\ \text { stl } & \text { stereolithography } \\ \text { TTL } & \text { transistor-to-transistor logic } \\ \text { UART } & \text { universal-asynchronous receiver-transmitter }\end{array}$




\section{LIST OF SYMBOLS}

\begin{tabular}{|c|c|}
\hline$\nabla$ & gradient operator \\
\hline$\nabla$ & divergence operator \\
\hline$a_{p}$ & discretization coefficient \\
\hline$A$ & surface area, $\left[\mathrm{m}^{2}\right]$ \\
\hline $\mathrm{Ar}$ & Archimedes number \\
\hline$b$ & linear system constant term \\
\hline$c_{v}$ & specific heat at constant volume, $\left[\mathrm{kJ} \mathrm{kg}^{-1} \mathrm{~K}^{-1}\right]$ \\
\hline$C_{\mu}$ & k-epsilon model coefficient \\
\hline $\mathrm{CoV}$ & temperature coefficient of variation, [-] \\
\hline$D_{h}$ & hydraulic diameter, $[\mathrm{m}]$ \\
\hline$e$ & internal energy, $\left[\mathrm{kJ} \mathrm{kg}^{-1}\right]$ \\
\hline$g$ & gravitational acceleration, $\left[\mathrm{m} \mathrm{s}^{-2}\right]$ \\
\hline$h$ & specific enthalpy, $\left[\mathrm{kJ} \mathrm{kg}^{-1}\right]$ \\
\hline$h$ & height, $[\mathrm{m}]$ \\
\hline$H$ & height, $[\mathrm{m}]$ \\
\hline$I$ & identity matrix \\
\hline$k$ & turbulent kinetic energy, $\left[\mathrm{m}^{2} \mathrm{~s}^{-2}\right]$ \\
\hline$k$ & thermal conductivity, $\left[\mathrm{W} \mathrm{m} \mathrm{m}^{-1} \mathrm{k}^{-1}\right]$ \\
\hline$K$ & kinetic energy per mass unit, $\left[\mathrm{kJ} \mathrm{kg}^{-1}\right]$ \\
\hline$L$ & length, $[\mathrm{m}]$ \\
\hline$p$ & static pressure, $\left[\mathrm{kg} \mathrm{m}^{-1} \mathrm{~s}^{-2}\right]$ \\
\hline$p_{r g h}$ & modified pressure, $\left[\mathrm{m}^{2} \mathrm{~s}^{-2}\right]$ \\
\hline
\end{tabular}




\begin{tabular}{|c|c|}
\hline$P$ & power, [W] \\
\hline $\operatorname{Pr}$ & Prandtl number \\
\hline $\operatorname{Pr}_{t}$ & turbulent Prandtl number \\
\hline$q$ & specific heat flow, $\left[\mathrm{W} \mathrm{m}^{-2}\right]$ \\
\hline$Q$ & heat flow, $[\mathrm{W}]$ \\
\hline$R$ & electrical resistance, $[\Omega]$ \\
\hline$R$ & universal gas constant, $\left[\mathrm{m}^{2} \mathrm{~kg} \mathrm{~s}^{-2} \mathrm{~K}^{-1} \mathrm{~mol}^{-1}\right]$ \\
\hline $\operatorname{Re}$ & Reynolds number \\
\hline$S$ & source term \\
\hline$T$ & temperature, $[\mathrm{K}]$ \\
\hline$T_{0}$ & initial temperature, $[\mathrm{K}]$ \\
\hline$T_{\text {in }}$ & inlet temperature, $[\mathrm{K}]$ \\
\hline$T_{\text {out }}$ & outlet temperature, $[\mathrm{K}]$ \\
\hline$T I$ & turbulent intensity, [\%] \\
\hline$u^{*}, v^{*}, w^{*}$ & intermediate velocity field, $\left[\mathrm{m} \mathrm{s}^{-1}\right]$ \\
\hline$u^{\prime}, v^{\prime}, w^{\prime}$ & fluctuating velocity component $\left[\mathrm{m} \mathrm{s}^{-1}\right]$ \\
\hline$u_{t}$ & friction velocity, $\left[\mathrm{m} \mathrm{s}^{-1}\right]$ \\
\hline$U$ & velocity, $\left[\mathrm{m} \mathrm{s}^{-1}\right]$ \\
\hline$\vec{U}$ & velocity vector, $\left[\mathrm{m} \mathrm{s}^{-1}\right]$ \\
\hline$U_{0}$ & initial velocity, $\left[\mathrm{m} \mathrm{s}^{-1}\right]$ \\
\hline$U_{\text {avg }}$ & average velocity, $\left[\mathrm{m} \mathrm{s}^{-1}\right]$ \\
\hline$U_{\max }$ & maximum velocity, $\left[\mathrm{m} \mathrm{s}^{-1}\right]$ \\
\hline
\end{tabular}




$\begin{array}{ll}U_{\min } & \text { minimum velocity, }\left[\mathrm{m} \mathrm{s}^{-1}\right] \\ \overrightarrow{U^{T}} & \text { transpose of velocity vector } \\ V & \text { volume, }\left[\mathrm{m}^{3}\right] \\ V & \text { voltage, [V] } \\ V, & \text { volume flow, }\left[\mathrm{m}^{3} \mathrm{~s}^{-1}\right] \\ \dot{V} & \text { volumetric flow, }\left[\mathrm{m}^{3} \mathrm{~s}^{-1}\right] \\ V_{0} & \text { reference voltage, }[\mathrm{V}] \\ V_{c c} & \text { voltage supply, [V] } \\ x, y, z & \text { spatial coordinates } \\ y & \text { distance wall to first cell center [m] } \\ y^{+} & \text {dimensionless wall distance } \\ W & \text { width [m] }\end{array}$

Greek letters

$\alpha$

under-relaxation factor

$\begin{array}{ll}\alpha_{e f f} & \text { effective thermal diffusivity }\left[\mathrm{kg} \mathrm{m}^{-1} \mathrm{~s}^{-1}\right] \\ \alpha & \text { molecular thermal diffusivity }\left[\mathrm{kg} \mathrm{m}^{-1} \mathrm{~s}^{-1}\right] \\ \alpha_{t} & \text { turbulent thermal diffusivity }\left[\mathrm{kg} \mathrm{m}^{-1} \mathrm{~s}^{-1}\right] \\ \alpha_{k} & \text { thermal diffusivity }\left[\mathrm{kg} \mathrm{m}^{-1} \mathrm{~s}^{-1}\right] \\ \beta & \text { thermal expansion coefficient }\left[\mathrm{K}^{-1}\right] \\ \Delta & \text { Laplacian operator } \\ \Delta \mathrm{T} & \text { temperature difference }[\mathrm{K}] \\ \Delta \mathrm{T}_{0} & \text { initial temperature difference }[\mathrm{K}]\end{array}$


$\varepsilon$

$\mu$

$\mu_{\text {eff }}$

$\mu_{t}$

$v$

$v_{t}$

$v_{e f f}$

$\bar{\mu}$

$\rho$

$\sigma$ turbulence dissipation rate $\left[\mathrm{m}^{2} \mathrm{~s}^{-3}\right]$

dynamic viscosity $\left[\mathrm{kg} \mathrm{m}^{-1} \mathrm{~s}^{-1}\right]$

effective dynamic viscosity $\left[\mathrm{kg} \mathrm{m}^{-1} \mathrm{~s}^{-1}\right]$

turbulent viscosity $\left[\mathrm{m}^{2} \mathrm{~s}^{-1}\right]$

kinematic viscosity $\left[\mathrm{m}^{2} \mathrm{~s}^{-1}\right]$

turbulent viscosity $\left[\mathrm{m}^{2} \mathrm{~s}^{-1}\right]$

effective viscosity $\left[\mathrm{m}^{2} \mathrm{~s}^{-1}\right]$

sample mean

density $\left[\mathrm{kg} \mathrm{m}^{-3}\right]$

standard deviation 


\section{INTRODUCTION}

\subsection{Context}

\subsubsection{Global warming}

Global warming is the process by which the Earth's average surface temperature is rapidly increasing, mostly because of anthropogenic emissions of greenhouse gases (GHG), such as carbon dioxide $\left(\mathrm{CO}_{2}\right)$, methane $\left(\mathrm{CH}_{4}\right)$ and nitrous oxide $\left(\mathrm{N}_{2} \mathrm{O}\right)$. In 2016, the average global annual temperature was $0.94^{\circ} \mathrm{C}$ above that of the $20^{\text {th }}$ century average, which was of $13.9^{\circ} \mathrm{C}$ (NOAA, 2017). Most of the severe consequences, however, remain to be seen. An increase of $2^{\circ} \mathrm{C}$ of the global mean temperature is commonly considered to be the limit below which, most of the severe consequences could be avoided. It is now very likely that this $2{ }^{\circ} \mathrm{C}$ threshold will be exceeded (Baer \& Mastrandrea, 2006).

\subsubsection{GHG emissions}

In terms of GHG emissions, a big gap remains between actions taken and actions needed, as evidenced by data reported in Table 0.1 . Although this data is a few years old due to the time required to collect it, this table highlights the importance of non-fuel related emissions. Reports only taking into account fuel-related emissions understate the level of pollution of all regions by 20 to $60 \%$. The values reported in Table 0.1 should be compared to a target of 1 ton of $\mathrm{CO}_{2}$-eq per capita. This target is the annual maximum that must be reached by 2050 to attain low probabilities (9-26\%) of exceeding the $2{ }^{\circ} \mathrm{C}$ limit. This corresponds to a $4 \%$ annual average of global reduction of emissions, starting back in 2007 (Baer \& Mastrandrea, 2006). All regions are from 4 to 23 times above the target and have a lot of work ahead of

them. Canada has an especially high level of emissions per capita (i.e. 23.3 tons $\mathrm{CO}_{2-}$ eq/capita. 
Table 0.1 GHG emissions per capita for 2012

\begin{tabular}{|c|c|c|}
\hline Region/Country & $\begin{array}{c}\text { Emissions from fuel } \\
\text { combustion only } \\
\text { (tons } \mathrm{CO}_{2} \text {-eq/capita) }\end{array}$ & $\begin{array}{c}\text { Total emissions }^{4} \\
\text { (tons } \mathrm{CO}_{2} \text {-eq/capita) }\end{array}$ \\
\hline World average & 4.5 & 6.7 \\
\hline United States & 16.2 & 8.1 \\
\hline China & 6.1 & 4.0 \\
\hline Africa & 1.0 & 23.3 \\
\hline Canada & 15.3 & $9.6^{2}$ \\
\hline Quebec & $6.8^{2}$ & $1.0^{3}$ \\
\hline $\mathrm{CO}_{2}$ budget in 2050 & - & 8.5 \\
\hline
\end{tabular}

${ }^{1}($ IEA, 2014)

${ }^{2}$ (Gouvernement du Québec, 2015)

${ }^{3}$ (Baer \& Mastrandrea, 2006)

4 (World Resources Institute, 2015)

The main sources of GHG in Quebec are presented in Table 0.2. Together, these six sources account for $88 \%$ of Quebec emissions. Road transport is by far the largest contributor, with $34 \%$ of emissions. Equal parts go to cars, light trucks and heavy trucks. Feed and chicken transportation emissions fall into this category. Industrial combustion emissions come from diversified sources, including broiler houses heating and bird feed production. $\mathrm{N}_{2} \mathrm{O}$ emissions from bird manure are part of the agriculture sector, which accounts for $6.4 \%$ of total emissions. The public is hardly aware of a link between diet and global warming (Wellesley, Happer, \& Froggatt, 2015), however broiler chicken production does connect in many ways to global warming. 
Table 0.2 Main GHG emissions sources in Quebec as a percentage of total emissions, 2014 data

\begin{tabular}{|l|c|}
\hline Emissions source & Value \\
\hline Road transport & $33.6 \%$ \\
\hline Industrial combustion (i.e. energy use) & $17.1 \%$ \\
\hline Industrial processes (i.e. non-energy use) & $14.1 \%$ \\
\hline Residential, commercial and institutional (mostly heating) & $10.4 \%$ \\
\hline Waste disposal emanations & $6.7 \%$ \\
\hline Agriculture (animal digestion and manure emanations) & $6.4 \%$ \\
\hline \multicolumn{1}{|c|}{ Subtotal } & $88.3 \%$ \\
\hline
\end{tabular}

Adapted from Gouvernement du Québec (2015)

\subsubsection{Broiler industry emissions}

Chicken products represent a substantial part of the Canadian economy, with a production of 1.2 billion kilograms of chicken (eviscerated weight) worth 2.5 billion C\$ in 2016 (AAFC, 2017). Chicken is popular worldwide and its popularity is increasing. Between 1990 and 2009 , world consumption of chicken increased by $77 \%$, while pork increased by $20 \%$ and beef decreased by 8\% (Henchion, McCarthy, Resconi, \& Troy, 2014). This can be partly explained by the lower relative price of chicken meat (Palmer, 2011). From an environmental perspective, this substitution trend is positive since poultry has a lower environmental impact than beef and pork in terms of land use, energy consumed, emissions, acidification potential and eutrophication potential (de Vries \& de Boer, 2010). Considering emissions of 3.7-6.9 kg $\mathrm{CO}_{2}$-eq/kg from chicken products (de Vries \& de Boer, 2010), Canadian emissions related to broiler production were $0.44-0.83 \mathrm{Mt} \mathrm{CO}_{2}$-eq in 2016. As poultry meat increases in popularity, these emissions are expected to increase. In comparison, total emissions in Canada for 2015 were $722 \mathrm{Mt} \mathrm{CO}$-eq (Government of Canada, 2017). 


\subsection{Description of problematic}

Chicken production methods differ following local climate. While South Asia for example mostly uses naturally-ventilated houses, cold-climate regions rely on closed buildings with mechanical ventilation and gas heaters. As chicks need to be in an air temperature of around 30-34 ${ }^{\circ} \mathrm{C}$, the operation is energy intensive (i.e. $4.5 \mathrm{MJ} \mathrm{kg}^{-1}$ carcass weight) (MacLeod et al., 2013). Although propane and natural gas prices are currently low, they suffered important variations in the last decade. Between 2006 and 2016, the average US residential propane price varied from US\$0.50 to 1.06 per litre (EIA, 2017), eliminating the profit margin of many producers. Higher heating costs brought energy efficiency to the attention of the sector, to latitudes as warm as Alabama, USA (Campbell, Donald, Simpson, \& Macklin, 2008). Although there are environmental benefits to energy efficiency, one must concede that economics is the real incentive behind the sudden mentality change of the broiler industry. Improved insulation and reduced air leaks help, but air renewal is essential to animal welfare and growth. (Dawkins, Donnelly, \& Jones, 2004) even sustains that chicken welfare is more influenced by housing conditions than by stocking density, which is limited to $38 \mathrm{~kg} \mathrm{~m}^{-2}$ in Canada.

Ventilation regulates temperature and humidity and evacuates contaminants such as ammonia, $\mathrm{CO}_{2}$, and dust. How these factors affect bird health and growth is discussed more thoroughly in Chapter 1. Maintaining ideal house conditions is essential to achieving high flock performance which is defined by metrics such as feed intake, growth rate, and feed conversion ratio. The feed conversion ratio (FCR) is defined as the ratio between the amount

of grain consumed and the weight gain of the animal, as defined in Equation (0.1). It can be calculated daily, over the full production cycle, or any useful period of time.

$$
\mathrm{FCR}=\frac{\text { Feed intake }[\mathrm{kg}]}{\text { Body weight gain }[\mathrm{kg}]}
$$


This ratio varies throughout the growth cycle. It is highest at the beginning with young chicks and lowest at the end. In fact, the length of the growth cycle is determined by the growth rate. Chickens are still growing at the end but since they are growing slower it is uneconomical to continue: the feed is better spent on a younger chick. FCR is also the reason why energy efficiency must not be done at the expense of housing conditions. Savings in propane could be voided by increased FCR or higher mortality rate. The same logic applies to GHG emissions. Sources of pollution produced from chicken farming are presented in Figure 0.1.

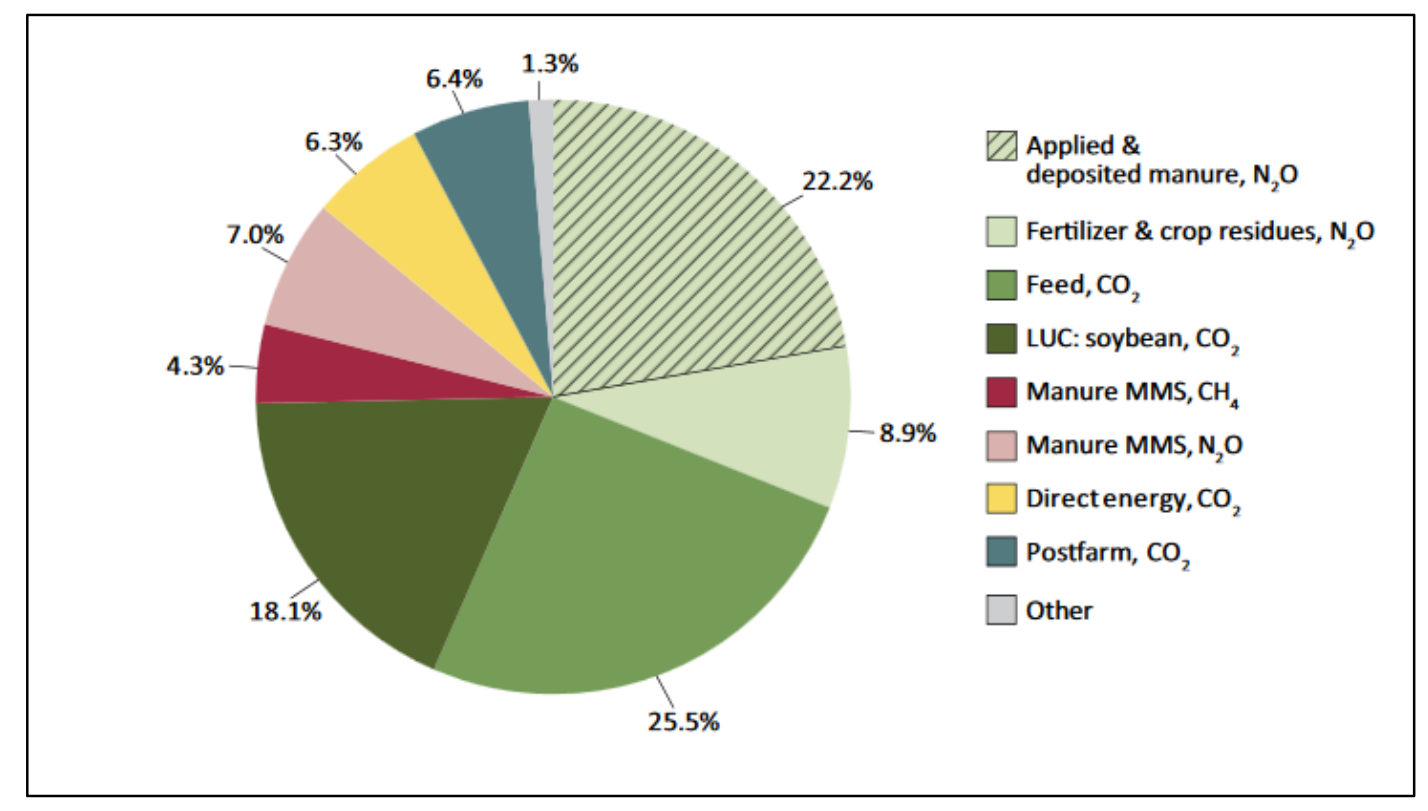

Figure 0.1 Breakdown of total global GHG emissions by category for chicken meat and egg layers. Source: (MacLeod et al., 2013)

It can be seen that direct energy consumption (i.e. heating, ventilation) represents only $6 \%$ of emissions. Over $75 \%$ of total GHG emissions come from:

1. applied and deposited manure $\left(\mathrm{N}_{2} \mathrm{O}\right)$;

2. fertilizer and crop residues $\left(\mathrm{N}_{2} \mathrm{O}\right)$;

3. feed-production-related emissions $\left(\mathrm{CO}_{2}\right)$;

4. emissions caused by land-use change (LUC) to soybean production $\left(\mathrm{CO}_{2}\right)$. 
Item 1 can be reduced by achieving a dryer litter. A dryer litter is an aerobic environment. Aerobic bacteria reduce the amount of $\mathrm{N}_{2} \mathrm{O}$ emissions. Items 2, 3, and 4 can be reduced by lowering the FCR because these emissions are proportional to the amount of feed consumed. This means that most of the emissions are dependent on housing conditions and flock performance.

Since flock performance depends on air quality, ventilation must be maintained but reduced to a minimum. Minimum ventilation rate at any given time varies according to management practices, bird age, sex and breed, climatic conditions, types of heating system, and building thermal performance. In recent buildings, ventilation regulation is increasingly done through an automated system which measures temperature, humidity, $\mathrm{CO}_{2}$ and ammonia concentrations, and adapts air flow and heating power, based on air temperature set-points and contaminant concentration established limits (Poultry Site, 2005).

To go further with energy efficiency, heat recovery must be integrated. Air-to-air heat exchangers partially recover the heat from exhausted air to preheat the incoming fresh air. Average heating demand is reduced. Maximum thermal power requirement is also reduced, lowering the capital cost of the heating system.

There are two ways by which an air-to-air heat exchanger can lower GHG emissions: direct emissions and indirect emissions. Direct emissions decrease by lowering the amount of fuel needed to provide the required air temperature. Indirect emissions are lowered when the FCR is lowered. More research is needed to confirm - on the field - that FCR is reduced by the use of heat exchangers (Bokkers, van Zanten, \& van den Brand, 2010). Reduced cold drafts, however, suggest that this is a possibility, given their negative impact on flock performance.

So far, studies about broiler house ventilation are mostly about direct ventilation improvement (Blanes-Vidal et al., 2008) and validating heat exchanger benefits in a general way, on the field ((Bokkers et al., 2010), (Han, Kim, Jang, Han, \& Lee, 2013)). To the best of the authors' knowledge, there is currently very little literature about how to efficiently 
position a heat exchanger in a broiler house, ensuring homogeneous housing conditions at bird height level. Mostafa et al. (2012) is the only numerical study that focused on air distribution in a broiler house equipped with a heat exchanger (HX). However, the studied heat exchangers were connected to a duct system for air distribution. It remains that air distribution for ductless HX is poorly understood. Ductless HX differentiates themselves from direct ventilation by their reduced number of inlets for fresh air and the reduced temperature gradient between inlet fresh air and indoor air. Airflow behaviour hence is expected to be quite different than direct ventilation. Han et al. (2013) used ductless HX in their field study and recommended more research about HX to improve ventilation system design and operation.

The main disadvantage of a heat exchanger in broiler houses is the maintenance required due to the buildup of dust and ice, which partly explains the low popularity of this technology so far. However, new products are available that mitigate the problem of maintenance. It appears important to understand how best to integrate heat exchangers before they are installed in farms around the world.

\subsection{Goals and methodology}

The main goal of this thesis is to identify one or more ventilation strategies that improve the housing conditions of an existing broiler house equipped with two HX. More specifically, this thesis is built in five parts:

1- Build and verify a numerical model of the existing broiler room;

2- Build an adequate experimental apparatus to take measurements in the broiler room;

3- Validate the model by comparing numerical and experimental data;

4- Create a comparative study to identify the best ventilation strategy;

5- Compare the results with appropriate parameters.

1- In the first part, a 3D numerical model using OpenFOAM is built. OpenFOAM is used because it is free, open-source, powerful, has a large user base worldwide and is entirely 
customizable. The disadvantage of OpenFOAM is that its learning curve is substantial. It is fully customizable but requires skills such as $\mathrm{C}++$ programming and mastering Linux OS. The numerical study is based on Reynolds Averaged Navier-Stokes (RANS) equations. Heat transfer is simulated; humidity, carbon dioxide $\left(\mathrm{CO}_{2}\right)$, ammonia $\left(\mathrm{NH}_{3}\right)$ and dust are not simulated.

2- An experimental setup is built. The setup is adapted to the needs of air measurements inside a broiler house. It measures air velocity, temperature, relative humidity $(\mathrm{RH})$ and carbon dioxide concentrations. Data acquisition is made with an Arduino. The rationale behind this choice is that Arduino has a short learning curve, the material is very affordable and the accuracy is sufficient for in-situ measurements when compared to National Instruments hardware, for instance. The project is an opportunity to develop a general acquisition system platform that is usable for future projects of the research group.

3- Air velocity and temperature measurements are compared with the simulation results, to validate the thermofluid model.

4- With the validated numerical model, a parametric study is carried out to compare different ventilation configurations. Three different configurations are compared with the original configuration.

5- Comparing the results makes it possible to identify the best ventilation strategy with respect to the initial configuration. Configurations are compared using field distribution of velocity, temperature and age of air.

This study focuses on steady-state simulations of cold weather ventilation. Only the first day of the production cycle is simulated because it involves the maximum air temperature, maximum gas consumption and is the moment with a maximum impact on the flock productivity. The last day has maximum contaminants from birds, but since chickens generate lots of heat at this point, direct ventilation can be used to keep contaminants below 
critical thresholds. No modifications of the heat exchanger geometry are considered. Only two HX are installed in the broiler room. More than two HX can be installed in a room, but as the number of HX increases, the airflow distribution importance should decrease. This dissertation contains three chapters after the introduction.

Chapter 1 consists of a literature review. The various air contaminants that occur in a broiler house and their impact on bird health are discussed. Experimental and numerical studies about broiler house ventilation are presented as well. Chapter 2 consists of an article and constitutes the main part of the thesis. The article is entitled CFD simulation to improve heat exchanger performance inside a cold climate broiler house, and it was submitted to Biosystems Engineering journal on July $13^{\text {th }} 2018$. Chapter 3 presents a general conclusion.

This thesis contains six annexes. Annex I presents the OpenFOAM validation case for turbulent buoyant flow, which is based on experimental data from Nielsen (1976). This annex is required to demonstrate the validation procedure of the suggested code. Annex II describes in detail the OpenFOAM main case of the broiler room which is investigated. The format of this thesis (by publication) calls for this. Annex III presents the experimental apparatus designed for measurements in the broiler house. Besides the numerical work, this thesis also involved design and experimental work which together represent a significant contribution. Annex IV presents the temperature measurement accuracy calculations. Annex V consists of the Arduino code that was used in the experimental apparatus. 



\section{CHAPTER 1}

\section{LITERATURE REVIEW}

\subsection{Introduction}

In the present chapter, first an overview of poultry housing conditions is presented. This includes guidelines about air temperature, relative humidity and common air contaminants. The possible impacts of poor housing conditions on bird health and performance are also covered. Two studies about heat exchanger performance on the field are reviewed with a level of details that was not possible in Chapter 2. Finally, a review of poultry ventilation numerical studies is presented.

\subsection{Overview of housing conditions for broiler production}

\section{Temperature}

Temperature is a critical factor of housing conditions. Air temperature must be maintained within a thermoneutral zone. The thermoneutral zone is a $1-2^{\circ} \mathrm{C}$ temperature range at which the animal does not have to regulate its body temperature (Ross, 2010). The thermoneutral zone varies with bird age. Air temperature is measured at broiler chicken height because air stratification can occur. Producers usually have one temperature sensor per floor section, which is by far not enough to guarantee uniform conditions throughout the floor. Cold spots can occur and negatively affect some of the birds. It is therefore important that homogeneous temperatures are maintained. Chickens will avoid cold spots but this strategy has its limits: space is limited and bird density might be too high in some areas, reducing comfort and access to feed and water. Homogeneous temperature favours uniform distribution of chickens across the floor (Bokkers et al., 2010). As they are unable to regulate their body temperature, young birds are more sensitive to the wind chill effect than older birds. During the first two weeks, air velocity at bird height should be below $0.25 \mathrm{~m} \mathrm{~s}^{-1}$ (Donald, 2003). Bird height is approximately $10 \mathrm{~cm}$ for day-old birds and reaches $20-25 \mathrm{~cm}$ for older birds. Low air temperature will cause slower growth, higher FCR and higher mortality (Dozier \& Donald, 
2001; G. T. Tabler, 2003). Recommended temperatures are not always met by producers who are trying to limit the propane consumption during periods of high fuel cost or extreme cold weather (T. Tabler, Wells, \& Zhai, 2012). Litter temperature is also a factor in bird health. It can occur that air temperature is adequate, but the litter is too cold, with increased humidity content.

\section{Air humidity}

Relative humidity is important for thermal comfort. It should be between $50-70 \%$ (Council, 2016). Humidity that is too low might hurt the bird respiratory system. Humidity that is too high will cause body overheating and damp litter. Litter moisture increases the risk of foot pad dermatitis (NFACC, 2013) and increases the rate of ammonia production. The sources of humidity are the heating system, the drinkers ${ }^{1}$ and the birds themselves. In the first days of their lives, the birds do not produce a significant amount of humidity.

\section{Ammonia}

Ammonia $\left(\mathrm{NH}_{3}\right)$ is a colourless, pungent gas, toxic at very low concentrations. The source of ammonia in a broiler room is the anaerobic decomposition of urine and feces in the litter. This bacterial activity also explains the litter heat production, which equals up to $10 \%$ of the thermal power of chicken at a given time (Rojano et al., 2015). Ammonia production is influenced by the level of litter humidity (Wheeler et al., 2003). Ammonia concentration should be below $25 \mathrm{ppm}$ at all times to avoid short-term damage to the respiratory system (Almuhanna, Ahmed, \& Al-Yousif, 2011), (Reece \& Lott, 1980). Ammonia concentrations of $25 \mathrm{ppm}$ have been shown to reduce growth by 4 to $8 \%$ and feed conversion ratio by 3 to 6\% (G. T. Tabler, 2003). It is recommended practice to keep ammonia concentration below 10 ppm (NFACC, 2016). The human nose can detect ammonia concentrations above 25 ppm, while birds can detect levels below 5 ppm. Smell cannot therefore be used as a monitoring tool. Several producers, exposed for years, cannot detect ammonia concentration below 50 ppm, which puts them at a high-level risk (PoultryWateringU, 2018).

\footnotetext{
${ }^{1}$ Drinkers are the water drinking system located on the floor of the broiler house.
} 


\section{Carbon dioxide}

Carbon dioxide $\left(\mathrm{CO}_{2}\right)$ is naturally present in low concentrations in the atmosphere (400 ppm) but in high concentrations will cause the birds to experience dizziness and lower their appetite, resulting in lower growth rate. Carbon dioxide concentration can reach $6000 \mathrm{ppm}$ without observable impact on bird behaviour and growth rate (Reece \& Lott, 1980). The sources of $\mathrm{CO}_{2}$ are the birds and the gas heaters of brooder type, which releases exhaust fumes inside the room. Gas furnaces do not present this problem. Although it is safer to monitor its prevalence in the broiler house, $\mathrm{CO}_{2}$ is usually not the driving factor for the ventilation rate. By controlling humidity levels, the producer keeps $\mathrm{CO}_{2}$ levels below the acceptable limit (Purswell et al., 2011).

\section{Dust}

In broiler houses, dust is composed of dried droppings, feather, skin, feed, microorganisms, spores and litter particles. High dust levels can lead to respiratory problems (e.g. airsacculitis) and other illnesses. Air should have less than $5 \mathrm{mg} \mathrm{m}^{-3}$ of dust at broiler height (UKAG, 2009). Dust level is mainly controlled by ventilation. Ironically, ventilation can also increase dust levels by lifting dust from the ground (NFACC, 2013). This undesired effect decreases with litter humidity. Hence, maintaining humidity above the minimum recommended level (i.e. $50 \% \mathrm{RH}$ ) reduces the level of dust.

\section{Dominant contaminant}

Reece et Lott (1980) showed that the first signs of chicken health problems (i.e. reduced weight gain) occur when $\mathrm{CO}_{2}$ levels exceed 12,000 ppm. However, Purswell et al. (2011) showed that this is rarely a concern since relative humidity level normally drives the air flow rate. Even when trying to maintain $\mathrm{CO}_{2}$ levels as low as $4,500 \mathrm{ppm}$, ventilation requirement to control relative humidity supersedes the ventilation requirement for $\mathrm{CO}_{2}$ concentration. Ammonia level is also influenced by air humidity level (Wheeler et al., 2003). Therefore, relative humidity is generally the most important contaminant to monitor and control in a broiler house. 


\subsection{Heat exchanger performance on the field}

Bokkers et al., (2010) initiated a large-scale study to determine whether or not HX used on the field, really decrease energy consumption and if they affect production cycle performance (FCR, mortality rate, and health). This study was done in the Netherlands on 25 farms. All

farms used a heating system that keeps fumes inside. Farms had various systems of ventilation (roof ventilation, backwall ventilation, combined system). One to five HX were installed in each farm, with circulation fans in the ridge. No information about HX positioning was given, although its importance was reduced by the presence of circulation fans. Based on the 13 farms that provided consumption data, the results showed a $38 \%$ reduction of gas consumption. Farmers noted a decrease in $\mathrm{CO}_{2}$ concentration in the house. An improvement of health with a decrease in diseases (respiratory problems, bacterial infection, and coccidiosis) was also observed. Litter quality improved as well, as it was drier. The authors observed an increase in daily weight gain, but no difference in other performance parameters although they stated that more data was needed to make proper conclusions. A large number of farmers noted a limited ability to clean the HX. The study suggests that HX provide real benefits to farms, both measurable and appreciated by the farmers.

Similarly, Han et al. (2013) studied a single broiler house in Korea, equipped with eight ductless heat exchangers $\left(8 \times 1300 \mathrm{~m}^{3} \mathrm{~h}^{-1}\right)$. The heating requirement was reduced by $55 \%$. The authors concluded that work should be done to optimize ventilation system design and operation protocols. From their work, it appears uniform distribution of fresh air is just as important with $\mathrm{HX}$ ventilation as it is with direct ventilation.

\section{$1.4 \quad$ Overview of poultry ventilation numerical studies}

Computational Fluid Dynamics (CFD) has already been applied with success to broiler house direct ventilation. The main characteristics of selected studies are shown in Table 1.1. 
Table 1.1 A selection of numerical studies dedicated to broiler house ventilation

\begin{tabular}{|l|c|c|c|c|c|}
\hline \multicolumn{1}{|c|}{ Study } & Climate & Ventilation & $\begin{array}{c}\text { With } \\
\text { HX }\end{array}$ & $\begin{array}{c}\text { On-site } \\
\text { validation }\end{array}$ & $\begin{array}{c}\text { Comparative } \\
\text { study }\end{array}$ \\
\hline $\begin{array}{l}\text { (Lee, Sase, \& Sung, 2007) } \\
\text { (Blanes-Vidal, Guijarro, Balasch, } \\
\text { \& Torres, 2008) }\end{array}$ & Hot & Natural & No & Yes & No \\
\hline (I. H. Seo et al., 2009) & Cold & Natural & No & No & Yes \\
\hline (Mostafa et al., 2012) & Cold & Mechanical & Yes & Yes & Yes \\
\hline (Bustamante et al., 2013) & Hot & Mechanical & No & Yes & No \\
\hline $\begin{array}{l}\text { (Rojano et al., 2015) } \\
\text { (Guerra-Galdo, Sanz, Barber, \& } \\
\text { Lopez-Jiménez, 2015) }\end{array}$ & Hot & Notural & No & Yes & No \\
\hline $\begin{array}{l}\text { (Bustamante, García-Diego, } \\
\text { Calvet, Torres, \& Hospitaler, 2015) }\end{array}$ & Hot & Mechanical & No & Yes & No \\
\hline Present study & Cold & Mechanical & Yes & Yes & Yes \\
\hline
\end{tabular}

Lee et al. (2007) simulated a 3D naturally-vented broiler house during hot weather, with the many challenges that this implies. Due to the unstable nature of weather, validation of the CFD model was done with Particle Image Velocimetry on a $1 / 20^{\text {th }}$ scale model. RNG k- $\varepsilon$ turned out to produce the best results with an average error of air velocities of $-6.2 \%$ and a turbulent intensity average error of $-26.0 \%$. The authors noted the importance of turbulence profile around the house to produce accurate results.

Blanes-Vidal et al. (2008) studied broiler production in a hot climate, where mechanical cross-ventilation is used to keep birds cool. The room had 56 inlets openings and 9 outlet fans. The 3D study focused mainly on identifying the most adequate boundary conditions among four sets. The best set proved to be the combination of prescribed air velocity at inlets and prescribed percentage of air flow at each outlet, as per measurements done with a hand-held anemometer. Average air velocity at bird height was $0.36 \pm 0.14 \mathrm{~m} \mathrm{~s}^{-1}$ for measurements and $0.54 \pm 0.22 \mathrm{~m} \mathrm{~s}^{-1}$ for the CFD simulation. After adjusting the CFD results with an experimental regression model, average air velocity was $0.33 \pm 0.13 \mathrm{~m} \mathrm{~s}^{-1}$.

I. H. Seo et al. (2009) simulated the upgrade of a naturally-vented broiler house. During the cold season, in a conventional South Korean building, the winch curtain walls are closed, and 
ventilation level becomes poor. Air is exhausted through central chimneys and fresh air is aspired through vents in the walls. Four alternative designs were created, in which auxiliary fans created a reverse flow. Fresh air distribution pipes and an additional curtain were elements used to elaborate the various designs. The four designs were modelled with 3D transient CFD simulation and compared with the conventional building. CFD model accuracy was not validated with experimental data since data points were too few and the weather was very unstable. Local ventilation rate and thermal uniformity were calculated to evaluate the performance of the five designs. Modifications were implemented in the original building for a second measurement session. Results indicated a $26 \%$ increase in thermal uniformity of the broiler zone and a 30\% decrease in energy use.

Mostafa et al. (2012) studied ventilation in a cold climate Korean broiler house already designed for mechanical ventilation. The original case was direct tunnel ventilation with multiple heaters across the room. Among the four alternative ventilation designs, three incorporated perforated ducts for inlet and/or outlets, and two incorporated HX. Temperature distribution and dilution of ammonia concentrations were used for validating a transient 3D CFD model. The highest temperature error value was $0.46 \%$ between CFD results and measurement results, which was considered very low and acceptable. Among the four alternative designs ( $\mathrm{C}-1$ to $\mathrm{C}-4)$, the most satisfactory results in terms of ventilation rate were those produced by C-4, which consisted of perforated inlet ducts on one side of the room and perforated outlet ducts on the opposite side. The C-2 design, which combined HX and ducts, produced the highest uniformity of temperature distribution. All designs showed a higher uniformity than the original configuration. This is coherent with the fact that tunnel ventilation is intended for cooling chickens in a hot climate, not providing uniform temperature during cold weather.

Bustamante et al. (2013) did a similar 3D study with higher accuracy. The authors compared CFD and experimental measurements with an analysis of variance (ANOVA) and concluded that the velocity values produced by numerical method were not statistically different from 
experimental values. Therefore, they concluded that the CFD method is sufficiently accurate to analyze the indoor environment of a broiler house.

Rojano et al. (2015) analyzed the early stage $(0.5 \mathrm{~kg})$ and late stage $(3 \mathrm{~kg})$ of the production cycle with a $2 \mathrm{D}$ simulation that integrated for the first time all sub-models pertinent to a broiler house (radiant model, humidity transport, combustion gases, bird outputs (heat, $\mathrm{CO}_{2}$, $\mathrm{RH})$ ).

(Guerra-Galdo et al., 2015) did 3D simulations of a hot climate broiler house, comparing tunnel and semi-tunnel configurations, looking to improve the spatial homogeneity of an Index of Temperature and Velocity (ITV). Although there was no experimental validation, authors concluded that for their best configuration, the comfort zone went from 91 to $95 \%$ of floor area, in terms of both ITV and temperature.

(Bustamante et al., 2015) did a 3D isothermal simulation of a typical tunnel-ventilated broiler house in a hot climate. The simulation was validated with experimental data and an analysis of variance (ANOVA) ( $\mathrm{p}$-value $=0.1155)$. The authors were able to identify dead zones near the inlets and excessive velocities near the outlets. 



\title{
CHAPTER 2
}

\section{CFD SIMULATIONS TO IMPROVE AIR DISTRIBUTION INSIDE COLD CLIMATE BROILER HOUSES INVOLVING HEAT EXCHANGERS}

\author{
Frédéric Coulombe ${ }^{1}$, Daniel R. Rousse ${ }^{1,2}$, Pierre-Luc Paradis ${ }^{1}$ \\ ${ }^{1}$ Industrial Research Group in Energy Technologies and Energy Efficiency (t3e), \\ École de technologie supérieure, Université du Québec, 1100, rue Notre-Dame \\ Ouest, Montréal (Québec), Canada, H3C 1K3 \\ ${ }^{2}$ Énergie Solutions Air, 400 rue Marquette, Sherbrooke (Québec), Canada, J1H 1M4
}

Article submitted for publication in Biosystems Engineering, July 2018

\subsection{Abstract}

Propane heating is both a financial and an environmental burden for broiler houses located in cold climate regions. Heat recovery can reduce significantly propane consumption, by preheating fresh air inflow with stalled air outflow. While there have been many studies on the improvement of broiler houses direct ventilation, little attention has been given to heat exchangers integration. In this study, an existent broiler house $\left(800 \mathrm{~m}^{2}\right)$ equipped with two air-to-air ductless heat exchangers $\left(0.38 \mathrm{~m}^{3} \mathrm{~s}^{-1}\right)$ was simulated. Computational fluid dynamics (CFD) software OpenFOAM was used to create a 3D steady-state buoyant simulation with RNG $k$ - $\varepsilon$ turbulence model. CFD model was validated with experimental data collected in a real broiler house. In the standard configuration, the two heat exchangers are aligned in parallel, positioned against the longitudinal wall. Three alternative geometrical configurations were simulated and analyzed in their ability to provide uniform velocity, temperature and age of air at birds height $(0.1 \mathrm{~m})$. One of these showed a $45 \%$ improvement on age of air and a $24 \%$ improvement on velocity distributions. These results confirm that ventilation performance can be improved by a careful analysis of heat exchangers position and its effects on airflow patterns.

Keywords: age of air, broiler house, CFD, heat exchanger, OpenFOAM

\subsection{Nomenclature}

$\begin{array}{ll}\text { Abbreviations } \\ \text { ACH } & \text { air change per hour, } \mathrm{h}^{-1} \\ \text { BC } & \text { boundary condition } \\ \text { BSF } & \text { buoyantSimpleFoam } \\ \text { CFD } & \text { computational fluid dynamics }\end{array}$


$\mathrm{CO}_{2} \quad$ carbon dioxide

$\mathrm{CO}_{2}$-eq equivalent to carbon dioxide

$\mathrm{CoV} \quad$ coefficient of variation

FCR feed conversion ratio

FVM finite volume method

GHG greenhouse gases

HX heat exchanger

HHV high heating value

RANS Reynolds Averaged Navier-Stokes

RNG renormalization-group

SIMPLE semi-implicit method for pressure-linked equations

\section{Symbols}

$\begin{array}{ll}\varepsilon & \text { turbulent dissipation rate, } \mathrm{m}^{2} \mathrm{~s}^{-3} \\ k & \text { turbulent kinetic energy, } \mathrm{m}^{2} \mathrm{~s}^{-2} \\ g & \text { gravitational acceleration, } \mathrm{m} \mathrm{s}^{-2} \\ h & \text { enthalpy energy, } \mathrm{kJ} \mathrm{kg}^{-1} \\ p & \text { static pressure, } \mathrm{Pa} \\ Q_{\text {min }} & \text { minimum ventilation rate, } \mathrm{m}^{3} \mathrm{~h}^{-1} \\ T & \text { temperature, }{ }^{\circ} \mathrm{C} \\ U & \text { velocity, } \mathrm{m} \mathrm{s}^{-1} \\ y+ & \text { dimensionless distance }\end{array}$

\section{Greek symbols}

$\alpha_{\text {eff }} \quad$ effective thermal diffusivity, $\mathrm{kg} \mathrm{m}^{-1} \mathrm{~s}^{-1}$

$\varepsilon \quad$ turbulence dissipation rate, $\mathrm{m}^{2} \mathrm{~s}^{-3}$

$\rho \quad$ density, $\mathrm{kg} \mathrm{m}^{-3}$

$\mu_{\text {eff }} \quad$ effective dynamic viscosity, $\mathrm{kg} \mathrm{m}^{-1} \mathrm{~s}^{-1}$ 


\subsection{Introduction}

Chicken production represents a substantial part of the Canadian economy. In 2016, 2,817 farmers produced 1.2 billion kilograms of chicken (eviscerated weight), for a value totalling 2.5 billion C\$. Between 1990 and 2009, the world consumption of chicken increased by 75\%, while pork increased by $20 \%$ and beef decreased by $8 \%$ (Henchion et al., 2014). From a climate change perspective, this substitution trend is positive since chicken meat has a lower specific environmental impact than pork and beef (de Vries \& de Boer, 2010). Production in cold climate regions relies on closed buildings with mechanical ventilation. Since young chickens require high air temperature $\left(32^{\circ} \mathrm{C}\right)$, the activity is energy intensive. Although propane and natural gas prices are currently low, these were subject to important variations in the last decade. Between 2006 and 2016, the average US residential propane price varied from US\$0.50 to $1.06 \$$ per litre or more than $100 \%$ variation (EIA, 2017), eliminating the profit margin of many producers.

With fluctuating heating costs, the sector developed an interest in energy efficiency. Improving building insulation and air tightness helps, but air change is still required to maintain environmental conditions suitable for broilers. Mechanical ventilation evacuates air contaminants as they build up and ensures that concentrations of contaminants remains between desirable brackets: relative humidity (50-70\%) (NFACC, 2016), $\mathrm{CO}_{2}$ $(<12,000 \mathrm{ppm})$ (Reece \& Lott, 1980), ammonia (<10 ppm) (NFACC, 2016), and particulate

matters $\left(<5 \mathrm{mg} \mathrm{m}^{-3}\right)$. Ventilation also helps to prevent excessive litter moisture. Dawkins et al. (2004) even concluded that environmental conditions are more important than stocking density regarding animal welfare.

In this context, air-to-air heat exchangers (HX) can significantly reduce the heating requirement associated with cold-climate ventilation (Bokkers et al., 2010; Han et al., 2013). Han et al. (2013) concluded that work should be done to optimize ventilation design and operation protocols. 
Computational Fluid Dynamics (CFD) has already successfully been applied to broiler-house simulation in a context of direct ventilation (Table 2.1). Overall, most of the studies focused on hot climate ventilation and HX were not part of the numerical simulations except, to the best of the authors' knowledge, for one study (Mostafa et al., 2012). Other notable CFD studies of large enclosures include a pork house (I.-h. Seo et al., 2012), an ice ring (Bellache, Ouzzane, \& Galanis, 2005), and an interior pool (Limane, Fellouah, \& Galanis, 2015).

Table 2.1 A selection of numerical studies dedicated to broiler house ventilation

\begin{tabular}{|l|c|c|c|c|c|}
\hline \multicolumn{1}{|c|}{ Study } & Climate & Ventilation & $\begin{array}{c}\text { With } \\
\text { HX }\end{array}$ & $\begin{array}{c}\text { On-site } \\
\text { validation }\end{array}$ & $\begin{array}{c}\text { Comparative } \\
\text { study }\end{array}$ \\
\hline (Lee et al., 2007) & Hot & Natural & No & Yes & No \\
\hline (Blanes-Vidal et al., 2008) & Hot & Mechanical & No & Yes & Yes \\
\hline (I. H. Seo et al., 2009) & Cold & Natural & No & No & Yes \\
\hline (Mostafa et al., 2012) & Cold & Mechanical & Yes & Yes & Yes \\
\hline (Bustamante et al., 2013) & Hot & Mechanical & No & Yes & No \\
\hline (Rojano et al., 2015) & Hot & Natural & No & Yes & No \\
\hline (Guerra-Galdo et al., 2015) & Hot & Mechanical & No & No & Yes \\
\hline (Bustamante et al., 2015) & Hot & Mechanical & No & Yes & No \\
\hline Present study & Cold & Mechanical & Yes & Yes & Yes \\
\hline
\end{tabular}

The main objective of this study is to simulate and compare cold climate broiler house ventilation configurations that include several air-to-air HX. The model makes it possible to predict airflow patterns and heat transfer in a specific broiler house with respect to the various positions of the HXs. Four configurations are compared by their ability to provide optimal environmental conditions (air temperature, air velocity and age of air) in the broiler zone, where birds are located. For day-old chicks, the broiler zone is defined as $0.1 \mathrm{~m}$ above the litter, instead of the more often used $0.2 \mathrm{~m}$ definition found in the literature (Blanes-Vidal et al., 2008). Obviously, the two-dimensional horizontal spatial distribution of temperature at this height should be as uniform as possible across the room so that the entire flock is exposed to the set-point temperature. Radiant heaters are an exception to this: they provide hot spots which give some thermal flexibility to each bird to find its own comfort according 
to its current metabolism. For days 0 to 14 of the flock, air velocity at bird height should be less than $0.25 \mathrm{~m} \mathrm{~s}^{-1}$ (Donald, 2003) to avoid a wind-chilling effect. The standard deviation of age of air in the broiler zone should also be minimized.

The configuration best meeting these requirements could reduce heating costs, improve productivity, and reduce the need for circulation fans. Higher spatial uniformity of air renewal could lower the required global ventilation rate, hence reducing heat losses. A lower standard deviation from optimal temperature could lower average feed conversion ratio (FCR). This FCR is defined as the ratio between consumed feed and weight gain. By decreasing the conversion ratio, a producer reduces direct feed costs and the indirect greenhouse gas emissions associated with feed production, estimated at $0.66 \mathrm{~kg} \mathrm{CO}$-eq. $\mathrm{kg}^{-1}$ by Nguyen, Bouvarel, Ponchant, et van der Werf (2012). It is essential that propane savings not be made at the expense of bird comfort, risking increased mortality rate, FCR, and flock weight variation.

\subsection{Materials and methods}

\subsubsection{Description of the broiler house}

The commercial two-story broiler house under investigation is located in Sainte-Mélanie, Québec, Canada $\left(46^{\circ} \mathrm{N}, 73^{\circ} \mathrm{W}\right)$. The average daily minimum temperature of the coldest month is $-19^{\circ} \mathrm{C}$. The second floor of the building was chosen. The broiler house is shown in Figure 2.1 and Figure 2.2. Inside dimensions of the rectangular cavity are $76.2 \times 10.5 \times$ $2.2 \mathrm{~m}\left(1760 \mathrm{~m}^{3}\right)$. A $4.2 \times 2.2 \mathrm{~m}$ closed space containing the staircase is located in the center. External walls are $0.15 \mathrm{~m}$ thick and are made of a wood frame, mineral wool insulation, a vapour barrier and a plywood internal surface. The wooden floor is covered with $10 \mathrm{~cm}$ of straw. The room has a capacity of 15,000 broiler chickens, with a $2 \mathrm{~kg}$ final weight target. Production cycle totals 34 days. Set-point temperature is $32^{\circ} \mathrm{C}$ for day-old chicks, and gradually decline, reaching $22^{\circ} \mathrm{C}$ on the last day. 


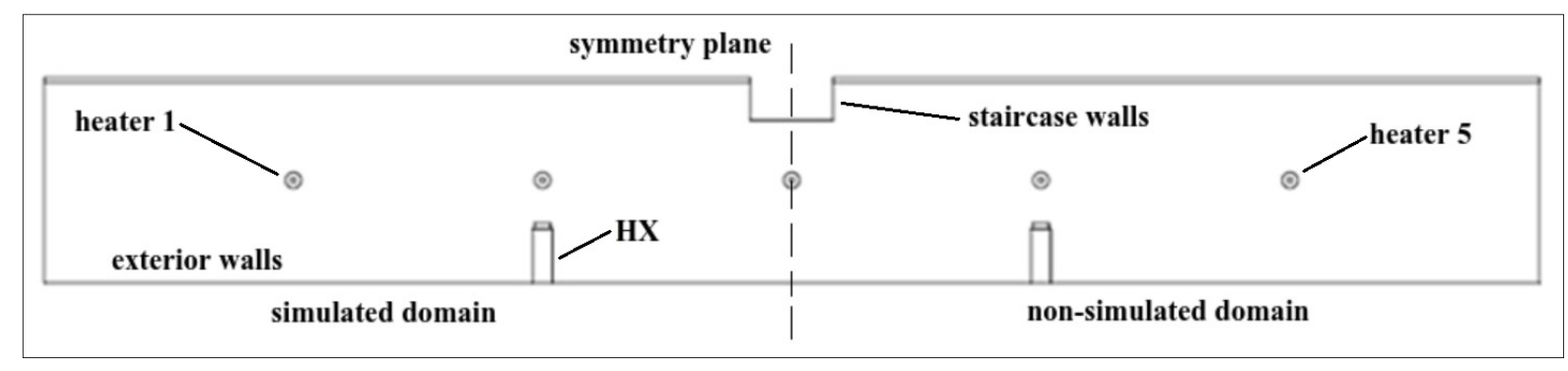

Figure 2.1 Top view of the broiler house in standard configuration, with HX, heaters

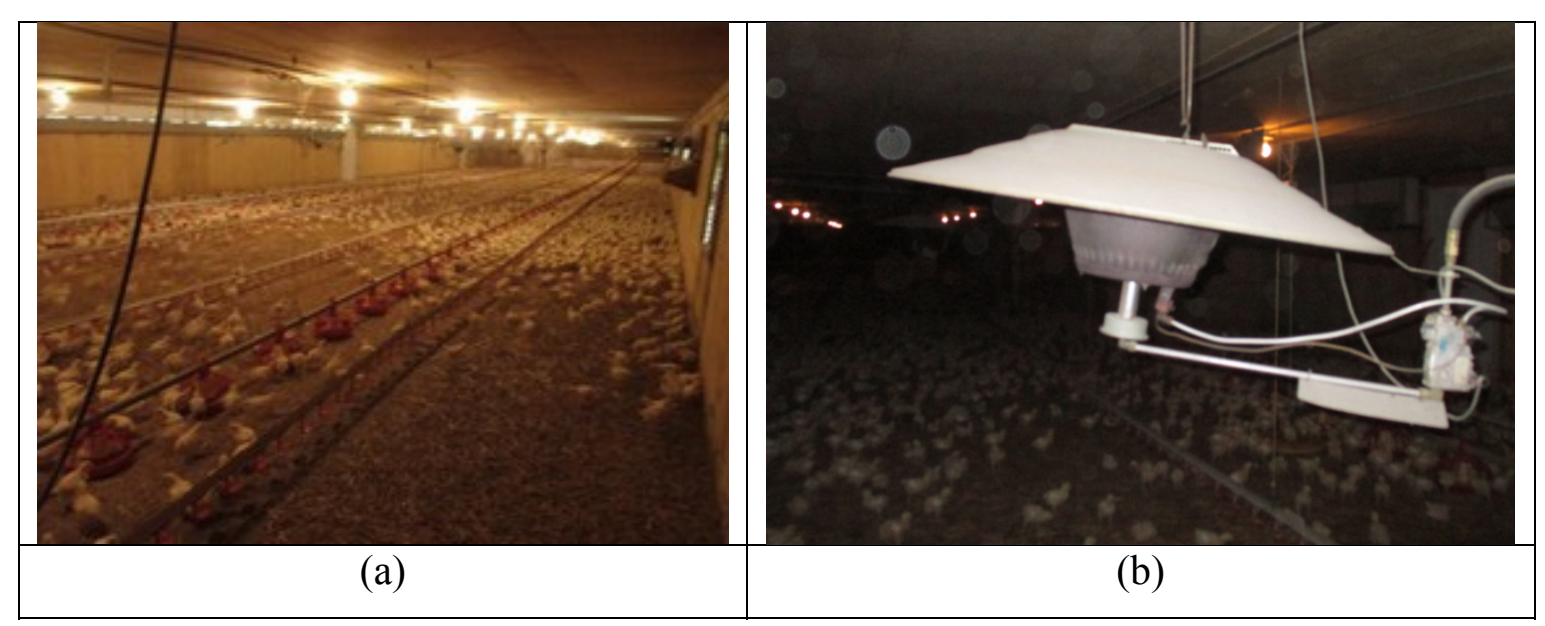

Figure 2.2 a) View of the broiler house studied b) A typical radiant propane heater

The simulated cavity includes two counter-flow air-to-air latent/sensible HX, as shown in Figure 2.3 in the standard configuration, hereafter called C0. This Figure shows two HX, located close to the ceiling, installed perpendicularly on one of the long walls of the building. HX core outer dimensions are $0.2 \times 1.0 \times 2.7 \mathrm{~m}$. Each $\mathrm{HX}$ provides a $0.378 \mathrm{~m}^{3} \mathrm{~s}^{-1}$ nominal flow rate in both inlet and outlet. In all simulations, the nominal ventilation rate corresponds to 1.55 air change per hour (ACH), based on a HX nominal flow. HX operate continuously at nominal flow. Figure 2.4 presents a more complete description of the HX units. The stale warm air is exhausted through peripheral slits (11) located around the unit in the external SS shell (09) and is expelled radially outside the building (04) while fresh air (03) is admitted in the inner part of the external module (02) and HX core (08) and projected inside the building (12) after heat recovery. A specially-designed ventilation unit involving a single fan (05) creates a balanced flow in both incoming (03 and 12) and outgoing directions (11 and 04), 
having a near-neutral effect on room pressure (ESA, 2018a). Based on on-site measurements, the ductless HX has an approximate thermal efficiency of $50 \%$, based on sensible heat. Louvers located at the exit of the cold flow can modify the direction of the incoming airflow (12).

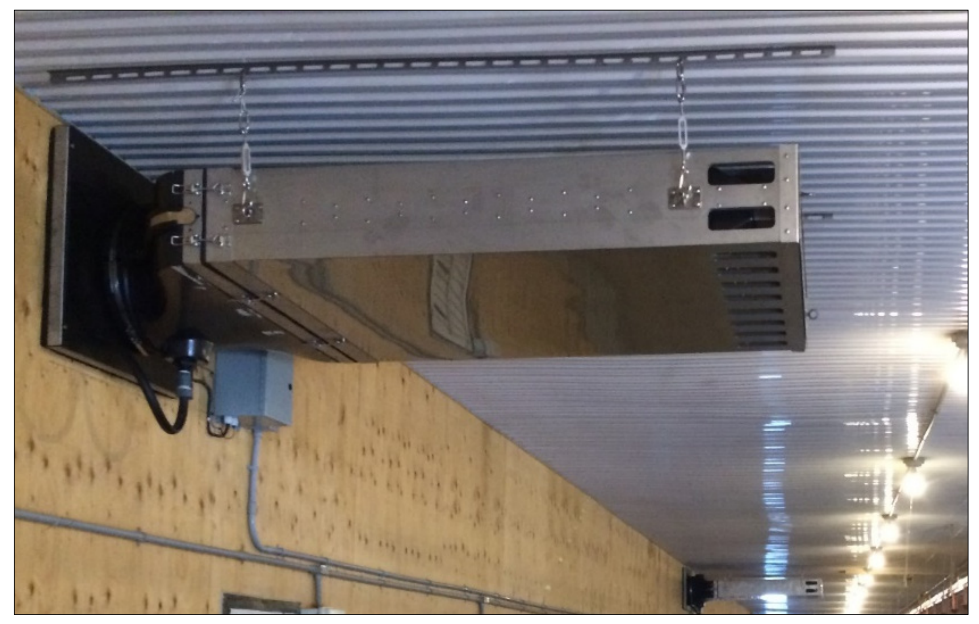

Figure 2.3 Counter-flow air-to-air HX unit installed in a broiler house

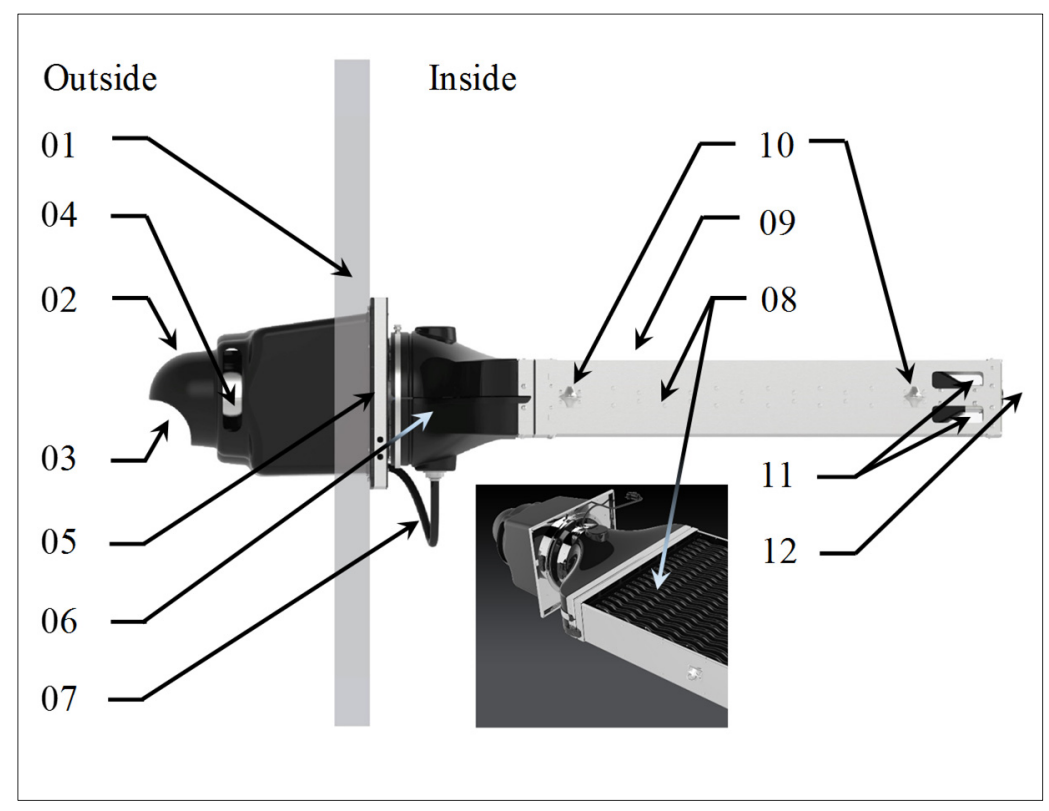

Figure 2.4 Schematic representation of the HX unit 
For the simulations, it is assumed that the incoming flow is uniform and perpendicular to the inlet. In the standard configuration $\mathrm{C} 0, \mathrm{HX}$ are positioned against the wall, parallel to each other, at $0.3 \mathrm{~m}$ from the ceiling (Figure 2.1 and Figure 2.3). The room is also equipped with a cross-ventilation mechanical system for summer weather. This air extraction system involves 11 outlets (i.e. negative-pressure variable speed fans) and variable-opening longitudinal traps along the opposite wall to induce forced air ventilation. This system is occasionally activated during the cold season when HX flow is insufficient to maintain housing conditions (i.e. high humidity or overheating) in one or more zones. However, in the simulation, direct ventilation is not considered.

The cavity contains five propane heaters $(12.3 \mathrm{~kW}$ each), $0.9 \mathrm{~m}$ in diameter, suspended at $0.5 \mathrm{~m}$ from the ceiling, as shown in Figure 2.2. Heater fumes are dissipated inside the cavity. This common method simplifies the heating system and maximizes heat recovery, although it increases the water vapour and $\mathrm{CO}_{2}$ concentration inside the room. Heater power is constant; the central computer adjusts the duty cycle of each burner every 5 minutes to regulate air temperature. During cold weather operation, propane consumption per floor can reach $194 \mathrm{~L} \mathrm{day}^{-1}$. This study concerns only the first day of production. It is the highest set-point temperature and the most critical period of the production cycle, as early stage conditions can affect beyond repair a flock's health, growth and performance (Dozier \& Donald, 2001; G. T. Tabler, 2003).

\subsubsection{Description of the investigated configurations}

Configurations are compared as to their ability to provide ideal environmental conditions in the broiler zone. Configurations are shown in Figure 2.5. For each of these configurations, only the HX's position is modified. The configurations are then defined as: 
C0- Standard configuration (parallel HX, positioned at third of length);

C1- Increased distance between HX (parallel HX, positioned at quarter of length);

C2- Modified HX orientation ( $30^{\circ}$ horizontal deviation);

C3- Opposite configuration (one HX at each end of the house).

The symmetric domain makes it possible to use symmetry to reduce the computational domain.

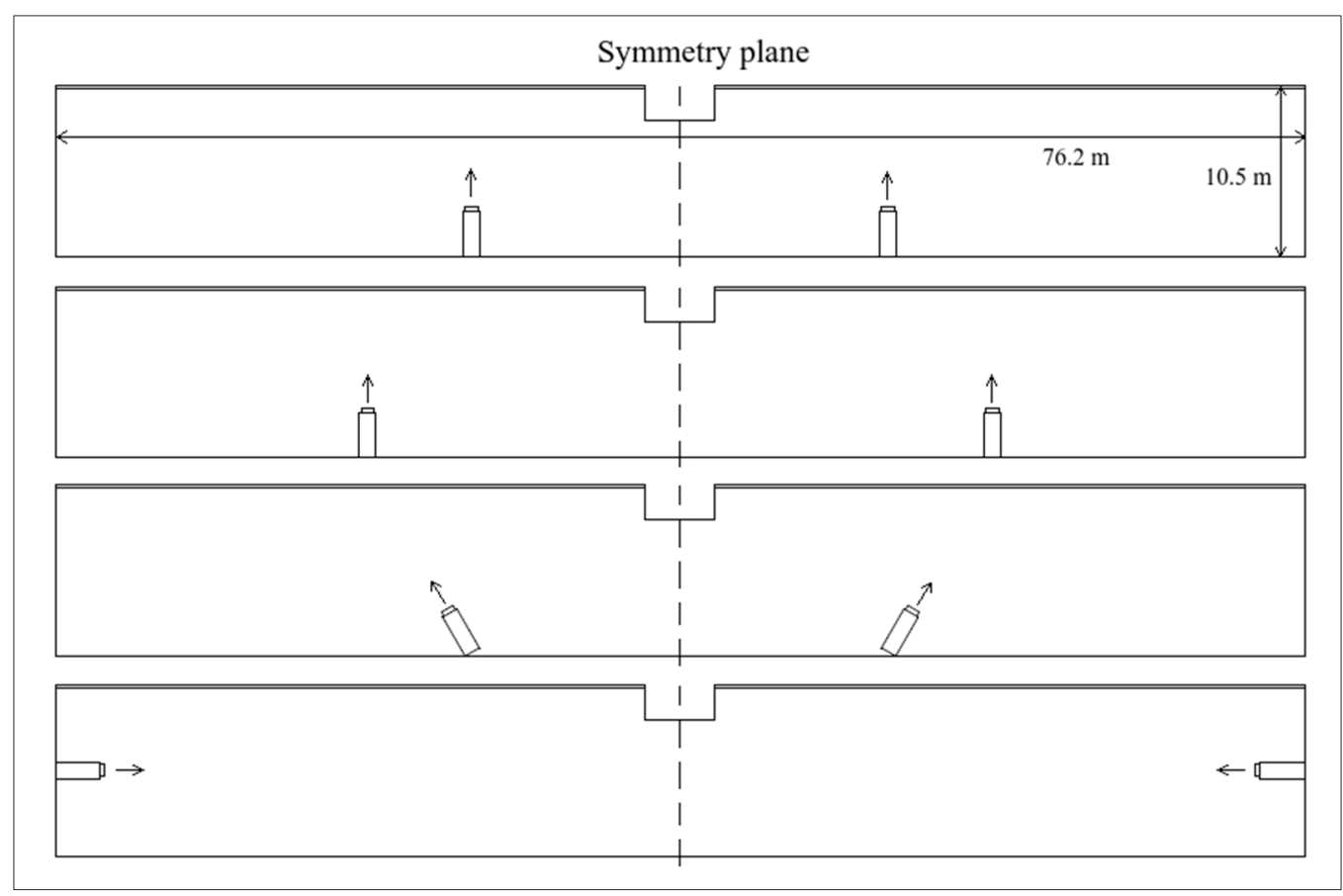

Figure 2.5 Top view of the standard and alternative ventilation configurations, $\mathrm{C} 0$ to $\mathrm{C} 3$, from top to bottom, with two $\mathrm{HX}$

\subsubsection{Numerical method}

OpenFOAM 3.0.1 software is used to solve Reynolds-averaged Navier-Stokes (RANS) equations for mass, momentum and energy conservation equations (2.1) to (2.4) using the Finite Volume Method (FVM). 


$$
\begin{gathered}
\nabla \cdot(\rho \vec{U})=0 \\
\nabla(\rho \vec{U}) \cdot \vec{U}-\nabla \cdot\left[\mu_{\mathrm{eff}}\left(\nabla \vec{U}+\nabla \vec{U}^{T}\right)-\frac{2}{3} \mu_{\mathrm{eff}}(\nabla \cdot \vec{U} \cdot \vec{I})\right]=-\nabla p_{r g h}-(\nabla \rho) \vec{g} \\
\nabla \cdot(\rho \vec{U} h)+\nabla \cdot(\rho \vec{U} K)-\nabla \cdot\left(\alpha_{\text {eff }} \nabla h\right)=\rho(\vec{U} \cdot \vec{g}) \\
\rho=\frac{p}{R T}
\end{gathered}
$$

A native OpenFOAM (OF) solver, buoyantSimpleFoam (BSF), is used. This steady-state pressure-based buoyant solver can handle the strong temperature gradients near the heaters. The pressure-velocity coupling is done with a variant of the SIMPLE algorithm (SemiImplicit Method for Pressure-Linked Equations) (S. Patankar, 1980). Air properties are considered constant except for density, which is calculated with the ideal gas law, and interpolated linearly between the nodes of the discretized calculation domain. Main CFD parameters are presented in Table 2.2. The iterative solution procedure to determine the discrete dependent variables over the calculation domain is stopped when the total relative residual values for $U, P, h, k$ and $\varepsilon$ have been reduced by several orders of magnitude and are stable. Under-relaxation is used to stabilize the simulation and ensure convergence of the iterative solution procedure.

Table 2.2 Main CFD inputs for all simulations

\begin{tabular}{|l|l|}
\hline Air laminar dynamic viscosity $(\mu)$ & $1.872 \mathrm{e}-05 \mathrm{~kg} \mathrm{~m}^{-1} \mathrm{~s}^{-1}$ \\
\hline Gravitational acceleration $(g)$ & $9.81 \mathrm{~m} \mathrm{~s}^{-2}$ \\
\hline Atmospheric pressure & $101,325 \mathrm{~Pa}$ \\
\hline Air laminar Prandtl number $(\mathrm{Pr})$ & 0.7282 \\
\hline Specific heat at constant pressure & $1007 \mathrm{~J} \mathrm{~kg}^{-1} \mathrm{~K}^{-1}$ \\
\hline Molecular Weight & $28.96 \mathrm{~kg} \mathrm{~mol}^{-1}$ \\
\hline
\end{tabular}

The generally acknowledged second-order centered scheme is used for the interpolation of the dependent variable in the diffusion terms (Kuznik, Rusaouën, et Brau (2007). A firstorder upwind scheme (S. Patankar, 1980) is used for convection terms to avoid flow instabilities as it was found sufficient to avoid severe false diffusion for cases investigated 
herein. The closure problem is solved with the RNG $k-\varepsilon$ turbulence model (Yakhot, Orszag, Thangam, Gatski, \& Speziale, 1992). This isotropic model is chosen for its ability to account for low-Reynolds number effects (Lee et al., 2007) and to simulate recirculation (Mohammadi \& Pironneau, 1993). Lee et al. (2007) found the Reynolds Stress model to simulate average velocities and turbulent profiles slightly more accurately in their broiler house, but its seven supplementary equations demanded higher memory and computational time. The RNG $k-\varepsilon$ model was therefore recommended for future ventilation studies of broiler houses.

The numerical domain considers the full interior space of the cavity, although a symmetry plane is used to reduce the computational requirements. The following simplifications are made: small geometric features such as feeders, drinkers and lights are neglected, leak points such as fan openings are neglected, litter thickness and roughness are neglected. Due to their early age, bird heat generation and movements are neglected as well.

A 3D non-structured mesh was generated with OF utility snappyHexMesh. The mesh consists mostly of hexahedrons with maximum size $0.1 \times 0.1 \times 0.1 \mathrm{~m}$. The $\mathrm{HX}$, with inlet and outlet is shown in Figure 2.6. The HX geometry was simplified to reduce mesh requirements, as evidenced by comparing the schematic representation depicted in Figure 2.6 to the detailed geometry of Figure 2.3. The HX inside space is excluded from the domain. Mesh is finer where strong gradients occur, near the HX and heaters. Mesh quality is evaluated with the utility checkMesh. The mesh for the standard configuration C 0 contains 1,373,252 cells. A mesh cut-view is shown in Figure 2.7. To ensure mesh independence of the numerical simulations, a mesh with $2,139,553$ cells was tested. Results variations were below $2 \%$ for all relevant variables. 


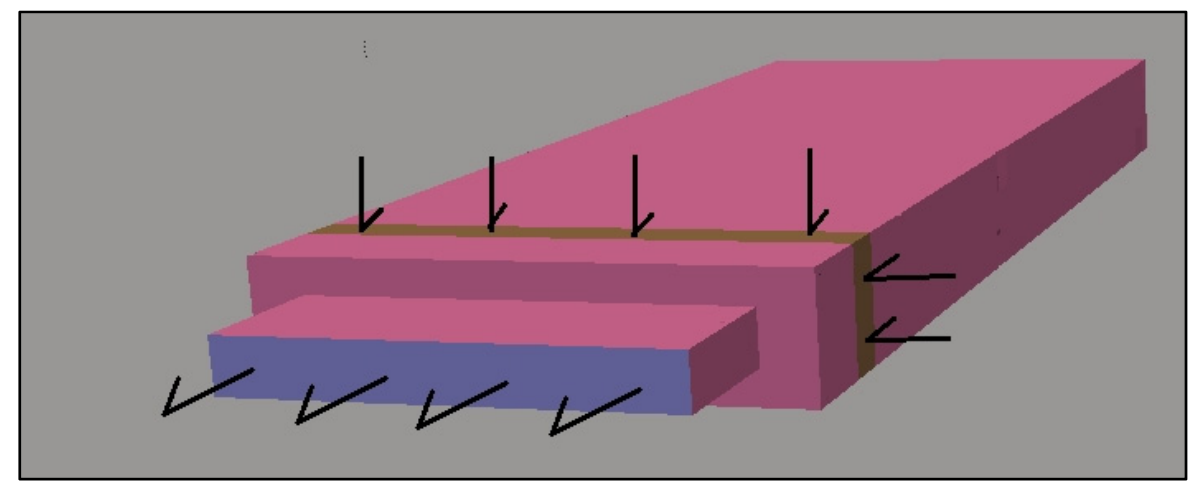

Figure 2.6 Room air inlet (blue) and outlet (brown) on HX (pink) against the exterior wall (grey)

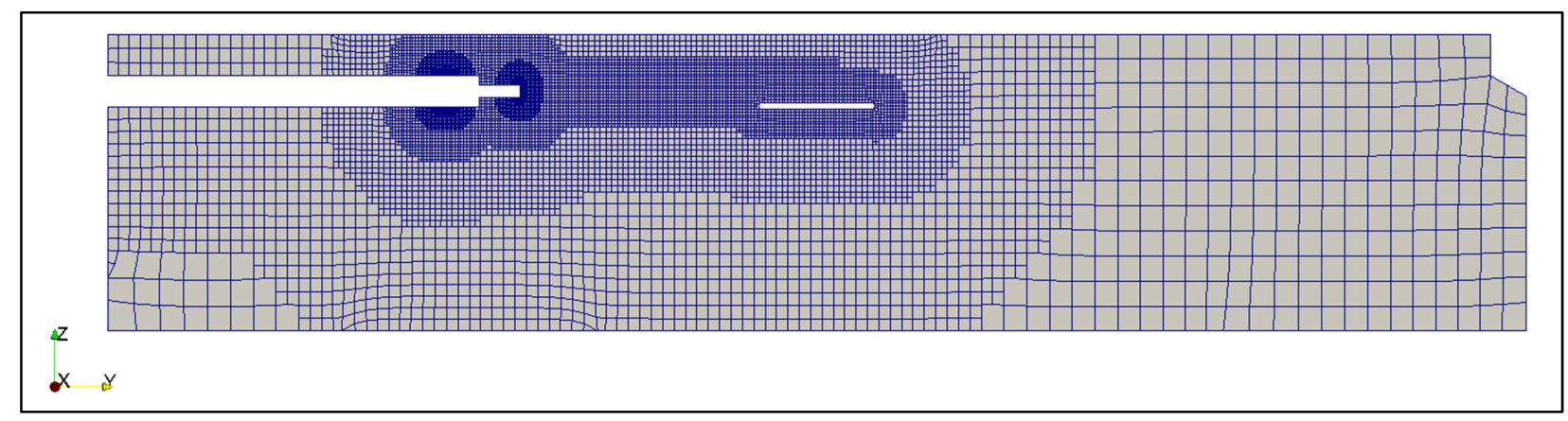

Figure 2.7 Cut view of the mesh for the standard configuration $\mathrm{C} 0$, vis-à-vis the longitudinal axis of the HX

Room inlet (HX) is prescribed for a uniform volumetric flow of $0.378 \mathrm{~m}^{3} \mathrm{~s}^{-1}$. Room outlet has a zero gradient velocity BC. The fixedFluxPressure boundary condition (BC) embedded in OF is used for every pressure boundary of the cavity, except for the room air outlet, which has a fixed pressure value. This fixedFluxPressure $\mathrm{BC}$ adapts the pressure value so that the velocity value imposed at the boundary is respected. All solid surfaces are considered to be smooth surfaces. The boundary layer is modelled by standard wall functions, reducing the mesh requirement near the surfaces (Bustamante et al., 2013). $y^{+}$values range between 30 and 500 for most of the regions (Versteeg, 1995).

Heat fluxes are imposed on every surface of the domain through the use of the externalWallHeatFluxTemperature boundary condition. Thermal boundary conditions are 
summarized in Table 2.3. Floor and ceiling surfaces are considered to be adiabatic. Daily averaged air temperature in January at the closest weather station is chosen as the relevant outside air temperature. Each heater operates at a partial load of $4.53 \mathrm{~kW}$. The thermal power is determined by the analytical estimation of heat losses for Day 1 operating conditions.

Propane heaters dissipate thermal power by infrared radiation, natural convection of combustion fumes and forced convection of air over the heater hot surfaces. The heater geometry is simplified, as seen in Figure 2.8, to lower computing cost (Rojano et al., 2015). The heater is modelled as a blunt solid with a uniform heat flux on its top surface. The reduced thickness combined with the slip condition avoids the development of instabilities similar to Von Karman vortices. Having the heat flux on top rather than lower surface reduces the amount of instability caused by natural convection.

Table 2.3 Thermal conditions of the numerical model for standard configuration $\mathrm{C} 0$

\begin{tabular}{|c|c|}
\hline Parameter & Value \\
\hline Air temperature set-point (target value) & $32^{\circ} \mathrm{C}$ \\
\hline Outside air temperature & $-12.9^{\circ} \mathrm{C}$ \\
\hline HX outlet air temperature & $9.6^{\circ} \mathrm{C}$ \\
\hline HX volumetric flow rate & $0.378 \mathrm{~m}^{3} \mathrm{~s}^{-1}$ \\
\hline Wall thermal conductivity (mineral wool) & $0.045 \mathrm{~W} \mathrm{~m}^{-1} \mathrm{~K}^{-1}$ \\
\hline Wall insulation thickness & $0.15 \mathrm{~m}$ \\
\hline Outside convection coefficient $(h)$ & $10 \mathrm{~W} \mathrm{~m}^{-2} \mathrm{~K}^{-1}$ \\
\hline Exterior wall total heat loss & $2.41 \mathrm{~kW}$ \\
\hline Thermal power per heater (heater surface) & $3.43 \mathrm{~kW}$ \\
\hline Thermal power per heater (floor surface) & $1.39 \mathrm{~kW}$ \\
\hline
\end{tabular}

In order to simplify the simulation, radiant power is represented as a uniform heat flux on a $3 \mathrm{~m}$ diameter circular zone on the floor surface. Nominal thermal power dissipated by each heater is rated $12.3 \mathrm{~kW}$, assuming nominal propane flow $(1.74 \mathrm{~L} / \mathrm{h})$ and perfect combustion 
(HHV). A portion of that power is latent heat, which is not taken into account since only sensible heat is simulated. The heater radiant power was unknown; the radiant heat profile was therefore measured on-site with an infrared radiant sensor (Coulombe, 2018). Results are presented in Table 2.4. Despite its name, it was found that the radiant heater transmits more than half its thermal power by convection. It is assumed that heat transfer mode proportions are constant, even at low duty cycle values.

Age of air (AoA) is used to evaluate air quality, as old air is more likely to contain high concentrations of contaminants. AoA value is the time that local air has spent inside the domain (Li, Li, Yang, \& Yang, 2003). AoA is calculated through a scalar transport equation non-coupled with other equations. Inlet air is considered fresh $(0 \mathrm{~s}$.

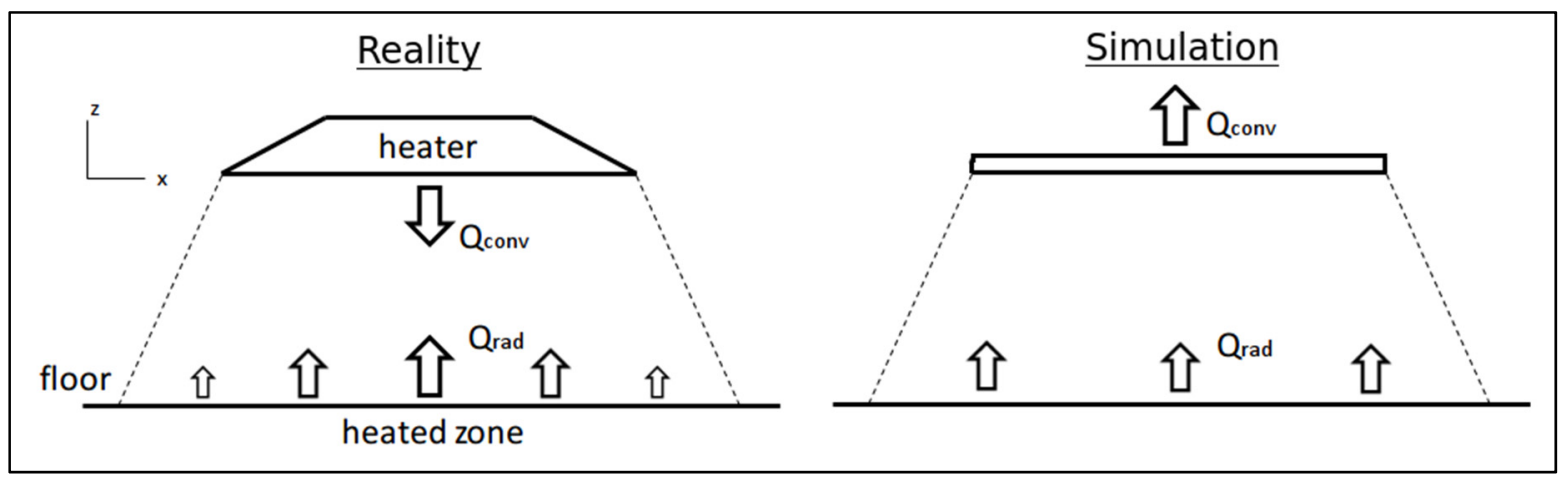

Figure 2.8 Schematic of propane heater modes of heat transfer

Table 2.4 Heat transfer distribution of a radiant propane heater operating at nominal power

\begin{tabular}{|l|c|c|}
\hline & $\begin{array}{c}\text { Power } \\
{[\mathrm{kW}]}\end{array}$ & $\begin{array}{c}\text { Power } \\
(\%)\end{array}$ \\
\hline Radiant heat on the floor & 3.5 & 28 \\
\hline Convection (fumes) & 7.9 & 64 \\
\hline Latent heat (fumes) & 1.0 & 8 \\
\hline Total energy & 12.4 & 100 \\
\hline
\end{tabular}




\subsubsection{Broiler house model validation}

The broiler house CFD model is validated with experimental data from a commercial broiler house in production. For logistic reasons, data was collected in a second broiler house on-site that is slightly different than the first: it has four parallel HX and the staircase is positioned in the corner of the house (Figure 2.9). The measurement locations are numerated from 1 to 11 and are represented by squares. The geometry and parameters of the CFD model were adapted to simulate this second broiler house. The full domain had to be simulated as no symmetry was present. In Table 2.5 and Table 2.6 are presented the power values used in the CFD model validation, based on energy balance.

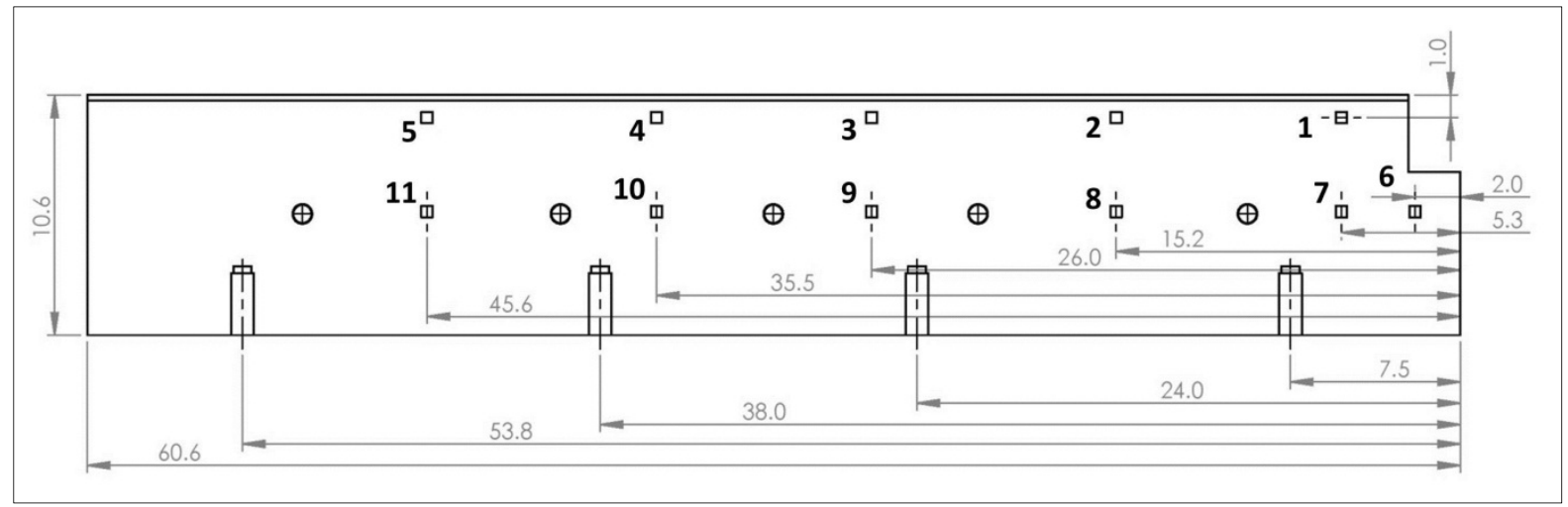

Figure 2.9 Top view of the second broiler house with measurement locations and dimensions, in meters 
Table 2.5 Numerical model thermal conditions for validation simulation

\begin{tabular}{|l|c|}
\hline Parameter & Value \\
\hline Air temperature set-point (target value) & $27.7^{\circ} \mathrm{C}$ \\
\hline Outside air temperature & $-3.2^{\circ} \mathrm{C}$ \\
\hline HX outlet air temperature & $13.1^{\circ} \mathrm{C}$ \\
\hline HX volumetric flow & $0.090 \mathrm{~m}^{3} \mathrm{~s}^{-1}$ \\
\hline Walls/Ceiling thermal conductivity & $0.045 \mathrm{~W} \mathrm{~m}^{-1} \mathrm{~K}^{-1}$ \\
\hline Walls insulation thickness & $0.15 \mathrm{~m}$ \\
\hline Ceiling insulation thickness & $0.15 \mathrm{~m}$ \\
\hline Attic air temperature & $10^{\circ} \mathrm{C}$ \\
\hline Outside convection coefficient $(h)$ & $10 \mathrm{~W} \mathrm{~m}{ }^{-2} \mathrm{~K}^{-1}$ \\
\hline Exterior walls total heat loss & $1.377 \mathrm{~kW}$ \\
\hline Ceiling total heat loss & $1.598 \mathrm{~kW}$ \\
\hline
\end{tabular}

Table 2.6 Heaters parameter values for validation simulation

\begin{tabular}{|c|c|c|c|c|c|}
\hline Zone & $\begin{array}{c}\text { Heaters } \\
\text { per zone }\end{array}$ & $\begin{array}{c}\text { Duty } \\
\text { cycle (\%) }\end{array}$ & $\begin{array}{c}\text { Radiant } \\
\text { power } \\
{[\mathrm{kW} / \mathrm{heater}]}\end{array}$ & $\begin{array}{c}\text { Convection } \\
\text { power } \\
{[\mathrm{kW} / \mathrm{heater}]}\end{array}$ & $\begin{array}{c}\text { Total } \\
\text { power } \\
{[\mathrm{kW} / \mathrm{heater}]}\end{array}$ \\
\hline Zone 1 & 1 & 0.29 & 1.03 & 2.32 & 3.35 \\
\hline Zone 2 & 1 & 0.13 & 0.47 & 1.06 & 1.53 \\
\hline Zone 3 & 2 & 0.02 & 0.09 & 0.19 & 0.28 \\
\hline Zone 4 & 1 & 0.32 & 1.13 & 2.56 & 3.69 \\
\hline Total & 5 & - & 2.81 & 6.32 & 9.13 \\
\hline
\end{tabular}

\subsubsection{Experimental data methodology}

A multi-sensor mobile measurement station was moved successively to different locations across the broiler house. This strategy was used successfully by Blanes-Vidal et al. (2008) . Air velocity is measured with four 2D ultrasonic anemometers (R.M. Young 85000). This 
type of anemometer was used by Bjerg, Svidt, Zhang, Morsing, et Johnsen (2002), is tolerant to high dust environments and has low-velocity threshold $(0.01 \mathrm{~m} / \mathrm{s})$. Temperature was measured with 7 thermistors (Analog Technologies ATH10K1R25). Measurement accuracy is $\pm 0.4{ }^{\circ} \mathrm{C}$ for temperatures between 0 and $50{ }^{\circ} \mathrm{C}$. Anemometers 1 to 4 are distributed on a vertical line at heights of $0.06,1.00,1.50,2.00 \mathrm{~m}$ from the floor. Thermistors 1 to 7 are distributed at heights $0.2,0.5,0.8,1.1,1.4,1.7,2.0 \mathrm{~m}$. Sensors are connected to an Arduino Mega 2560 for data acquisition, treatment and wireless transmission to a PC.

Eleven measurements locations were distributed across the room (Figure 2.9). Each individual HX was characterized by measuring its inlet air velocity with the ultrasonic anemometers. Thirty measurements per inlet were taken (Mostafa et al., 2012). They proved to have reduced flow, due to old age. The measurement frequency is $0.1 \mathrm{~Hz}$ (every $10 \mathrm{~s}$ ) The measurement period at each location is 5 min (ASHRAE, 2010). The total time between the beginning and end of the procedure was $140 \mathrm{~min}$. Measurements were performed on February $1^{\text {st }}, 2018$ between $16 \mathrm{~h} 35$ and $18 \mathrm{~h} 55$. During that period, the external temperature varied from -3.2 to $-2.8^{\circ} \mathrm{C}$, as measured by the on-site weather station.

\subsection{Results and discussion}

\subsubsection{CFD model validation}

Figure 2.10 and Figure 2.11 present a comparison between the numerical and experimental data for velocity and temperature respectively. 44 velocity measurements and 77 temperature measurements are distributed over the 11 locations shown in Figure 2.9. The maximum discrepancy for velocity is $0.18 \mathrm{~m} \mathrm{~s}^{-1}$. For temperatures, the results are generally more accurate near the ceiling than near the floor with discrepancies varying from 0 to $2.2^{\circ} \mathrm{C}$. Despite the use of first-order discretization schemes for advection terms, numerical results are found to be in good agreement with the experimental measurements. The CFD model is deemed accurate enough to evaluate the performance of the alternative ventilation configurations described earlier. 


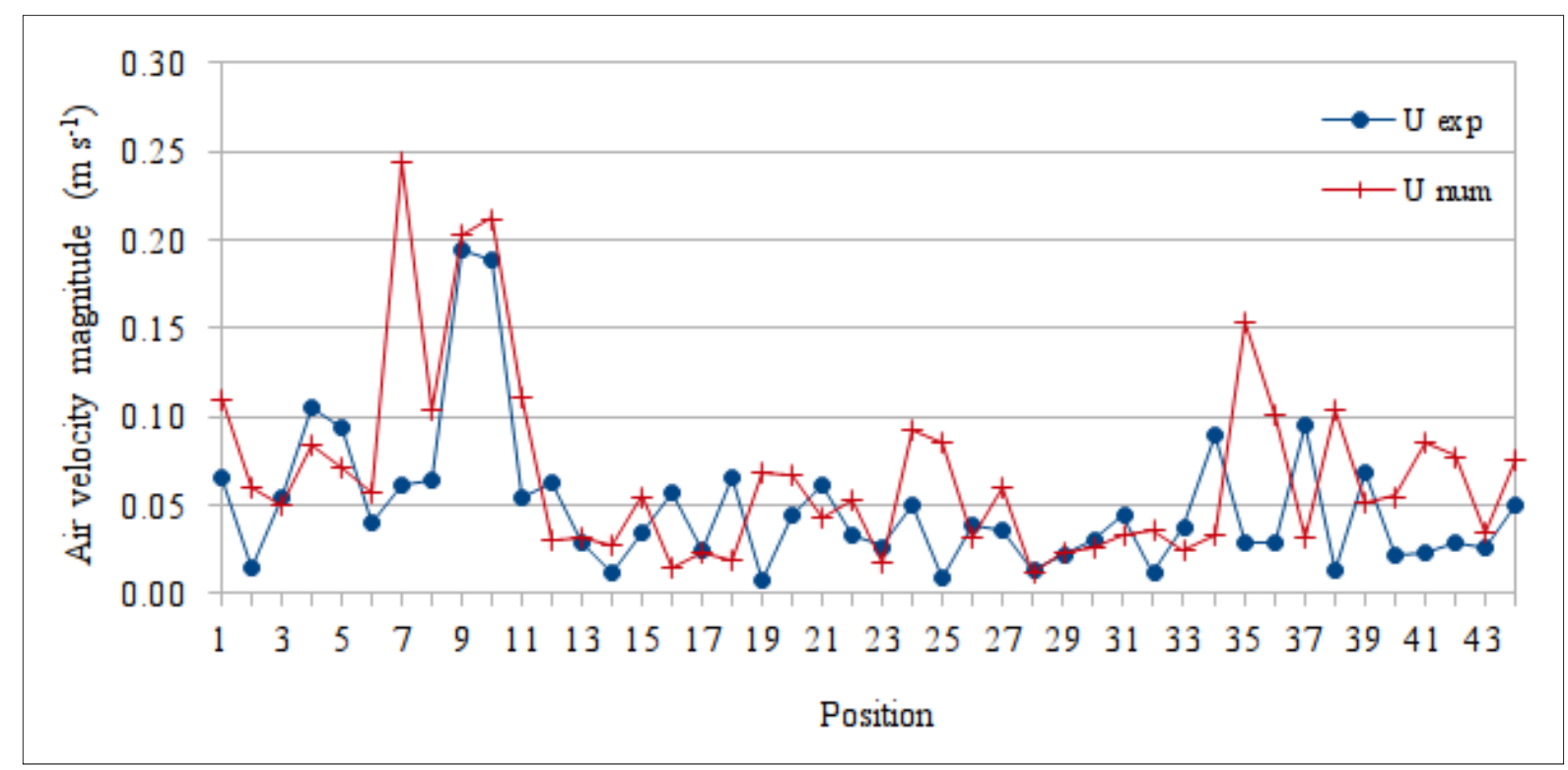

Figure 2.10 Air velocities at 44 positions inside the broiler house, experimental versus numerical results

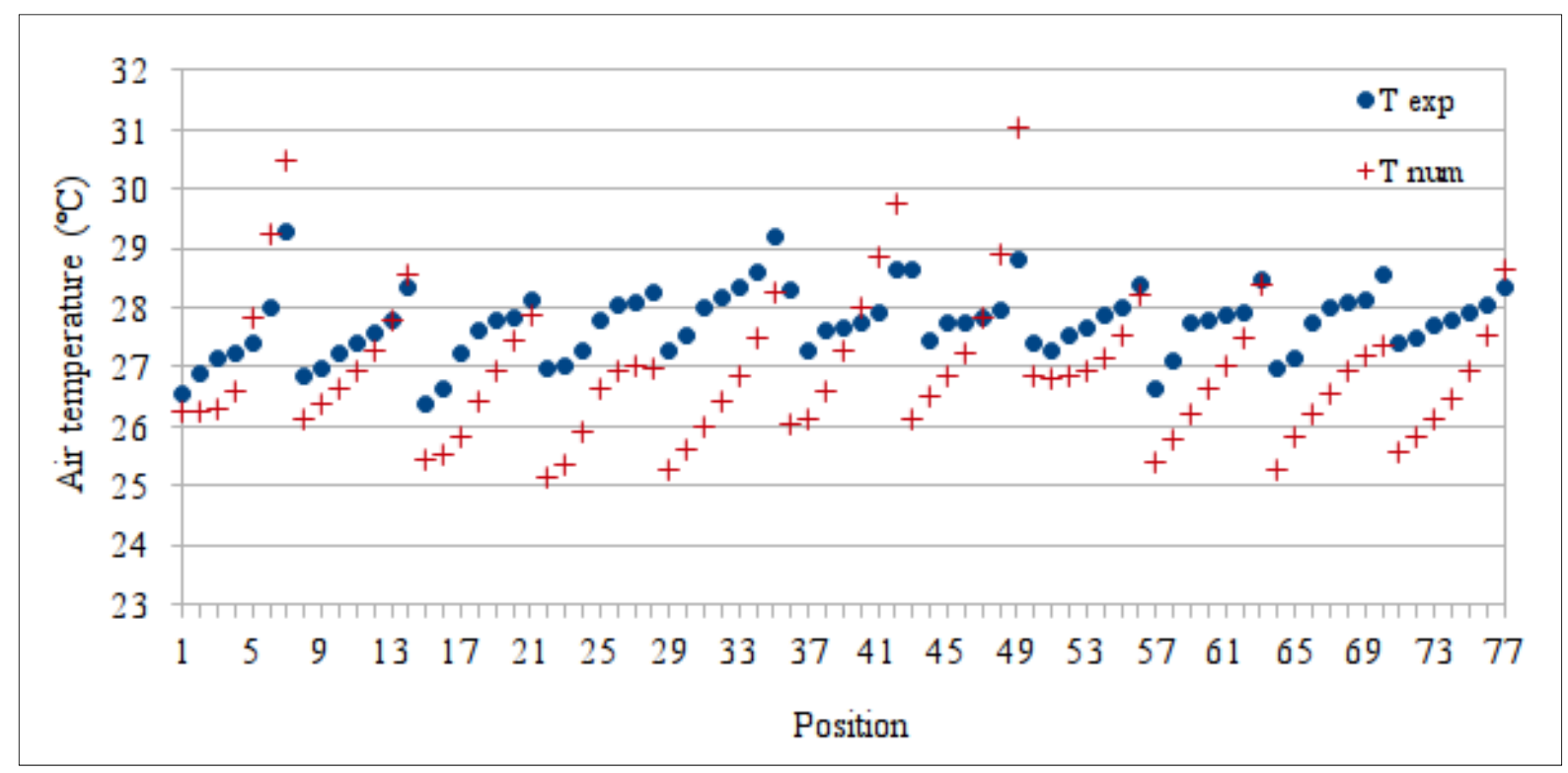

Figure 2.11 Air temperature at 77 positions inside the broiler house, experimental versus numerical results 


\subsubsection{Standard configuration $\mathrm{CO}$}

Figure 2.12 presents the velocity magnitude field for the $y z$ plane that crosses the center of one of the HX. The figure shows that a jet flow develops in front of the HX, surrounds the heater geometry and reaches the opposite wall in a very diffuse manner. The jet is deflected towards the ceiling as natural convection induces an upward movement. However, the original high velocity of the jet provides a momentum that makes air flow almost straight to the opposite wall. This was also confirmed by smoke tests carried out in another installation (ESA, 2018b) providing confidence in the predictions. Velocities are weak below the HX (left in Figure 2.12) where air circulates quite less than in the other area (right). Other relevant fields are presented in Figure 2.13 along with the comparative study results for all configurations.

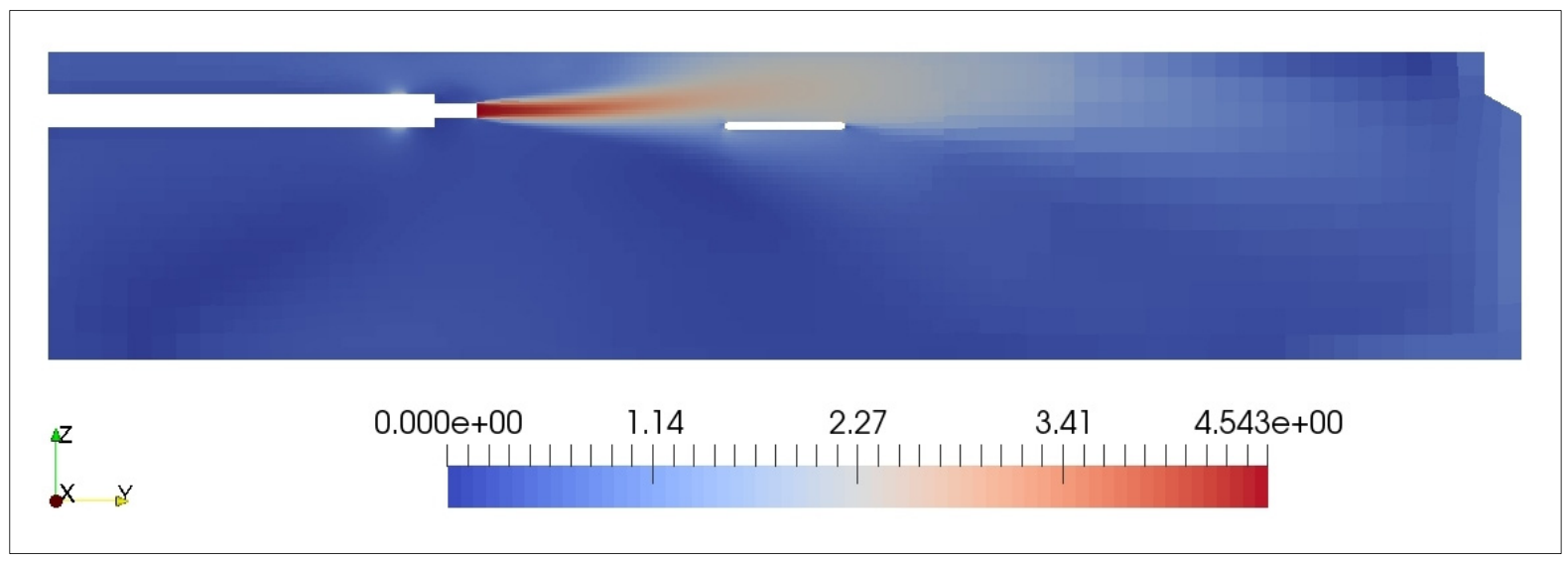

Figure 2.12 Velocity magnitude $\left[\mathrm{m} \mathrm{s}^{-1}\right]$ distribution at $y z$ plane $x=25.4 \mathrm{~m}$ for the standard configuration $\mathrm{C} 0$

\subsubsection{Comparative study results}

Table 2.7 and Figure 2.13 present the comparative study results for velocity $(U)$, temperature $(T)$ and age of air $(A o A)$. Table 2.7 presents figures to allow for some \% calculations and other calculations of discrepancies between each configuration while Figure 2.13 presents qualitative results for a horizontal plane located at height, $z=0.1 \mathrm{~m}$. Figure 
2.13 presents results for the left-hand side of the calculation domain; the right boundary is a symmetry plane. Here, the coefficient of variation $(\mathrm{CoV})$ is defined as the ratio of the standard deviation to the average of the predicted dependent variable.

Table 2.7 Performance data of ventilation configurations at bird height $(z=0.1 \mathrm{~m})$

\begin{tabular}{|c|c|c|c|c|c|c|c|c|c|c|c|}
\hline & \multicolumn{3}{|c|}{ Velocity $(U)$} & \multicolumn{4}{c|}{ Temperature $(T)$} & \multicolumn{4}{c|}{ Age of Air $(A o A)$} \\
\hline \multirow{2}{*}{} & avg & $\max$ & $\operatorname{CoV}$ & $\operatorname{avg}$ & $\min$ & $\max$ & $\operatorname{CoV}$ & avg & $\min$ & $\max$ & $C o V$ \\
\cline { 2 - 13 } & {$\left[\mathrm{m} \mathrm{s}^{-1}\right]$} & {$\left[\mathrm{m} \mathrm{s}^{-1}\right]$} & {$[\%]$} & {$\left[{ }^{\circ} \mathrm{C}\right]$} & {$\left[{ }^{\circ} \mathrm{C}\right]$} & {$\left[{ }^{\circ} \mathrm{C}\right]$} & {$[\%]$} & {$[\mathrm{s}]$} & {$[\mathrm{s}]$} & {$[\mathrm{s}]$} & {$[\%]$} \\
\hline $\mathrm{C} 0$ & 0.24 & 0.87 & 71 & 30.7 & 27.3 & 34.7 & 4 & 2144 & 1629 & 2710 & 13 \\
\hline $\mathrm{C} 1$ & 0.30 & 0.89 & 55 & 28.8 & 26.2 & 34.5 & 5 & 2145 & 1820 & 2565 & 8 \\
\hline $\mathrm{C} 2$ & 0.28 & 0.78 & 54 & 29.2 & 26.7 & 34.9 & 4 & 2113 & 1811 & 2510 & 7 \\
\hline $\mathrm{C} 3$ & 0.24 & 0.91 & 67 & 31.6 & 27.4 & 39.8 & 6 & 2140 & 1764 & 2703 & 10 \\
\hline
\end{tabular}

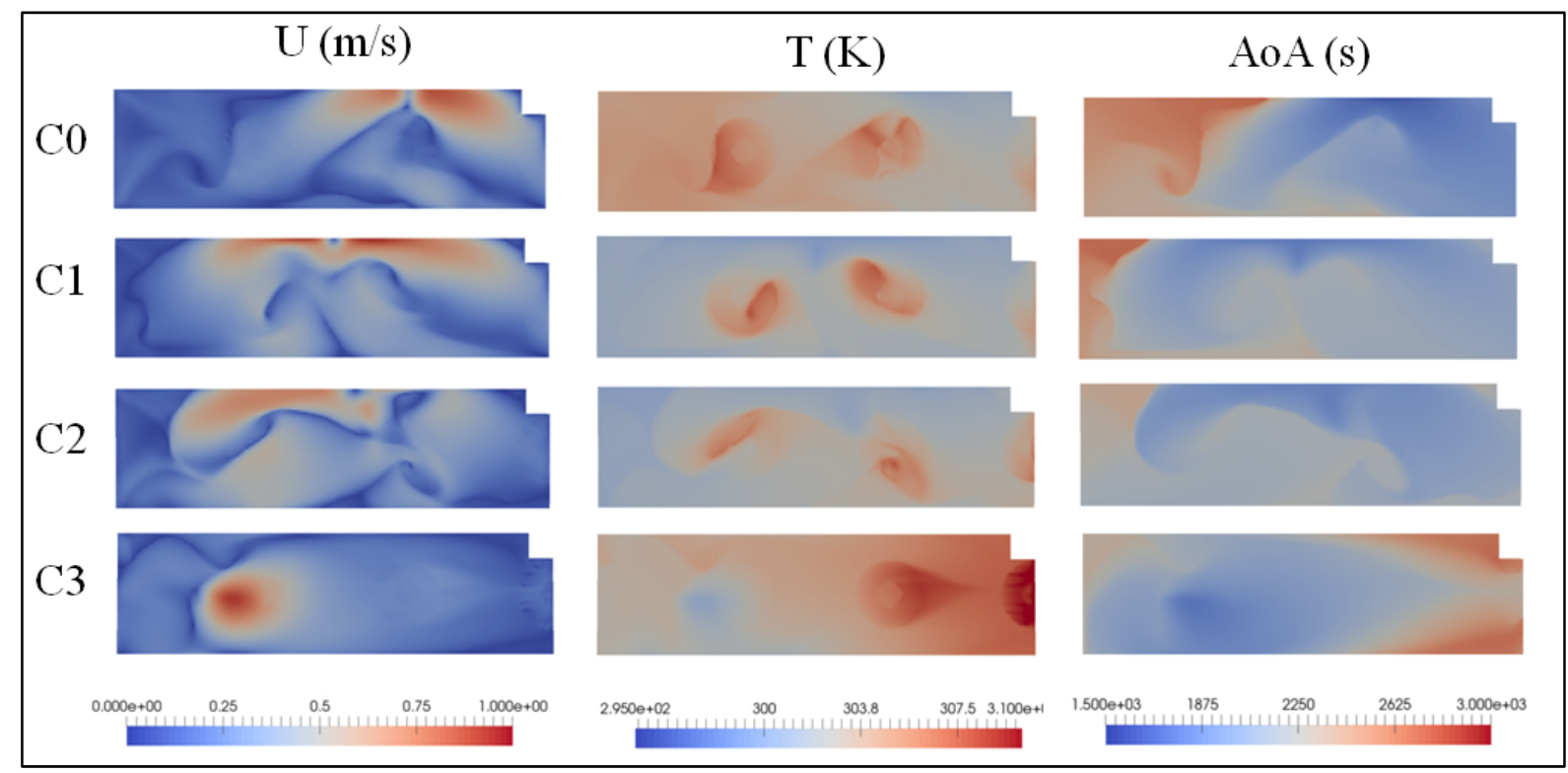

Figure 2.13 Comparative study results with a top view of relevant fields at bird height $(z=0.1 \mathrm{~m})$

\subsubsection{Velocity}

In $\mathrm{C} 0$ and $\mathrm{C} 1$, velocities are high (pink to red areas) where the jet flow hits the wall, reaching nearly $1 \mathrm{~m} \mathrm{~s}^{-1}$. In $\mathrm{C} 0$, air velocity is low on the left-hand side. Dark blue lines are spawn 
across the domain where velocity is negligible (below $0.1 \mathrm{~m} \mathrm{~s}^{-1}$ ) indicating that two recirculation zones face each other. These recirculation zones form a complex highly threedimensional flow structure (that cannot be seen herein). This is possibly a consequence of having the air inlet very close to the outlet. This confirms the relevance of 3D rather than 2D simulations to evaluate $\mathrm{HX}$ integration. In $\mathrm{C} 1$, the velocity pattern is more symmetrical than $\mathrm{C} 0$, probably because the $\mathrm{HX}$ is positioned in the middle of the half-domain. In $\mathrm{C} 2$, the maximum velocity is lower $\left(0.78 \mathrm{~m} \mathrm{~s}^{-1}\right)$; most likely because the jet flow travels a longer distance before hitting the wall at an angle. The flow has no symmetry and is quite complex, as it involves full tridimensional patterns. Velocity coefficient of variation is $54 \%$, which is a $24 \%$ improvement relative to $\mathrm{C} 0$. One should note that all configurations exceed the desired limit threshold of velocity $0.25 \mathrm{~m} \mathrm{~s}^{-1}$. In C3, velocities are weak in the area far from the HX, which constitutes a large recirculation zone. In this configuration, the maximum velocity in the broiler zone occurs near the HX, where the jet flow touches the floor. Configurations $\mathrm{C} 1$, $\mathrm{C} 2$ and $\mathrm{C} 3$ presented minor flow instabilities that made them more difficult to analyze with a steady-state solver. Post-treatment values for $U, T$ and $A o A$ were obtained by averaging data over the 4000 final iterations.

\subsubsection{Temperature}

In all cases, the maximum temperature variation is about $15^{\circ} \mathrm{C}$ from the lowest to the highest temperature. In $\mathrm{C} 0$, the $\mathrm{HX}$ is closer to the right side of the room and the temperature is incidentally lower in that region. There are no significant temperature gradients near the exterior walls, suggesting that level of insulation is sufficient, given the velocity magnitude inside the broiler house. The circular zones where radiant heat is applied are visible in red, even at $0.1 \mathrm{~m}$ above ground level because straw is directly heated, with streaks of heat in the direction of air velocity, thus deforming the original pattern of the heated area. With $\mathrm{C} 0$, birds looking for warmer air would also be living in the less ventilated areas (left-hand side of the figure). The HX is perfectly aligned with the heater geometry. The jet flow surrounds the solid blunt, absorbing its thermal output, therefore mixing cool and warm air as it exits 
the HX. However, Figure 2.13 shows that this does not seem to provide any valuable advantage in terms of heat distribution.

Temperatures outside the heater zones are more uniform in $\mathrm{C} 1$ than $\mathrm{C} 0$ except for the two areas depicted in red, which is the desired effect: a uniform field with the exception of the heater zones which provide some thermal flexibility to birds. This improvement is not reflected in the $\operatorname{CoV}_{T}$ value because it is defined for all areas on the plane of interest (here $\mathrm{z}=0.1 \mathrm{~m}$ ). Thus, this definition does not distinguish heater zones from non-heater zones in the plane. Perhaps, two definitions would be required: one that would allow an evaluation of the uniformity of the heated areas and another for the rest of the floor area. Nevertheless, the global definition provides an excellent uniformity indicator and therefore indicates the overall tendency of the birds to gather or conversely to spread-out over the entire surface.

$\mathrm{C} 2$ is similar to $\mathrm{C} 1$ in terms of heat distribution, with a little more heat dispersion of the radiant heat $\left(\mathrm{CoV}_{T}=0.4 \%\right)$. C3 is the worst temperature distribution due to very low circulation near the symmetry plane. The mean temperature is higher $\left(31.6^{\circ} \mathrm{C}\right)$ due to heat accumulating in poorly ventilated regions. While one would expect the flow to reach far into the room before returning to $\mathrm{HX}$, the trajectory is quite short, folding itself within a few meters in order to reach the exit. Lateral walls closer to the HX could explain the difference in flow behaviour between $\mathrm{C} 3$ and $\mathrm{C} 0$. A higher velocity $\mathrm{HX}$ might perform better in configuration $\mathrm{C} 3$.

\subsubsection{Age of air}

For $\mathrm{C} 0$, the expected age of air average, based on the conventional ventilation rate, is $2261 \mathrm{~s}$, while the numerical value at cavity outlet is $2226 \mathrm{~s}$, which constitutes a $-1.5 \%$ numerical discrepancy. Age of air distribution is poor in $\mathrm{C} 0$, with the highest variation of all configurations $\left(\mathrm{CoV}_{A O A}=13 \%\right)$. This is due to the presence of a large recirculation area at the left-end side of the broiler house. This recirculation zone is smaller in $\mathrm{C} 1\left(\mathrm{CoV}_{T}=8 \%\right)$, and almost negligible in $\mathrm{C} 2(\mathrm{CoV}=7 \%) . \mathrm{C} 2$ represents a $45 \%$ improvement in age of air 
distribution. C3 does not perform very well in terms of air age. While the middle of the room is well ventilated, the zone near the symmetry plane is poorly ventilated, with poor mixing of fresh air, especially near the walls and corners. One can notice that the age of air average value in the broiler zone is slightly inferior to the average value for the entire cavity (i.e. 2261 s). This is true for all configurations. This implies that the space near the floor is slightly better ventilated than the rest of the cavity.

\subsubsection{Recommendations}

Overall, there is considerable variation of performance between configurations in terms of uniformity of the fields of the relevant dependent variables. Standard configuration $\mathrm{C} 0$ is not the configuration that performs the best. Configuration $\mathrm{C} 2$ offered the best performance for all criteria. While using an unconventional orientation of $\mathrm{HX}$, it shows significant improvement in terms of temperature, velocity and air quality distribution. Having the jet impact the opposite wall at an angle other than a right angle with respect to a horizontal plane is desirable. Simulations show that all configurations exhibit velocities above the threshold in some areas, but $\mathrm{C} 2$ has a lower maximum velocity. It achieves this by spreading its fresh air jet flow over an increased area. $\mathrm{C} 2$ also avoids dead zones, due to the absence of symmetry in its flow structure and the absence of closed recirculation loops. However, $\mathrm{C} 2$ implies some problems for the HX installation. It is not sure that any HX can be installed at such an angle, in any farm. HX louvers could provide a pattern similar to $\mathrm{C} 2$, but this must be tested numerically. If configuration $\mathrm{C} 2$ is not possible, $\mathrm{C} 1$ is still a major improvement over $\mathrm{C} 0$. Blocking the fall of the jet on the opposite wall, after air strikes it, in configurations $\mathrm{C} 0$ and $\mathrm{C} 1$ could prevent high air velocities at bird level. Finally, as shown by $\mathrm{C} 0$, it is more important to have overall good air circulation than to align the HX flow with a heater geometry. 


\subsection{Conclusion}

The high level of propane consumption in cold climate broiler houses is both a financial and an environmental burden. Heat exchangers can help lower the energy requirement, but the effect of their integration in this type of building is relatively unknown as very few publications exist on the subject. In this study, CFD software OpenFOAM was used to create a 3D steady-state buoyant simulation of an existing broiler house in Canada, already equipped with two HX. A CFD model was validated with experimental data collected at the participating broiler house. Then, three alternative configurations (geometric position and orientation) were investigated in their ability to provide more uniform housing conditions at broiler height $(0.1 \mathrm{~m}$ above the litter level), based on three predominant parameters of interest : velocity, temperature and age of air. Two configurations (C1, C2) showed an improvement of performance at birds height while the third (C3) performed worse than the standard configuration (C0). Compared to $\mathrm{C} 0, \mathrm{C} 2$ showed a $45 \%$ improvement in age of air distribution and $24 \%$ in velocity distribution. Temperature also improved outside heater zones, but it was not reflected in the coefficient of variation for temperature, CoV. Despite some improvements, all tested configurations exceeded the recommended velocity threshold in some areas.

Many relevant questions remain to be addressed. What are the GHG savings associated with the housing conditions improvement? What is the sensitivity of the results to HX flow rate, exterior temperature, room dimensions (geometry), and height of heaters? What circulation fan airflow rate would be needed to eliminate dead zones, if they occur? What are the interesting configurations for a producer who decides to test a single HX in his house? How does the central computer heating algorithm interfere with the ventilation configuration? In all configurations, it was observed that age of air is slightly better near the floor than the cavity average. What device or strategy could increase this desirable effect? In sum, much work remains to be done to improve the integration of heat exchangers to broiler houses. 


\section{CONCLUSION}

Chicken meat production is a significant source of GHG, mainly due to feed production. Producers located in cold climates require an additional energy input for space heating. The associated propane consumption is both a financial and an environmental burden. During winter ventilation, heat exchangers can help lower the energy requirement, but their integration in this type of building is relatively unknown. Many authors have studied the improvement of direct ventilation, aiming to achieve adequate and uniform housing conditions near the floor, where the birds live. However, no equivalent literature is dedicated to heat exchanger ventilation, with the exception of Mostafa et al. (2012), who studied heat exchangers coupled with an air distribution duct system. Ductless heat exchangers usually imply a lower number of air inlets and outlets in the room, increasing the importance of air distribution. Improved distribution can increase the efficiency of the heat exchanger system, and ensure that propane savings are not done at the expense of uniform housing conditions.

In this thesis, an existent broiler house $\left(800 \mathrm{~m}^{2}\right)$ with two air-to-air ductless heat exchangers $\left(0.38 \mathrm{~m}^{3} \mathrm{~s}^{-1}\right)$ was simulated. Computational fluid dynamics (CFD) software OpenFOAM was used to create a 3D steady-state buoyant simulation with RNG $k$ - $\varepsilon$ turbulence model. The model was validated with experimental data collected at the participating broiler house. Air temperature, air velocity and age of air were used as criteria for evaluating housing conditions. The standard configuration $(\mathrm{C} 0)$ proved to have poor distribution of fresh air, due to a large recirculation zone at one end of the room. Three alternative configurations were investigated, which consisted of modifying the position and orientation of the heat exchangers. Two configurations $(\mathrm{C} 1, \mathrm{C} 2)$ showed an improvement of performance, while the longitudinal configuration (C3) performed worse than the standard configuration $(\mathrm{C} 0)$ on all criteria. Compared to $\mathrm{C} 0, \mathrm{C} 2$ showed a $45 \%$ improvement in age of air distribution and $24 \%$ in velocity distribution. Temperature also improved outside heater zones, but it was not reflected in the $\mathrm{CoV}$. The authors conclude it is generally best to avoid airflow symmetries

and recirculation zones. It was learned that the falling jet flow of fresh air causes excessive 
velocities in the broiler zone and that no tested configuration could reduce this problem significantly.

Much work thereby remains to be done in terms of heat exchanger integration to broiler house. The sensitivity of the results to HX flow rate, outside temperature and room dimensions, only to name a few, must be evaluated. General guidelines for HX positioning would be useful. Progress was made, but there is obviously still room for improvement. Propane price fluctuations and carbon taxes will continue to push producers to reduce their energy consumption and improve their housing conditions.

This thesis can also be viewed as a small step towards sustainable meat production. Transition to carbon-neutral meat will be required in order to meet the 2050 target of 1 ton $\mathrm{CO}_{2}$-eq per capita. Energy efficiency might lead to propane substitution with renewable energy, just like energy efficiency made electric cars possible. Work must also be done on the electrification of transport and agricultural machinery, which are responsible for the chicken feed embedded emissions. Nitrous oxide emissions from manure and fertilizer must be reduced to zero. The task is immense, but in the end, one can ask: is it easier to reduce the ecological footprint of meat or to convince billions of people to become vegetarians within 20 years? 


\section{APPENDIX I}

\section{OPENFOAM SOLVER VALIDATION CASE}

In this annex is presented the validation of the OpenFOAM code for 3D turbulent buoyant thermal flow by comparing it with experimental data from Nielsen (1976).

\section{Context}

Nielsen (1976) is a doctoral thesis that studies the thermal flow inside heated cavities. The study includes numerical and experimental data. While Nielsen studied many configurations, only one configuration is studied here, presented in Figure-A I-1. Air enters the cavity from the top, a wall jet develops near the ceiling, and a large recirculation forms in the cavity. The flow exits through the bottom right pipe. Cavity dimensions are: $\mathrm{H}=0.127 \mathrm{~m}$, $\mathrm{W}=4.7 \mathrm{H}=0.5969 \mathrm{~m}, \mathrm{~L}=3 \mathrm{H}=0.381 \mathrm{~m}, \mathrm{~h}=0.056 \mathrm{H}=0.007112 \mathrm{~m}, \mathrm{u}=0.16 \mathrm{H}=0.02032 \mathrm{~m}$.

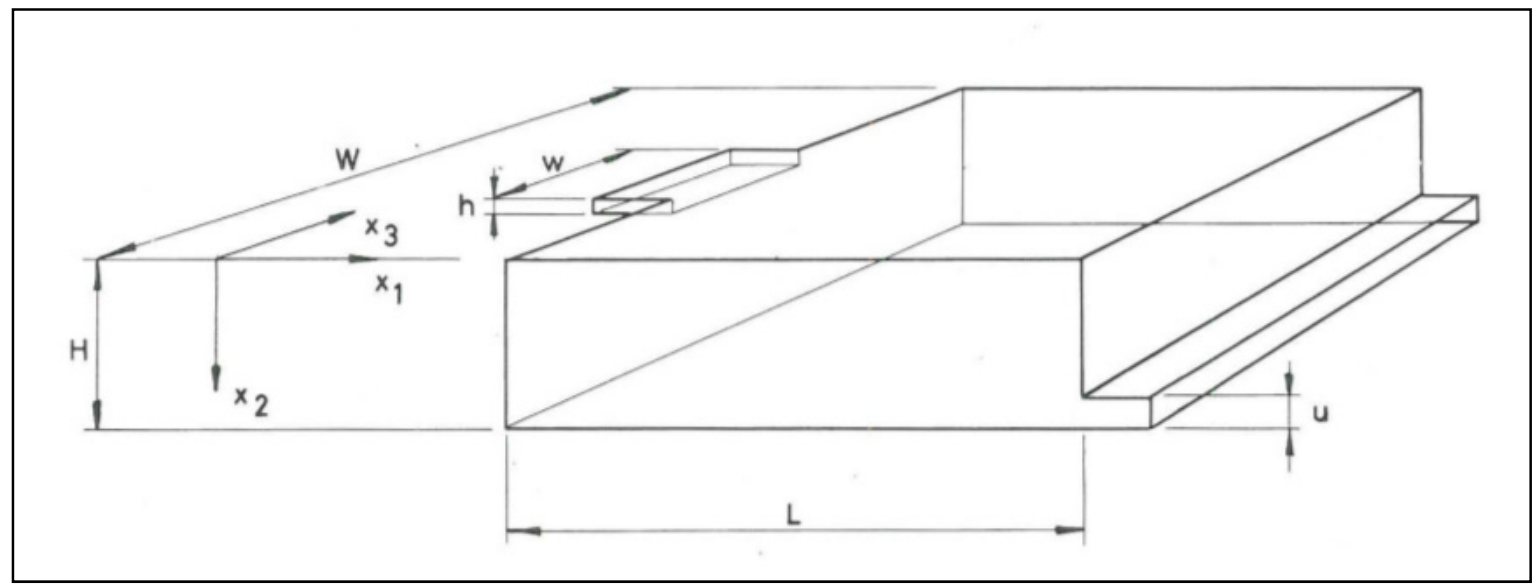

Figure-A I-1 Cavity geometry

Taken from Nielsen (1976)

\section{Calculating inlet velocity from Reynolds number indicated by Nielsen}

While Nielsen did not mention the inlet velocity, he indicated the Reynolds number of his simulations.

$$
\operatorname{Re}=\frac{\rho U_{0} L}{\mu}=7100
$$

where

$\mu=1.825 \mathrm{e}-05 \mathrm{~kg} \mathrm{~m}^{-1} \mathrm{~s}^{-1}$ (dry air at $20^{\circ} \mathrm{C}$ and 1 bar) (Çengel, 2007)

$\rho=1.204 \mathrm{~kg} \mathrm{~m}^{-3}$ (dry air at $20^{\circ} \mathrm{C}$ and 1 bar) (Çengel, 2007)

$\mathrm{L}=\mathrm{h}=0.007112 \mathrm{~m}$

Hence, 


$$
U_{0}=\frac{\operatorname{Re} \mu}{\rho L}=15.12 \mathrm{~ms}^{-1}
$$

Calculating temperature gain $\Delta T_{0}$ from Archimedes number

$\Delta \mathrm{T}_{0}$ is defined as average temperature gain of air between the inlet and the outlet of the cavity. Archimedes number is defined by Nielsen (1976) as:

$$
A r=\frac{\beta g h \Delta T_{0}}{U_{0}^{2}}
$$

where

$\mathrm{Ar}=1.8 \mathrm{e}-06$

$\beta=0.00343 \mathrm{~K}^{-1}$ (air at $20^{\circ} \mathrm{C}$ and $1 \mathrm{~atm}$ ) (Çengel, 2007)

$\mathrm{g}=9.81 \mathrm{~m} \mathrm{~s}^{-2}$

$\mathrm{h}=0.007112 \mathrm{~m}$

$\mathrm{U}_{0}=15.12 \mathrm{~m} \mathrm{~s}^{-1}$

Hence,

$$
\Delta T_{0}=\frac{A r U_{0}^{2}}{\beta g h}=1.72^{\circ} \mathrm{C}
$$

Thermal power required to achieve temperature gain $\Delta T_{0}$

Inlet area $\mathrm{A}_{\mathrm{i}}=\mathrm{W} * \mathrm{~h}=0.5969 \times 0.007112=0.00425 \mathrm{~m}^{2}$

Outlet area $\mathrm{A}_{\mathrm{o}}=\mathrm{W}^{*} \mathrm{u}=0.5969 \times 0.02032=0.0121 \mathrm{~m}^{2}$

Floor Area $\mathrm{A}_{\mathrm{f}}=\mathrm{W}^{*} \mathrm{~L}=0.5969 \times 0.381=0.2274 \mathrm{~m}^{2}$

Considering

$\dot{V}=\mathrm{U}_{0} \mathrm{x}$ area $=15.1 * 0.00425=0.064175 \mathrm{~m}^{3} \mathrm{~s}^{-1}$

$\rho=1.205 \mathrm{~kg} \mathrm{~m}^{-3}$

$\mathrm{c}_{\mathrm{p}}=1004.4 \mathrm{~J} \mathrm{~kg}^{-10} \mathrm{C}^{-1}$

Thermal power $\mathrm{Q}$ is calculated as

$$
Q=m c_{p} \Delta T_{0}=V \rho c_{p} \Delta T_{0}=133.59 \mathrm{~W}
$$

and specific thermal power $\mathrm{q}$ is

$$
q=\frac{Q}{A_{f}}=\frac{133.59}{0.2274}=587 \mathrm{~W} \mathrm{~m}^{-2}
$$

\section{Experimental method}

The cavity floor was heated with an electric heating film laid out on its surface. The inlet temperature was measured with one thermocouple. Two thermocouples were placed above 
each other in the outlet. The temperatures were averaged because air temperature in the outlet is not uniform. More details about the experimental methodology can be found in Nielsen (1976).

\section{Numerical method}

The numerical flow is simulated with the software OpenFOAM 3.0.1. The mesh is created with gmsh and contains 44,688 cells. Mesh is presented in Figure-A I-2. The buoyantSimpleFoam solver is used. Calculations were done on an Intel i7 processor with $8 \mathrm{~GB}$ of RAM. The flow is assumed to be stationary, turbulent, and buoyant. A Newtonian fluid is assumed and the ideal gas law is used as the equation of state. One should mention that the inlet tube is part of the domain. This ensures that a boundary is not positioned in a critical location where the pressure and velocity gradients are high. Walls are smooth and standard wall functions are used. The simulation was stopped after 9000 iterations when probe values converged and all residual values were inferior to $10 \mathrm{e}-06$. Boundary conditions are presented in Table-A I-1 Boundary conditions for validation case and OpenFOAM selected numerical schemes are presented in Table-A I-2. Air quality distribution is evaluated with the use of Age of Air (Li et al., 2003).

Table-A I-1 Boundary conditions for validation case

\begin{tabular}{|l|l|}
\hline Boundary Condition & Value \\
\hline Inlet velocity & $15.12 \mathrm{~m} \mathrm{~s}^{-1}$ \\
\hline Inlet pressure & zero gradient \\
\hline Outlet velocity & zero gradient \\
\hline Outlet pressure & $101,325 \mathrm{~Pa}$ \\
\hline Inlet temperature & $22^{\circ} \mathrm{C}$ \\
\hline Floor specific heat flux & $587 \mathrm{~W} \mathrm{~m}^{-2}$ \\
\hline
\end{tabular}

Table-A I-2 Main CFD inputs for all simulations

\begin{tabular}{|l|l|}
\hline Air laminar dynamic viscosity $(\mu)$ & $1.825 \mathrm{e}-05 \mathrm{~kg} \mathrm{~m}^{-1} \mathrm{~s}^{-1}$ \\
\hline Gravitational acceleration $(g)$ & $9.81 \mathrm{~m} \mathrm{~s}^{-2}$ \\
\hline Atmospheric pressure & $101,325 \mathrm{~Pa}$ \\
\hline Air laminar Prandtl $(\mathrm{Pr})\left(20^{\circ} \mathrm{C}, 1 \mathrm{~atm}\right)$ & 0.7309 \\
\hline Specific heat at constant pressure & $1004.4 \mathrm{~J} \mathrm{~kg}^{-1} 1 \mathrm{~K}^{-1}$ \\
\hline Molecular weight & $28.96 \mathrm{~kg} \mathrm{~mol}^{-1}$ \\
\hline
\end{tabular}


Table-A I-3 Discretization schemes used in OpenFOAM

\begin{tabular}{|l|l|}
\hline grad & pointCellsLeastSquare \\
\hline $\operatorname{div}($ phi,U) & bounded Gauss linearUpwind limited \\
\hline $\operatorname{div}($ phi,k) & bounded Gauss limitedLinear 1; \\
\hline $\operatorname{div}($ phi,K) & bounded Gauss limitedLinear 1; \\
\hline $\operatorname{div}($ phi,h $)$ & bounded Gauss limitedLinear 1; \\
\hline $\operatorname{div}($ phi,epsilon $)$ & bounded Gauss limitedLinear 1; \\
\hline $\operatorname{div}($ phi,AoA) & bounded Gauss limitedLinear 1; \\
\hline $\operatorname{div}\left(\left((\text { rho*nuEff })^{*} \operatorname{dev} 2(\mathrm{~T}(\operatorname{grad}(\mathrm{U})))\right)\right.$ & Gauss linear corrected \\
\hline laplacianSchemes default & Gauss linear corrected \\
\hline snGradSchemes & corrected \\
\hline
\end{tabular}

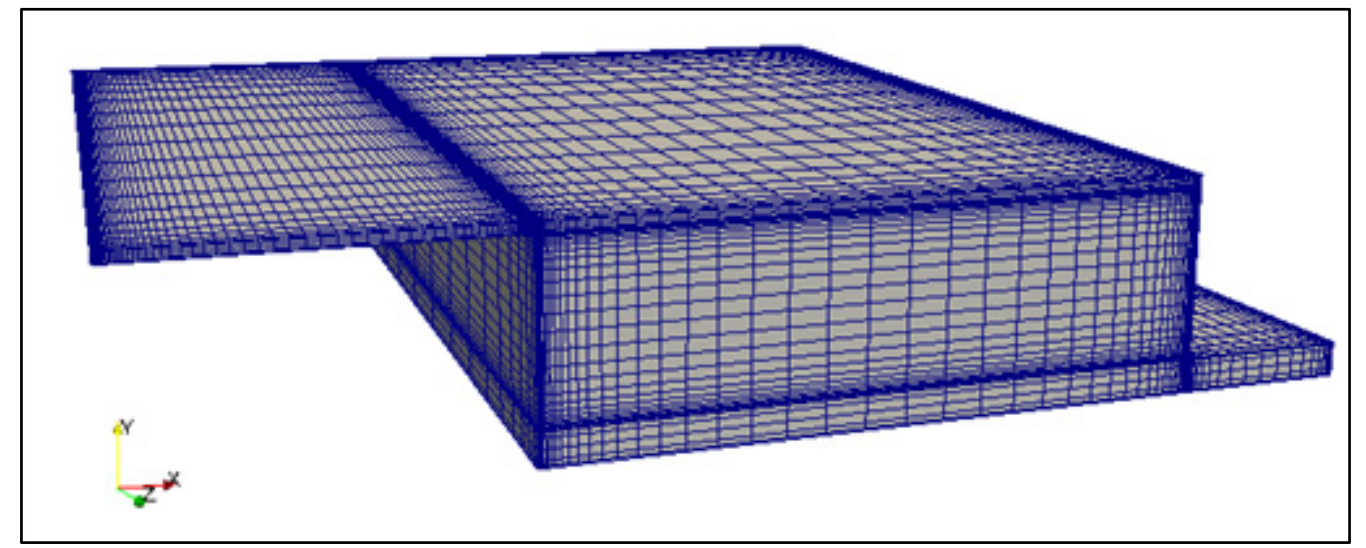

Figure-A I-2 Overview of mesh for validation case

\section{Results}

In this section are presented the main experimental and numerical results. Relative total residual values are presented in Figure-A I-3.Velocity profiles are presented in Figure-A I-4. Temperature profiles are presented in Figure-A I-5. Key values are compared in Table-A I-4. With RNG k-epsilon model, recommended values for $\mathrm{y}^{+}$are 30 to 500 . In the present simulation, $\mathrm{y}^{+}$values range between 1 and 150. While major surfaces have $\mathrm{y}^{+}$values below the recommended limit, results are not affected negatively by it. Results for age of air are presented in Table-A I-5. 


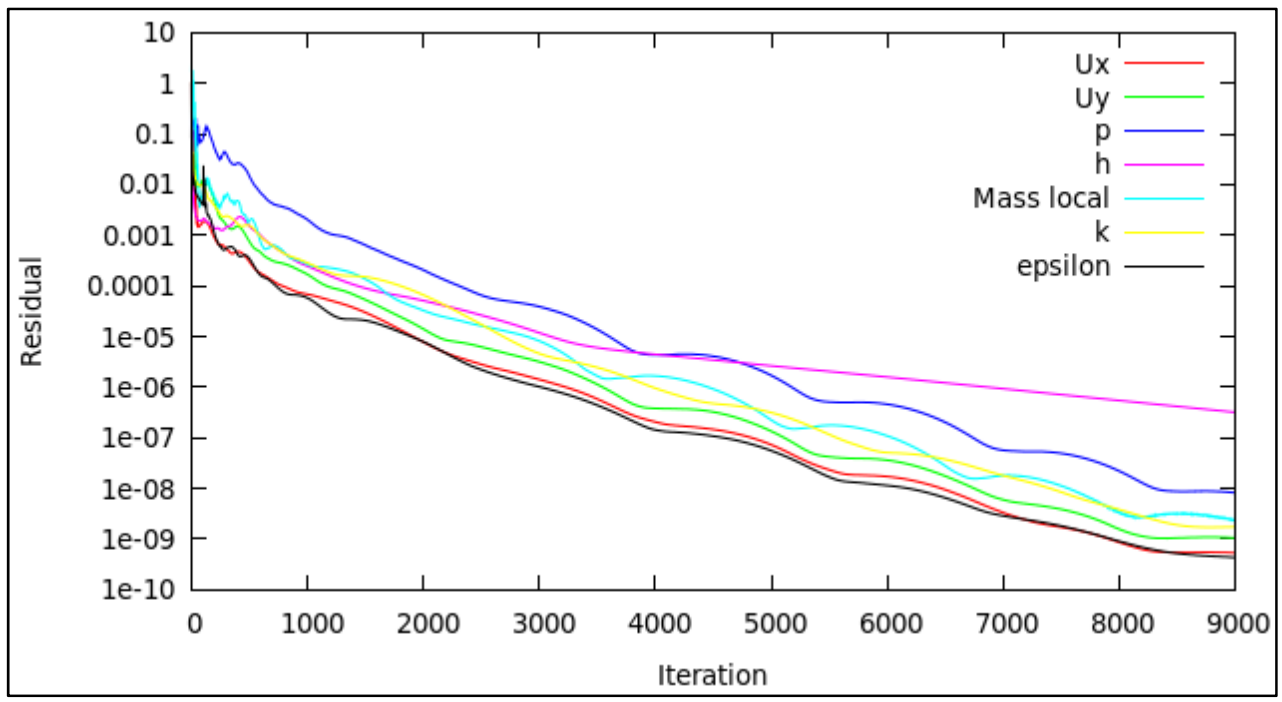

Figure-A I-3 Relative global residual values of numerical simulation

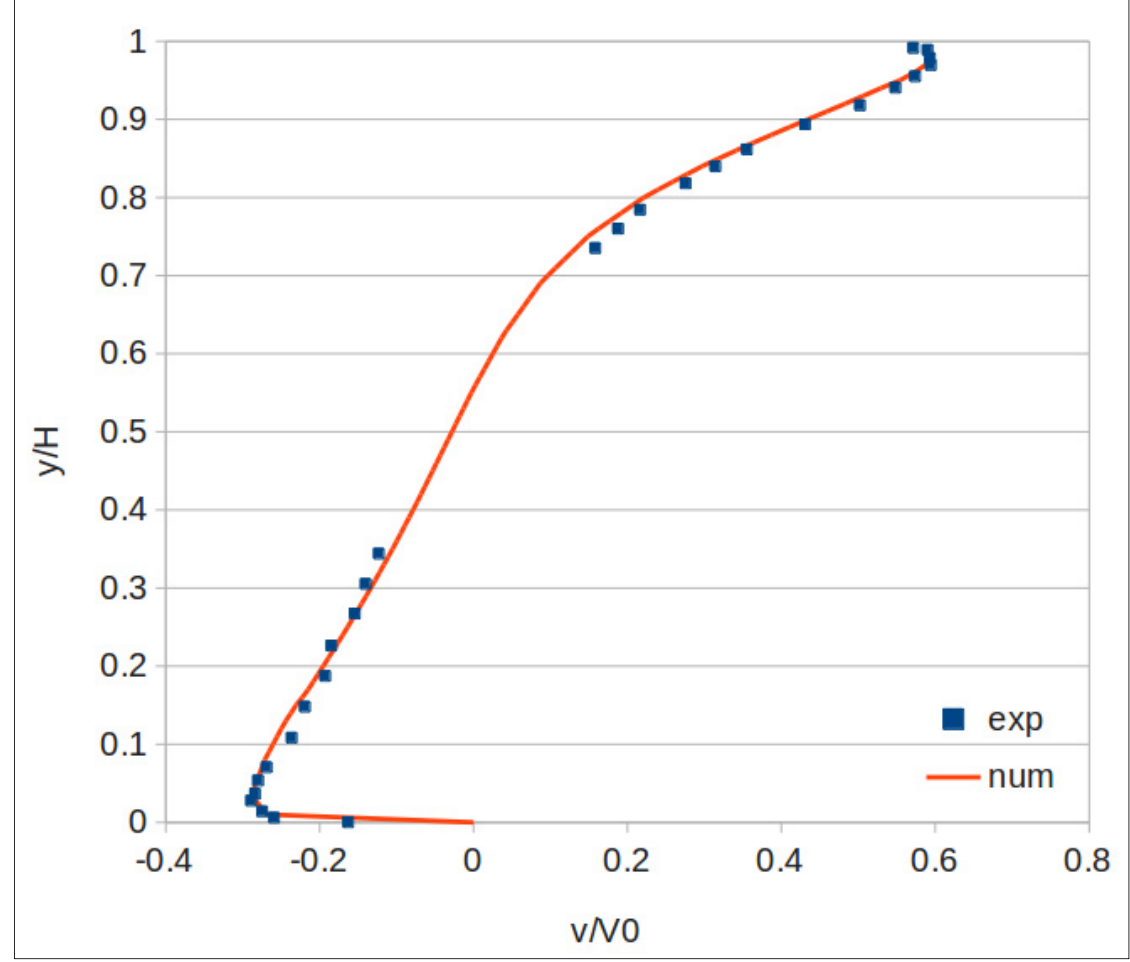

Figure-A I-4 Normalized $\mathrm{x}$-velocity along $\mathrm{y}$ axis $(\mathrm{x}=2 \mathrm{H}, \mathrm{z} / \mathrm{W}=0)$ 


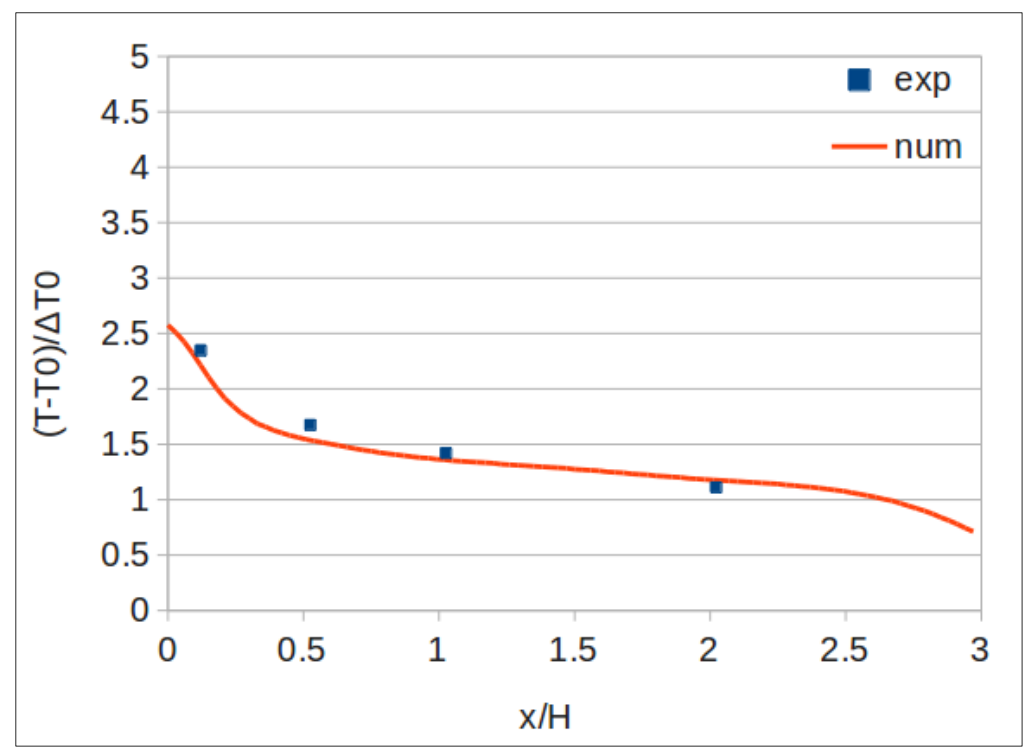

Figure-A I-5 Normalized air temperature along $\mathrm{x}$ axis

$$
(\mathrm{y}=0.25 \mathrm{H}, \mathrm{z} / \mathrm{W}=0.17)
$$

Table-A I-4 Comparing numerical results with experimental data

\begin{tabular}{|l|c|c|c|}
\hline & Experimental & Numerical & Relative error \\
\hline $\mathrm{U}_{\min }$ relative $\left(\mathrm{U} / \mathrm{U}_{0}\right)$ & -0.289 & -0.287 & $-0.8 \%$ \\
\hline $\mathrm{U}_{\max }$ relative $\left(\mathrm{U} / \mathrm{U}_{0}\right)$ & 0.594 & 0.594 & $-0.1 \%$ \\
\hline$\Delta \mathrm{T}\left({ }^{\circ} \mathrm{C}\right)$ & 1.72 & 2.19 & $28.1 \%$ \\
\hline
\end{tabular}

Although thermal energy is conserved, measured $\Delta \mathrm{T}$ differs from analytical value because temperature distribution at outlet varies according to flow distribution. To properly compare thermal results with those of Nielsen, it is important to normalize the temperature profile with the $\Delta \mathrm{T}$ obtained numerically. It is worth noting that Nielsen evaluated outlet temperature with only two points located at centerline of outlet. 
Table-A I-5 Validation results for the Age of Air method

\begin{tabular}{|l|c|}
\hline AoA at inlet & $0 \mathrm{~s}$ \\
\hline AoA at outlet (numerical value) & $0.4837 \mathrm{~s}$ \\
\hline Volume flow (numerical value) & $0.06401 \mathrm{~m}^{3} \mathrm{~s}^{-1}$ \\
\hline Domain size (numerical value) & $0.03094 \mathrm{~m}^{3}$ \\
\hline AoA at outlet (analytical value) & $0.4827 \mathrm{~s}$ \\
\hline Error (numeral/analytical) & $0.2 \%$ \\
\hline Mean spatial AoA (numerical value) & $0.6245 \mathrm{~s}$ \\
\hline
\end{tabular}

Results from Table-A I-5 confirm that the method for age of air is good. Air age at the outlet is equal to the expected value, and the spatial average is higher than output value because air distribution is not homogenous. 



\section{APPENDIX II}

\section{OPENFOAM BROILER ROOM SIMULATION DESIGN}

This section presents the numerical simulation done with OpenFOAM 3.0.1. OpenFOAM (Open Source Field Operation and Manipulation) is an open-source collection of C++ programs and libraries that, taken together, work as a CFD toolbox. OpenFOAM is based on the Finite Volume Method (Versteeg, 1995). This method evaluates the conservation equations over small control volumes that discretize the studied domain into a mesh. Here are related the most important simulation and parameters with their justification in the context of the present project. Main parameters concerning meshing, equations discretization, solvers, and boundary conditions are shown and justified. For general information about OpenFOAM functionality, refer to the OpenFOAM user guide, the OpenFOAM programmer's guide and books devoted to the subject (e.g. (Maric, 2014)). OpenFOAM case file for configuration C0 is available upon request at frederic.coulombe@hotmail.com.

\section{Numerical domain}

Only half of the broiler house interior space is included in the numerical domain to reduce the computational requirement of the simulation. The longitudinal trap is closed, coherent with cold weather operation. The inside of heat exchangers is not part of the numerical domain to reduce computational load.

Stereolithography files (.stl) are used to define the geometries to be meshed. The files are generated with a CAD software. A global assembly is generated before various STL files are exported. Each one corresponds to a zone (patch) that will receive a unique set of boundary conditions in the CFD simulation.

\section{PARTS $\rightarrow$ ASSEMBLY $\rightarrow$ PATCHES (.stl)}

The patches are presented in Table-A II-1. It should be noted that the heat exchanger is entirely independent. It includes its own inlet and outlet surfaces. It can be positioned anywhere in the domain, and does not have to be in contact with the walls. If it is positioned in the middle of the room, it behaves as if invisible pipes provided inflow and outflow to the exterior of the domain. The utility surfaceFeatureExtract is used to transform the STL files into the required file format (triSurfaceMesh (*.emesh)). 
Table-A II-1 Patches defined in the CFD simulation

\begin{tabular}{|l|l|}
\hline Filename & Description \\
\hline HX_inlet & Heat exchanger fresh air inlet \\
\hline HX_outlet & Heat exchanger staled air outlet \\
\hline HX & Heat exchanger walls \\
\hline ExteriorWalls & All exterior walls (significant heat losses) \\
\hline Staircase & Interior walls (negligible heat losses) \\
\hline Bottom1, Bottom2, Bottom3 & Bottom surface of heater (adiabatic surface) \\
\hline Heater1, Heater2, Heater3 & Top surface of heater (hot surface) \\
\hline HotSpot1, HotSpot2, HotSpot3 & $\begin{array}{l}\text { Floor area where radiant heat flux from heater is } \\
\text { applied }\end{array}$ \\
\hline UnheatedFloor & Remaining floor area \\
\hline Ceiling & Ceiling area (negligible heat losses) \\
\hline SymmetryPlane & Symmetry plane that cuts the room in two \\
\hline
\end{tabular}

\section{Meshing}

The mesh is created in several steps. The utility blockMesh builds the initial mesh, made of cubic hexahedrons with dimensions of $0.25 \mathrm{~m}$. Cubes are chosen because snappyHexMesh, provides better results when working from a cubic initial mesh. snappyHexMesh is an automatic split hex mesher, that splits cells and snaps points to the surface of the geometry. The three successive steps available in snappyHexMesh are, in order: castelling, snapping and addLayers. Only the castelling and snapping steps are used in the present case. Castelling processing is illustrated in Table-A II-1. snappyHexMesh parameters for castelling and snapping are presented in Table-A II-2 to Table-A II-5. Although the resulting matrix is sparse, it is not a structured mesh: snappyHexMesh generates unstructured meshes.

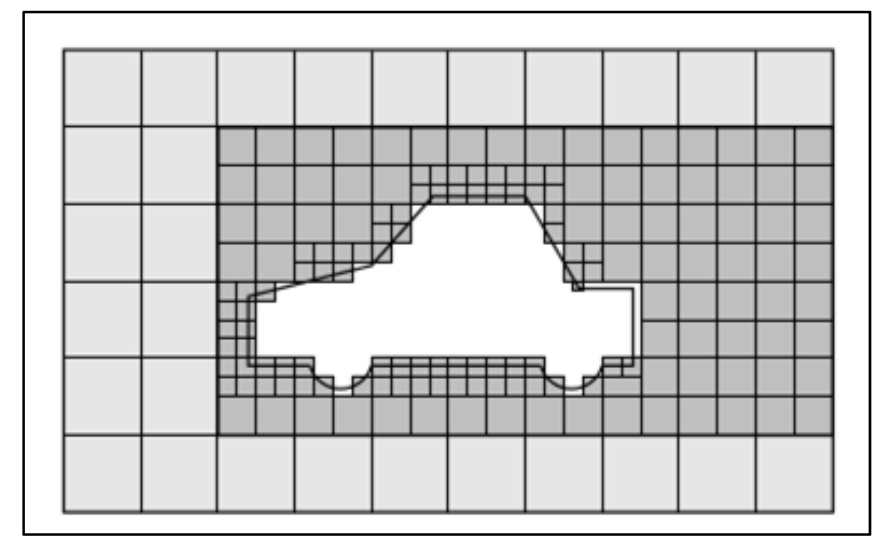

Figure-A II-1 Illustration of the concept of castelling around a car (OpenFOAM, 2015) 


\section{Refinement regions}

Many regions are defined inside the snappyHexMeshDict. The cells inside those regions are refined according to a specified level. Refinement is done by recursively subdividing by eight octants. Some refinement regions are tied to the heat exchanger. They are defined through a stl file as well. That way, the mesh quality near heat exchangers remains constant as the heat exchangers are moved around in the parametric study.

Table-A II-2 Refinement level of various regions defined in the snappyHexMesh process

\begin{tabular}{|l|c|}
\hline Region names & Refinement level \\
\hline Boxes & 3 \\
\hline
\end{tabular}

Table-A II-3 Refinement level of various surfaces defined in the snappyHexMesh process

\begin{tabular}{|l|c|}
\hline Surfaces names ExteriorWalls, HotSpot1, & Refinement level \\
\hline Ceiling, & 0 \\
$\begin{array}{l}\text { HotSpot2,HotSpot3, Staircase, UnheatedFloor, } \\
\text { SymmetryPlane }\end{array}$ & \\
\hline HX & 1 \\
\hline HX_inlet, HX_outlet & 5 \\
\hline $\begin{array}{l}\text { Heater1, Heater2, Heater3, Bottom1, Bottom2, } \\
\text { Bottom3 }\end{array}$ & 3 \\
\hline
\end{tabular}

Table-A II-4 Parameters for the castellating step of the meshing process

\begin{tabular}{|l|c|}
\hline Parameter & Value \\
\hline maxLocalCells & 3000000 \\
\hline maxGlobalCells & 3500000 \\
\hline minRefinementCells & 0 \\
\hline maxLoadUnbalance & 0.1 \\
\hline nCellsBetweenLevels & 11 \\
\hline resolveFeatureAngle & 30 \\
\hline
\end{tabular}


Table-A II-5 Parameters for the snapping step of the meshing process

\begin{tabular}{|l|c|}
\hline Parameter & Value \\
\hline nSmoothPatch & 0 \\
\hline tolerance & 0.9 \\
\hline nSolveIter & 30 \\
\hline nRelaxIter & 10 \\
\hline nFeatureSnapIter & 10 \\
\hline implicitFeatureSnap & false \\
\hline explicitFeatureSnap & true \\
\hline multiRegionFeatureSnap & true \\
\hline
\end{tabular}

Meshing quality is controlled by default or user-defined parameters. The automatic meshing process only stops when the mesh quality parameters are respected or that the maximum number of iteration is exceeded. Therefore, snappyHexMesh can produce non-compliant meshes if not used properly.

Flow characterization

The flow regime is evaluated by calculating the approximate Reynolds number at the inlet of the cavity. The heat exchanger inlet hydraulic diameter is chosen as the characteristic length. The heat exchanger airflow into the cavity is considered a jet flow. Average velocity is

$$
U_{\text {avg }}=\frac{\dot{V}}{A}=\frac{0.378 \mathrm{~m}^{3} \mathrm{~s}^{-1}}{0.08 \mathrm{~m}^{2}}=4.72 \mathrm{~m} \mathrm{~s}^{-1}
$$

For the rectangular inlet of the heat exchanger, the hydraulic diameter $D_{h}$ is defined as

$$
D_{h}=\frac{2 a b}{a+b}=\frac{2 \cdot 0.08 \cdot 0.1}{0.08+0.1}=0.18 m
$$

Considering a molecular viscosity of $1.864 \mathrm{E}-5 \mathrm{~kg} \mathrm{~m}^{-1} \mathrm{~s}^{-1}$ and a density of $1.2 \mathrm{~kg} \mathrm{~m}^{-3}$, the Reynolds value is

$$
\operatorname{Re}=\frac{\rho U_{\text {avg }} D_{h}}{\mu}=54,020
$$

This Reynolds value is high above the critical value of 10,000 for rectangular ducts; hence a turbulent model is required. The heat exchanger fan also induces some flow instabilities.

\section{CFD solver}

Assuming that no physical instabilities occur in the room and that a steady state exists inside the cavity, a steady-state solver was selected. buoyantSimpleFoam (BSF) is the pressurebased segregated solver used to solve the case. BSF is a solver for buoyant lightlycompressible flow. The fluid behaviour inside the cavity is affected by both the HX jet flow 
and the heaters buoyancy flow (i.e. mixed convection). The conservation equations to be solved are the compressible steady state Reynolds-Averaged Navier-Stokes (RANS) equations in their conservative form (Eulerian reference frame). They are

$$
\begin{gathered}
\nabla \cdot(\rho \bar{U})=0 \\
\nabla \cdot(\rho \bar{U} \otimes \bar{U})-\nabla \cdot\left[\mu_{\mathrm{eff}}\left(\nabla \bar{U}+\nabla \bar{U}^{T}\right)-\frac{2}{3} \mu_{\mathrm{eff}}(\nabla \cdot \bar{U} \cdot I)\right]=-\nabla p-\rho \bar{g} \\
\nabla \cdot(\rho \bar{U} h)+\nabla \cdot(\rho \bar{U} K)-\Delta\left(\alpha_{e f f} h\right)=\rho(\bar{U} \cdot \vec{g})
\end{gathered}
$$

Note that the viscous dissipation source term is not included in the energy equation of the BSF solver. To link pressure with density, the set of equations is completed by an equation of state (i.e. ideal gas law) which is

$$
\rho=\frac{p}{R T}
$$

The effective viscosity $\mu_{\text {eff }}$ is defined as

$$
\mu_{e f f}=\mu+\mu_{t}
$$

The laminar viscosity $\mu$ is given by the thermophysical model and the turbulent viscosity $\mu_{t}$ is calculated by the turbulence model. In a similar fashion, effective thermal diffusivity $\alpha_{\text {eff }}$ is calculated as

$$
\alpha_{e f f}=\alpha_{\text {lam }}+\alpha_{t}=\frac{\rho v}{\operatorname{Pr}}+\frac{\rho v_{t}}{\operatorname{Pr}_{t}}
$$

Since enthalpy is selected as energy variable, kinetic energy is considered in the energy equation. Kinetic energy $\mathrm{K}$ is defined as

$$
K=\frac{|u|^{2}}{2}
$$

In the solver code, it can be seen that the terms $-\nabla p+\rho \vec{g}$ are in fact substituted with $-\nabla p_{r g h}-(\vec{g} \cdot \vec{r}) \nabla \rho$. The equivalence can be shown as

$$
\begin{aligned}
-\nabla p+\rho \vec{g} & =-\nabla\left(p_{r g h}+\rho \vec{g} \cdot \vec{r}\right)+\rho \vec{g} \\
& =-\nabla p_{r g h}-(\vec{g} \cdot \vec{r}) \nabla \rho-\rho \vec{g}+\rho \vec{g} \\
& =-\nabla p_{r g h}-(\vec{g} \cdot \vec{r}) \nabla \rho
\end{aligned}
$$

where $p_{r g h}$ is a modified static pressure defined as $p_{r g h}=p-\rho \vec{g} \cdot \vec{r}$ and $\vec{r}$ is the position vector. 
In BSF, the equation energy can be solved with internal energy or sensible enthalpy. In the present case, sensible enthalpy is chosen (Limane et al., 2015). For an ideal gas, enthalpy and internal energy are defined as

$$
\begin{gathered}
h=e+\frac{p}{\rho} \\
e=c_{v} T
\end{gathered}
$$

The BSF algorithm is similar to the SIMPLER algorithm, and proceeds in the following way:

1- Solve discretized momentum equations

2- Solve the energy equation

3- Solve the pressure equation (not a pressure correction equation)

4- Solve other transport equations $\varphi$ (i.e. k, epsilon, Age of Air)

5 - Verify convergence criteria and repeat cycle if convergence is not attained.

Contrarily to the traditional SIMPLE algorithm as defined originally by (S. V. Patankar, 1980), BSF does not use a staggered mesh to avoid the advent of a checkerboard pressure field. Instead, BSF uses a collocated mesh with Rhie-Chow interpolation.

Air quality is evaluated with the transport of a scalar quantity AoA. A source term equal to density ensures that age of air is proportional to time spent inside the cavity. Volume mode is specific, meaning the injection rate is $\rho \mathrm{s} \mathrm{m}^{-3}$. AutoSchemes 'False' means that the velocity discretization scheme was not applied to AoA transport, but rather that it has its own scheme defined in fvSchemes.

Thermodynamic model

heRhoThermo is a thermodynamic model for a constant mixture, based on density. Parameters are presented in Table-A II-6 and Table-A II-7. It assumes a constant molecular viscosity (mu) and Prandtl number ( $\mathrm{Pr}$ ). Heat of fusion is irrelevant since the sensible form of enthalpy is chosen to solve the energy equation; hence it is set to zero. The perfect gas law is chosen as the equation of state. This allows calculating density, which is a supplementary unknown quantity when using a compressible solver. The specific heat, molecular viscosity and Prandtl value are based on a temperature of $303 \mathrm{~K}\left(30^{\circ} \mathrm{C}\right)$, which is the approximate temperature set-point in the room. Molecular weight is based on dry air. It is irrelevant to prescribe the thermal conductivity $k$ since the Prandtl number is prescribed. Prandtl number is defined as

$$
\operatorname{Pr}=\frac{\mu c_{p}}{k}
$$


Table-A II-6 Thermodynamic model parameters

\begin{tabular}{|l|l|}
\hline Parameter & Value \\
\hline type & heRhoThermo \\
\hline mixture & pureMixture \\
\hline transport & const \\
\hline thermo & hConst \\
\hline equationOfState & perfectGas \\
\hline specie & specie \\
\hline energy & sensibleEnthalpy \\
\hline
\end{tabular}

Table-A II-7 Fluid properties

\begin{tabular}{|l|l|l|}
\hline Parameter & OpenFOAM notation & Value \\
\hline molecular weight & molWeight & $28.96 \mathrm{~g} \mathrm{~mol}^{-1}$ \\
\hline specific heat at constant pressure & $\mathrm{Cp}$ & $1007 \mathrm{~J} \mathrm{~kg}^{-1} \mathrm{~K}^{-1}$ \\
\hline heat of fusion & $\mathrm{Hf}$ & $0 \mathrm{~J} \mathrm{~mol}^{-1}$ \\
\hline molecular viscosity & $\mathrm{mu}$ & $1.872 \mathrm{e}-05 \mathrm{~kg} \mathrm{~m}^{-1} \mathrm{~s}^{-1}$ \\
\hline Prandtl number & $\mathrm{Pr}$ & 0.7282 \\
\hline
\end{tabular}

\section{Turbulence model}

The closure problem is solved by including the RNG k- $\varepsilon$ turbulence model, which is a twoequation turbulence model. This turbulence model is valid for fully turbulent flow. OpenFOAM 3.0 implements the version described by (Yakhot et al., 1992). The standard kepsilon model uses constant values for the turbulent Prandtl number, defined by the user, while the RNG model uses analytical equations to derive some of the constants $\left(\mathrm{C}_{1}, \mathrm{C}_{2}\right)$. $\mathrm{RNG}$ model main difference is the additional dissipation production term $\mathrm{R}_{\varepsilon}$. In strained flow, it induces a lower turbulent viscosity than the standard k- $\varepsilon$ model. Turbulent kinetic energy is a way to express the amount of energy contained in the velocity fluctuations caused by turbulence.

$$
k=\frac{1}{2}\left(\overline{u_{x}^{\prime} u_{x}^{\prime}}+\overline{u_{y}^{\prime} u_{y}^{\prime}}+\overline{u_{z}^{\prime} u_{z}^{\prime}}\right)
$$

Therefore, for an isotropic turbulence model,

$$
k=\frac{3}{2} u^{\prime 2}
$$

OF default values for the RNG k-epsilon model are used. Turbulent viscosity (nut) field is calculated from the result of those equations. 


$$
\mu_{t}=\frac{\rho C_{\mu} k^{2}}{\varepsilon}
$$

Steady-state solvers are unstable by nature and require under-relaxation. The ideal underrelaxation factor for each field is a compromise between simulation stability (e.g. avoid flow oscillations) and rapidity of convergence. Adequate factors are flow dependent and the relaxation factors used are presented in Table-A II-8. Two types of under-relaxation can be used: equation relaxation, which involves modifying the solution matrix and source before each iteration (also called implicit relaxation) or field relaxation in which the field is directly modified (also called explicit relaxation). An example of the under-relaxation of the velocity equation is

$$
\frac{a_{p} u^{\text {new }}}{\alpha}=\sum_{n b} a_{n b} u_{n b}+b+\frac{1-\alpha}{\alpha} a_{p} u^{\text {old }}
$$

where $\alpha$ is the under-relaxation factor, $u^{\text {new }}$ is the present velocity of the given cell, $u^{\text {old }}$ is the previous iteration velocity, $\mathrm{b}$ is the source term, $a_{p}$ is the coefficient for the current cell, and $a_{n b}$ designates the coefficients of the neighbour cells (ANSYS, 2014a). An example of the under-relaxation of the velocity field is

$$
u^{\text {new }}=\alpha u+(1-\alpha) u^{\text {old }}
$$

where $\mathrm{u}$ is the velocity cell value obtained from the non-relaxed equation.

Table-A II-8 Under-relaxation factors

\begin{tabular}{|l|l|}
\hline Zone/Surface & Value \\
\hline field relaxation & \\
\hline $\mathrm{p}$ & 0.3 \\
\hline equation relaxation & \\
\hline $\mathrm{U}$ & 0.4 \\
\hline $\mathrm{k}$, epsilon & 0.3 \\
\hline $\mathrm{h}$ & 0.7 \\
\hline
\end{tabular}

Algebraic solver

While the CFD solver prescribes the differential equations and the algorithm by which they are linked, the algebraic solver is the algorithm by which the resulting algebraic system is solved. The solver for the pressure equation is the Generalized Geometric-Algebraic MultiGrid $(G A M G)$ solver. The solver for the $\mathrm{U}, \mathrm{h}, \mathrm{k}, \varepsilon$ equations is the smoothSolver. The smoother used for all equations is the Gauss-Seidel smoother.

To reduce the calculation time, domain parallelization is done. The calculation effort is split between four processors, with the openMPI utility. The OpenFOAM dictionary decomposeParDict prescribes the way the numerical domain is split between procesors. The method used is the simple method, which is not related to the SIMPLE algorithm. Residual values are calculated with the L2-norm of the normalized residual vector. Normalization is 
done with respect to absolute residual values of the first iteration. Simulation is stopped when residual values have reduced by three orders of magnitude and are stable.

Discretization schemes

Discretization schemes transform partial derivatives terms into algebraic terms to form an algebraic system of equations. The schemes are all based on Gauss integration. The advected field $(\varphi)$ is interpolated to the cell faces by one of a selection of schemes (e.g. upwind, linearUpwind, linear). Discretization schemes used in this simulation are presented in TableA II-9. The term corrected refers to an explicit correction added to maintain second-order accuracy with non-orthogonal mesh. limitedLinear is a "scheme that limits towards upwind in regions of rapidly changing gradient and requires a coefficient, where 1 is the strongest limiting, tending towards linear as the coefficient tends to 0" (OpenFOAM, 2015). By adding the term bounded, the term $\nabla \cdot U$ of the material derivative is included in the discretization. This helps maintain boundedness of the solution variable and improve convergence.

Table-A II-9 Discretization schemes

\begin{tabular}{|c|c|c|}
\hline OpenFoam term & $\begin{array}{l}\text { Mathematical } \\
\text { expression }\end{array}$ & Discretization scheme \\
\hline ddt (default) & $\frac{\partial}{\partial t}$ & steadyState \\
\hline gradient (default) & $\nabla$ & Gauss linear \\
\hline $\operatorname{div}$ (default) & $\nabla$. & none; \\
\hline $\operatorname{div}(\mathrm{phi}, \mathrm{U})$ & $\nabla \cdot(\varphi u)$ & bounded Gauss upwind corrected; \\
\hline $\operatorname{div}(\mathrm{phi}, \mathrm{K})$ & $\nabla \cdot(\varphi K)$ & bounded Gauss upwind corrected; \\
\hline $\operatorname{div}(\mathrm{phi}, \mathrm{k})$ & $\nabla \cdot(\varphi k)$ & bounded Gauss upwind corrected; \\
\hline $\operatorname{div}(p h i, h)$ & $\nabla \cdot(\varphi h)$ & bounded Gauss upwind corrected; \\
\hline $\operatorname{div}($ phi,epsilon) & $\nabla \cdot(\varphi \varepsilon)$ & bounded Gauss upwind corrected; \\
\hline $\operatorname{div}(\mathrm{phi}, \mathrm{AoA})$ & $\nabla \cdot(\varphi A o A)$ & bounded Gauss upwind corrected; \\
\hline $\begin{array}{l}\operatorname{div}\left(\left((\operatorname{rho} * \text { nuEff })^{*}\right.\right. \\
\operatorname{dev} 2(T(\operatorname{grad}(U)))))\end{array}$ & $\nabla \cdot\left(\left(\rho v_{e f f}\right) \nabla \cdot\left((\nabla \vec{U})^{T}\right)\right.$ & Gauss linear corrected \\
\hline laplacian (default) & $\Delta$ & Gauss linear corrected \\
\hline interpolation (default) & N/A & linear \\
\hline surface normal gradient (default) & $\mathrm{N} / \mathrm{A}$ & corrected \\
\hline
\end{tabular}


Boundary conditions (BC)

In this section, information is given about the various boundary conditions of the numerical simulation. Detailed boundary conditions for configuration $\mathrm{C} 0$ are presented in Table-A II-10 to Table-A II-18. Terms are formatted in compatibility with the OpenFOAM code.

\section{$\operatorname{Velocity}(U)$}

The inlet designates the fresh air entering the room, while the outlet designates the staled air leaving the room. Inlet velocity is uniform and prescribed by the $\mathrm{BC}$ called flowRateInletVelocity. A uniform inlet velocity is provided by prescribing a fixed mass flow rate and an inlet density. Outlet velocity is set as variable with the $\mathrm{BC}$ zeroGradient.

Wall functions are used to approximate velocity profiles near the surfaces. All surfaces are treated this way. Wall functions reduce the mesh requirement, by assuming a logarithmic profile near the wall. To be accurate, the size of the first layer must be within a certain range. For the RNG k-epsilon turbulence model, the first layer must have a $\mathrm{Y}+$ value between 30 and 500 .

\section{Modified pressure (p_rgh)}

fixedFluxPressure is a pressure BC used instead of zeroGradient for buoyant flows.

\section{Static pressure (p)}

At all boundaries, static pressure is calculated from the modified pressure, using the calculated $\mathrm{BC}$.

\section{Turbulent kinetic energy (k)}

Turbulent kinetic energy at cavity inlet is prescribed with a BC based on turbulent intensity, turbulentIntensityKineticEnergyInlet. Turbulent intensity (TI) is defined as

$$
T I=\frac{u^{\prime}}{U}
$$

where $\mathrm{u}^{\prime}$ is the root-mean-square of the turbulent velocity fluctuations. Based on measurements, TI is fixed to $13 \%$, which is considered a medium turbulence level (ANSYS, 2014b). A wall function, kqRwallFunction, models the evolution of turbulent quantities $\mathrm{k}$ and epsilon near solid surfaces. This standard wall function assumes an equilibrium turbulent boundary layer, which is not always the case in a ventilated cavity but provides some acceptable results (Bustamante et al., 2013). Dimensionless wall distance is defined as

$$
y+=\frac{u_{T} y}{v}
$$

where $u_{T}$ is the frictional velocity, $\mathrm{y}$ is the distance between wall and first cell center and $v$ is the molecular kinematic viscosity. Fields $\mathrm{k}$ and $\varepsilon$ are initiated to non-zero values to avoid division by zero (i.e. Floating Point Exception error) as turbulent viscosity is calculated during first iteration. 


\section{Turbulent kinetic energy dissipation rate (epsilon)}

At inlet, $\varepsilon$ is a function of turbulence intensity TI. For solid walls, boundaries, epsilonWallFunction is used.

\section{Kinematic turbulent viscosity (nut)}

nutkWallFunction wall function is used for the kinematic turbulent viscosity field.

\section{Thermal diffusivity (at)}

Near the walls, thermal diffusivity is calculated by a wall function named alphatWallFunction. While turbulent Prandtl tends to be near 1 for many flows, it is generally lower near walls. The recommended value is 0.85 (ANSYS, 2014b).

\section{Temperature (T)}

The thermal $\mathrm{BC}$ for exterior walls is a fixed flux, with $\mathrm{BC}$ called exteriorWallTemperature. Heat losses are approximated from energy balance and Fourier's law and then prescribed as a uniform heat flux over the entire surface of exterior walls. This ensures energy balance over the domain. It also ensures that the walls do not provide any heat whatever the temperature of air in a cell next to the boundary.

\section{Age of Air (AoA)}

Like all other fields, the transport scalar AoA field needs BC. Inlet BC is set to fixedValue 0, implying that incoming air is perfectly fresh. Walls are set to a zero gradient $\mathrm{BC}$, so that no scalar quantity is lost or gained through the walls. Age of Air internal field is initialized to a non-zero value to avoid a division by zero when calculating post-treatment variables for the first iteration.

Table-A II-10 Velocity (U) boundary conditions $\left[\mathrm{m} \mathrm{s}^{-1}\right]$

\begin{tabular}{|c|c|}
\hline Patch & Parameter/Value \\
\hline internalField (initial guess) & value uniform $\left(\begin{array}{lll}0 & 0 & 0\end{array}\right)$; \\
\hline HX_inlet & 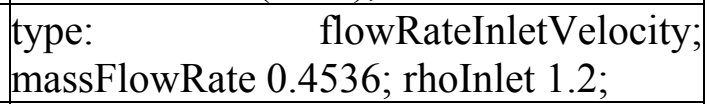 \\
\hline HX_outlet & $\begin{array}{l}\text { type zeroGradient; } \\
\text { value uniform }\left(\begin{array}{lll}0 & 0 & 0\end{array}\right)\end{array}$ \\
\hline $\begin{array}{l}\text { ExteriorWalls, Staircase, HeatersTop, Heater1, } \\
\text { Heater2, Heater3, HotSpot1, HotSpot2, } \\
\text { HotSpot3, UnheatedFloor, Ceiling }\end{array}$ & type: fixedValue; value uniform $\left(\begin{array}{lll}0 & 0 & 0\end{array}\right)$; \\
\hline $\begin{array}{l}\text { HX, Heater1, Heater2, Heater3, Bottom1, } \\
\text { Bottom2, Bottom3 }\end{array}$ & slip \\
\hline SymmetryPlane & symmetry \\
\hline
\end{tabular}


Table-A II-11 Modified pressure (p_rgh) boundary conditions $\left[\mathrm{kg} \mathrm{m}^{-1} \mathrm{~s}^{-2}\right]$

\begin{tabular}{|l|l|}
\hline Patch & Parameter/Value \\
\hline internalField (initial guess) & $101325[\mathrm{~Pa}]$ \\
\hline HX inlet & type: fixedFluxPressure \\
\hline HX_outlet & type: fixedValue; value uniform 101325 \\
\hline $\begin{array}{l}\text { HX, ExteriorWalls, Bottom1, Bottom2, } \\
\text { Bottom3, Staircase, Heater1, Heater2, Heater3, } \\
\text { HotSpot1, HotSpot2, HotSpot3, }\end{array}$ & \\
\hline $\begin{array}{l}\text { UnheatedFloor, Ceiling } \\
\text { SymmetryPlane }\end{array}$ & \\
\hline
\end{tabular}

Table-A II-12 Static pressure (p) boundary conditions $\left[\mathrm{kg} \mathrm{m}^{-1} \mathrm{~s}^{-2}\right]$

\begin{tabular}{|l|l|}
\hline Patch & Parameter/Value \\
\hline internalField (initial guess) & $101325[\mathrm{~Pa}]$ \\
\hline HX_inlet, HX_outlet, HX, ExteriorWalls, & type: calculated; \\
Heater1, Heater2, Heater3, HotSpot1, & \\
HotSpot2, HotSpot3, UnheatedFloor, Ceiling, & \\
Bottom1, Bottom2, Bottom3 & \\
\hline SymmetryPlane & symmetry \\
\hline
\end{tabular}

Table-A II-13 Turbulent kinetic energy (k) boundary conditions $\left[\mathrm{m}^{2} \mathrm{~s}^{-2}\right]$

\begin{tabular}{|l|l|}
\hline Patch & Parameter/Value \\
\hline internalField (initial guess) & uniform 0.01; \\
\hline HX_inlet & $\begin{array}{l}\text { type: } \\
\text { turbulentIntensityKineticEnergyInlet; } \\
\text { intensity 0.13; }\end{array}$ \\
\hline HX_outlet & type: zeroGradient; \\
\hline $\begin{array}{l}\text { HX, ExteriorWalls, Staircase, Heater1, } \\
\text { Heater2, Heater3, HotSpot1, HotSpot2, } \\
\text { HotSpot3, UnheatedFloor, Ceiling, Bottom1, } \\
\text { Bottom2, Bottom3 }\end{array}$ & \\
\hline SymmetryPlane & type: kqRWallFunction; \\
\hline
\end{tabular}


Table-A II-14 Turbulent dissipation ( $(\varepsilon)$ boundary conditions $\left[\mathrm{m}^{2} \mathrm{~s}^{-3}\right]$

\begin{tabular}{|l|l|}
\hline Patch & Parameter/Value \\
\hline internalField (initial guess) & uniform 0.01; \\
\hline HX_inlet & $\begin{array}{l}\text { type: } \\
\text { turbulentIntensityKineticEnergyInlet; } \\
\text { intensity } 0.05 ;\end{array}$ \\
\hline HX_outlet & type: zeroGradient; \\
\hline HX, ExteriorWalls, Staircase, Heater1, & type: epsilonWallFunction; \\
Heater2, Heater3, HotSpot1, HotSpot2, \\
$\begin{array}{l}\text { HotSpot3, UnheatedFloor, Ceiling, Bottom1, } \\
\text { Bottom2, Bottom3 }\end{array}$ \\
\hline SymmetryPlane & \\
\hline
\end{tabular}

Table-A II-15 Kinematic turbulent viscosity (nut) boundary conditions $\left[\mathrm{m}^{2} \mathrm{~s}^{-1}\right]$

\begin{tabular}{|l|l|}
\hline Patch & Parameter/Value \\
\hline internalField (initial guess) & uniform 0.01; \\
\hline HX_inlet & type: calculated \\
\hline HX_outlet & type: calculated; \\
\hline HX, ExteriorWalls, Staircase, Bottom1, & type: nutkWallFunction \\
Bottom2, Bottom3, Heater1, Heater2, Heater3, & \\
HotSpot1, HotSpot2, HotSpot3, & \\
UnheatedFloor, Ceiling, Bottom1, Bottom2, & \\
Bottom3 & \\
\hline SymmetryPlane & symmetry \\
\hline
\end{tabular}

Table-A II-16 Turbulent thermal diffusivity (alphaT) boundary conditions $\left[\mathrm{kg} \mathrm{m}^{-1} \mathrm{~s}^{-1}\right]$

\begin{tabular}{|l|l|}
\hline Patch & Parameter/Value \\
\hline internalField (initial guess) & uniform 0; \\
\hline HX_inlet & type: calculated; \\
\hline HX_outlet & type: calculated; \\
\hline HX, ExteriorWalls, Staircase, Heater1, & type compressible::alphatWallFunction; \\
Heater2, Heater3, HotSpot1, HotSpot2, \\
$\begin{array}{l}\text { HotSpot3, UnheatedFloor, Ceiling, Bottom1, } \\
\text { Bottom2, Bottom3 }\end{array}$ & \\
\hline SymmetryPlane & symmetry \\
\hline
\end{tabular}


Table-A II-17 Age of Air (AoA) boundary conditions [-]

\begin{tabular}{|l|l|}
\hline Patch & Parameter/Value \\
\hline internalField (initial guess) & uniform 0; \\
\hline HX_inlet & type: fixedValue; uniform 0; \\
\hline HX_outlet, HX, ExteriorWalls, Staircase, & type: zeroGradient; \\
Heater1, Heater2, Heater3, HotSpot1, & \\
HotSpot2, HotSpot3, UnheatedFloor, Ceiling, & \\
Bottom1, Bottom2, Bottom3 & \\
\hline SymmetryPlane & symmetry \\
\hline
\end{tabular}

Table-A II-18 Temperature (T) boundary conditions [K]

\begin{tabular}{|c|c|}
\hline Patch & Parameter/Value \\
\hline internalField (initial guess) & uniform $305.15[\mathrm{~K}]\left(32^{\circ} \mathrm{C}\right)$; \\
\hline HX_inlet & type: fixedValue uniform $282.7[\mathrm{~K}]\left(9.55^{\circ} \mathrm{C}\right)$ \\
\hline HX outlet & type: zeroGradient; \\
\hline $\mathrm{HX}$ & type: zeroGradient; \\
\hline ExteriorWalls & $\begin{array}{l}\text { type: externalWallHeatFluxTemperature; } \\
\text { kappa: fluidThermo; } \\
\text { q: uniform }-12.71 ;[\mathrm{W} / \mathrm{m} 2] \\
\text { value: uniform } 300.0 ; \\
\text { kappaName: none; } \\
\text { Qr: none; } \\
\text { relaxation: } 1 ;\end{array}$ \\
\hline Heater1, Heater2, Heater3 & $\begin{array}{l}\text { (idem ‘ExteriorWalls' except:) } \\
\text { q: uniform } 6817 ;\left[\mathrm{W} \mathrm{m}^{-2}\right]\end{array}$ \\
\hline HotSpot1, HotSpot2, HotSpot3 & $\begin{array}{l}\text { (idem 'ExteriorWalls' except:) } \\
\text { q: uniform } 54 ;\left[\mathrm{W} \mathrm{m}^{-2}\right]\end{array}$ \\
\hline $\begin{array}{l}\text { Ceiling, Bottom1, Bottom2, } \\
\text { Bottom3, UnheatedFloor, } \\
\text { Staircase }\end{array}$ & type: zeroGradient; \\
\hline SymmetryPlane & symmetry \\
\hline
\end{tabular}

\section{$\underline{\text { Post-treatment }}$}

Post-treatment utilities are used to quantify spatial distribution of variables of interest, which are mean values and Coefficient of Variation for the fields $\mathrm{U}, \mathrm{T}$ and AoA. Coefficient of Variation $(\mathrm{CoV})$ is defined as:

$$
\operatorname{CoV}=\frac{\sigma}{\bar{\mu}}
$$


where $\sigma$ is the standard deviation of a population and $\mu$ is the spatial average value over a given plane. $\mathrm{CoV}$ is calculated with the faceSource function object and the $\mathrm{CoV}$ operation. $\mu$ is calculated with the same object and the weightedAreaAverage operation. 



\section{APPENDIX III}

\section{EXPERIMENTAL APPARATUS DESIGN}

A low cost, mobile apparatus was specifically designed and built for experimental measurements inside a broiler room. The apparatus can measure 4 air velocities, 8 temperatures, 2 relative humidity values and one $\mathrm{CO}_{2}$ concentration. This annex presents in details the experimental apparatus, its components, and how it works.

\section{Overview of the experimental apparatus}

The structural basis of the apparatus is a hand truck, so it can easily roll in the alleys of the broiler room. A structure is built over the truck with slotted angles. Bolts and metal tie-wraps are used to assemble the structure. The slotted holes allow quickly modifying the position of the various sensors. A single person can disassemble the apparatus and transport it in a compact car. A cement block is added in the bottom of the apparatus to lower the gravity center and improve the stability of the cart. The apparatus is seen on Figure-A III-1 Overview of experimental apparatus. One anemometer is installed upside down to able measurements closer to the ground.

The electronic circuit is soldered on a protoboard. No shielding is used on cables. A 5V supply is used to power to Arduino. 12V supply is used to power the anemometers. Both voltages are supplied by a single battery unit (TALENTCELL Rechargeable 12V $6000 \mathrm{mAh} / 5 \mathrm{~V}$ 12000mAh DC Output Lithium Ion Battery Pack). The wireless apparatus allows a faster measurement procedure. Electronic circuits are put into a closed container on the bottom of the hand truck. This location reduces the perturbation of the flow. The container prevents bird damage and dust accumulation.

Collected data is not stored on the apparatus. An XBee radio shield is used to transmit data from the Arduino to a computer equipped with the Linux Mint OS. The XBee shield uses a ZigBee protocol to transmit wireless numeric data. XBee radio Series 1 has a nominal lineof-sight range of $70 \mathrm{~m}$ inside a building. The laptop computer is equipped with an Xbee USB receiver and positioned in the center of the room to maximize range. Even with that strategy, reception can be bad when exceeding $30 \mathrm{~m}$. An executable program saves incoming data from the serial monitor to a text file. A Gnuplot script is used to visualize latest data in real time, as shown in Figure-A III-2. This is useful to make sure that as the procedure takes place the apparatus is still functioning properly. When all sensors are activated, data acquisition period is $20 \mathrm{sec}$. If only temperatures and velocity sensors are activated, data acquisition period is $10 \mathrm{sec}$. The autonomy of the system on battery is over 3 hours, which is sufficient for the needs of the project. One weak point of the design is the vibration induced by the weight of the cantilevered anemometers on one side of the hand truck. The position of sensors is shown in Table-A III-2. Thermistor \#1 has direct contact with the floor, in order to measure floor temperature. Overall view of the data acquisition hardware is shown in Figure-A III-3. Main electronic components are shown in Figure-A III-4. 


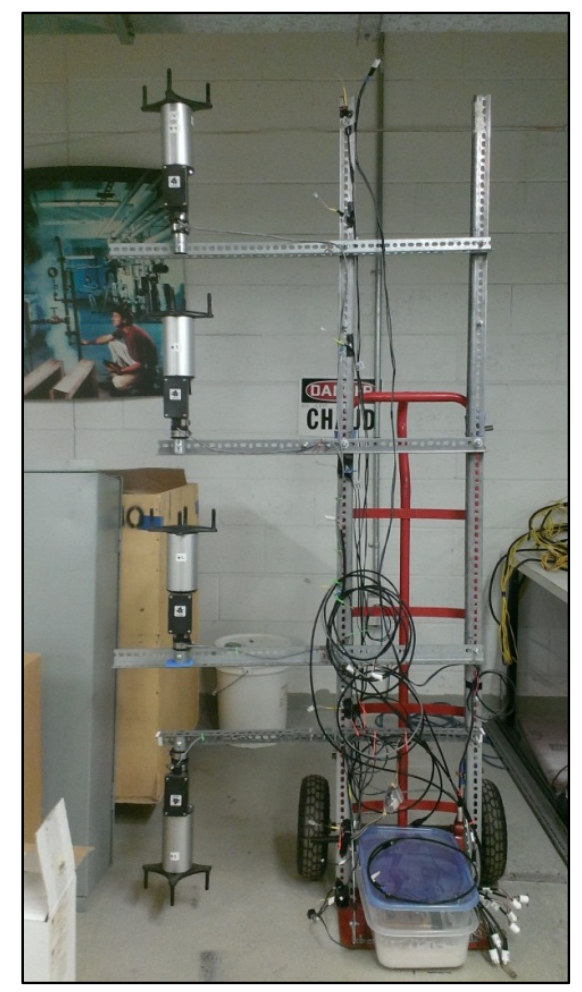

Figure-A III-1 Overview of experimental apparatus

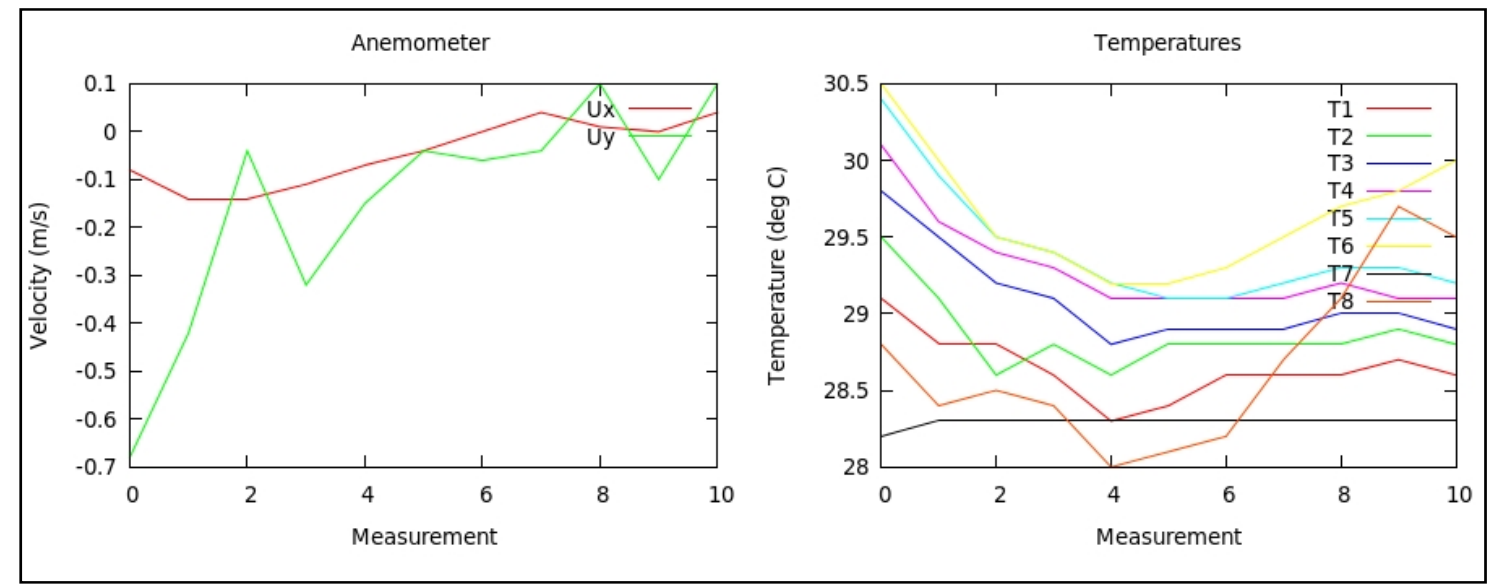

Figure-A III-2 Example of data displayed by the gnuplot program

An example of system output to text file looks like the following: "10/21/2017 21:22:28 \#

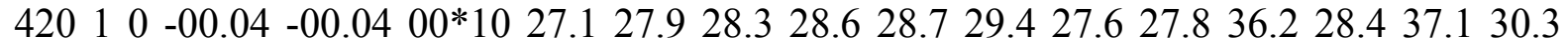
487'. Interpretation of this single line of data is shown in Table-A III-1. 
Table-A III-1 Interpretation of the raw data example

\begin{tabular}{|l|l|}
\hline Date and time & $10 / 21 / 201721: 22$ and 28sec \\
\hline Measurement number & 420 \\
\hline Anemometer \#1 [u v] & {$[-00.04-00.04] \mathrm{m} \mathrm{s}^{-1}$} \\
\hline Temperatures [T1 to T8] humidity \#1 with & $36.2 \%, 28.4^{\circ} \mathrm{C}$ \\
\hline $\begin{array}{l}\text { Relative humidity \#1 with } \\
\text { temperature reference }\end{array}$ & $37.1 \%, 30.3^{\circ} \mathrm{C}$ \\
\hline $\begin{array}{l}\text { Relative hul } \\
\text { temperature reference }\end{array}$ & $487 \mathrm{ppm}$ \\
\hline $\mathrm{CO}_{2}$ concentration &
\end{tabular}

List of sensors present:

- 4X YOUNG 85000 Ultrasonic 2D anemometer

- 8X ANALOG TECHNOLOGIES ATH10K1R25 thermistor

- 2X AOSONG DHT22 polymer capacitor digital package

- 1X SANDBOX ELECTRONICS CO2 $\mathrm{MHZ16}$ sensor 10,000 ppm

Table-A III-2 Position of sensors

\begin{tabular}{|l|c|l|l|}
\hline Device & $\begin{array}{l}\text { Height from the } \\
\text { ground }(\mathrm{m})\end{array}$ & Device & $\begin{array}{l}\text { Height from the } \\
\text { ground }(\mathrm{m})\end{array}$ \\
\hline Anemometer \#1 & 0.06 & Thermistor \#1 & 0.0 \\
\hline Anemometer \#2 & 1.0 & Thermistor \#2 & 0.2 \\
\hline Anemometer \#3 & 1.5 & Thermistor \#3 & 0.5 \\
\hline Anemometer \#4 & 2.0 & Thermistor \#4 & 0.8 \\
\hline Humidity sensor \#1 & 0.2 & Thermistor \#5 & 1.1 \\
\hline Humidity sensor \#2 & 2.0 & Thermistor \#6 & 1.4 \\
\hline $\mathrm{CO}_{2}$ sensor & 0.2 & Thermistor \#7 & 1.7 \\
\hline & & Thermistor \#8 & 2.0 \\
\hline
\end{tabular}




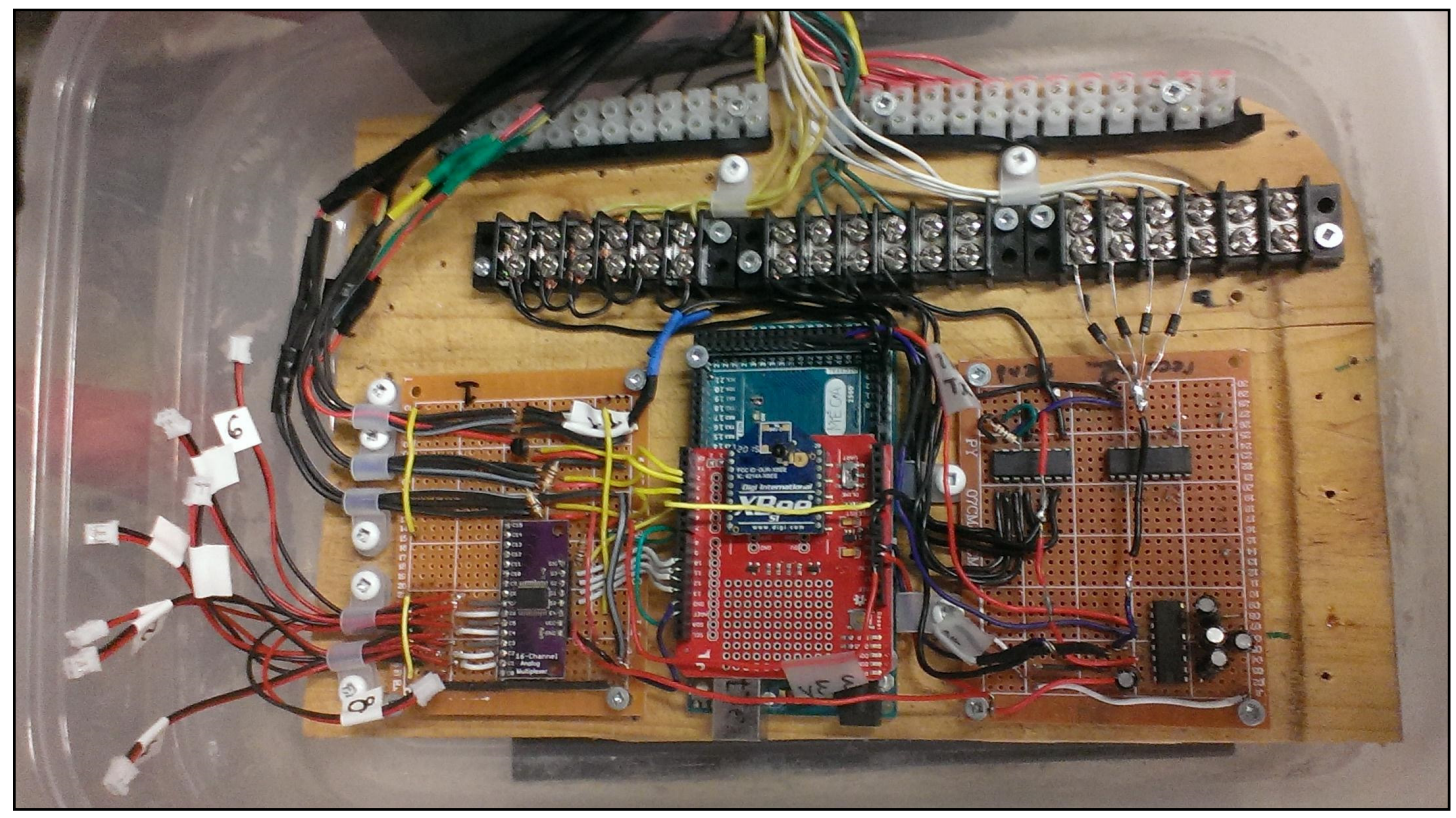

Figure-A III-3 Global view of the data acquisition hardware

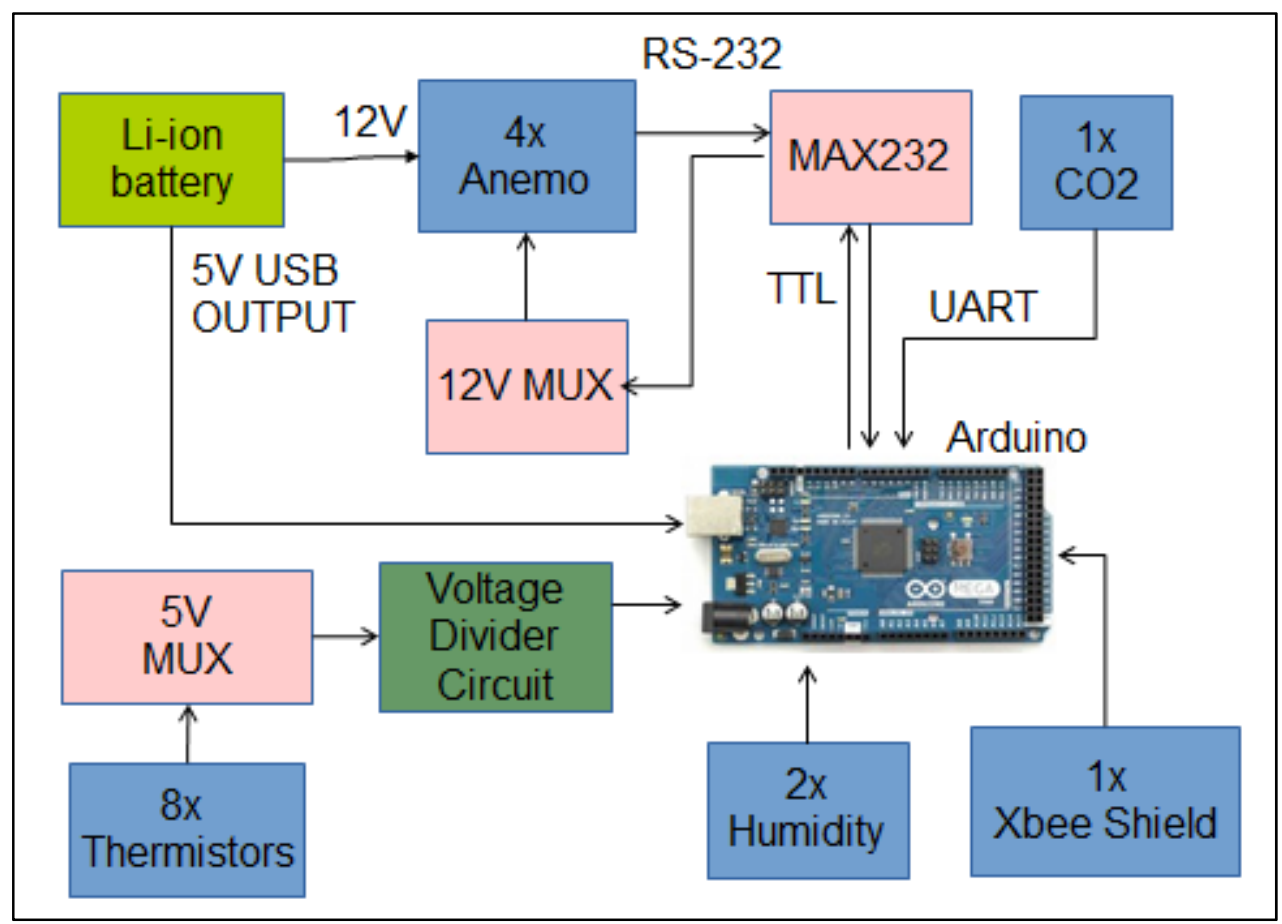

Figure-A III-4 Main components of the electronic components of the apparatus 
Arduino is an open-source platform for low-cost electronic prototyping. It is used by hobbyists and scientists for various needs, including data acquisition. The Arduino Mega 2560 rev3 was chosen over the Arduino Uno for its higher number of I/O pins at a stage where the project requirements were uncertain. The Arduino Uno can also be used. Arduino Mega 2560 specifications are shown in Table-A III-3.

Table-A III-3 Arduino Mega 2560 specifications

\begin{tabular}{|l|l|}
\hline Microcontroller & ATMega2560 \\
\hline Operating Voltage & $5 \mathrm{~V}$ \\
\hline Input Voltage (recommended) & $7-12 \mathrm{~V}$ \\
\hline Input Voltage (limit) & $6-20 \mathrm{~V}$ \\
\hline Digital I/O Pins & 54 (of which 15 provide PWM output) \\
\hline Analog Input Pins & 16 \\
\hline DC Current for I/O Pin & $20 \mathrm{~mA}$ \\
\hline DC Current for 3.3V Pin & $50 \mathrm{~mA}$ \\
\hline Flash Memory & $256 \mathrm{~KB}$ of which $8 \mathrm{~KB}$ used by bootloader \\
\hline SRAM & $8 \mathrm{~KB}$ \\
\hline EEPROM & $4 \mathrm{~KB}$ \\
\hline Clock Speed & $16 \mathrm{MHz}$ \\
\hline Length & $101.52 \mathrm{~mm}$ \\
\hline Width & $53.3 \mathrm{~mm}$ \\
\hline Weight & $37 \mathrm{~g}$ \\
\hline
\end{tabular}

Arduino pins attribution

In Table-A III-4 to Table-A III-6 are presented the pin attribution for the Arduino Mega2560. The pin layout is presented in Figure-A III-5. A number of digital pins are able to function as a software serial. With the help of a native Arduino library, these pins are able to function as a serial port. This is helpful to communicate with many devices since the Arduino has only one hardware serial port, which is occupied by the Xbee shield in this project.

Table-A III-4 Power related pins on the Arduino

\begin{tabular}{|l|l|}
\hline Pin & Component / usage \\
\hline $5 \mathrm{~V}$ & Power supply for multiplexor, humidity sensors and $\mathrm{CO}_{2}$ sensor \\
\hline $3.3 \mathrm{~V}$ & Power supply for thermistor voltage divider \\
\hline GND & Ground reference for thermistors, humidity sensors and $\mathrm{CO}_{2}$ sensor \\
\hline GND (POWER) & Ground reference for anemometer signal conversion \\
\hline AREF & Thermistors voltage divider reference \\
\hline
\end{tabular}


Table-A III-5 Arduino analog pins configuration

\begin{tabular}{|l|l|}
\hline Pin & Component / usage \\
\hline A0 & Thermistor input signal \\
\hline A2 & Output signal to control $\mathrm{CO}_{2}$ sensor power supply transistor \\
\hline A13 & $\mathrm{CO}_{2}$ sensor control signal (Tx) (software serial) \\
\hline A14 & $\mathrm{CO}_{2}$ sensor data signal (Rx) (software serial) \\
\hline
\end{tabular}

Table-A III-6 Arduino digital pins configuration

\begin{tabular}{|l|l|}
\hline Digital pin & Component / usage \\
\hline 0 & XBee shield (Rx) \\
\hline 1 & XBee shield (Tx) \\
\hline 3 & Humidity sensor \#2 data input \\
\hline 4 & Humidity sensor \#1 data input \\
\hline 10 & Thermistor multiplexer control (S3) \\
\hline 11 & Thermistor multiplexer control (S2) \\
\hline 12 & Thermistor multiplexer control (S1) \\
\hline 13 & Thermistor multiplexer control (S0) \\
\hline 40 & Anemometer MUX control pin C \\
\hline 42 & Anemometer MUX control pin B \\
\hline 44 & Anemometer MUX control pin A \\
\hline 50 & Anemometer Rx (software serial) \\
\hline 52 & Anemometer Tx (software serial) \\
\hline
\end{tabular}

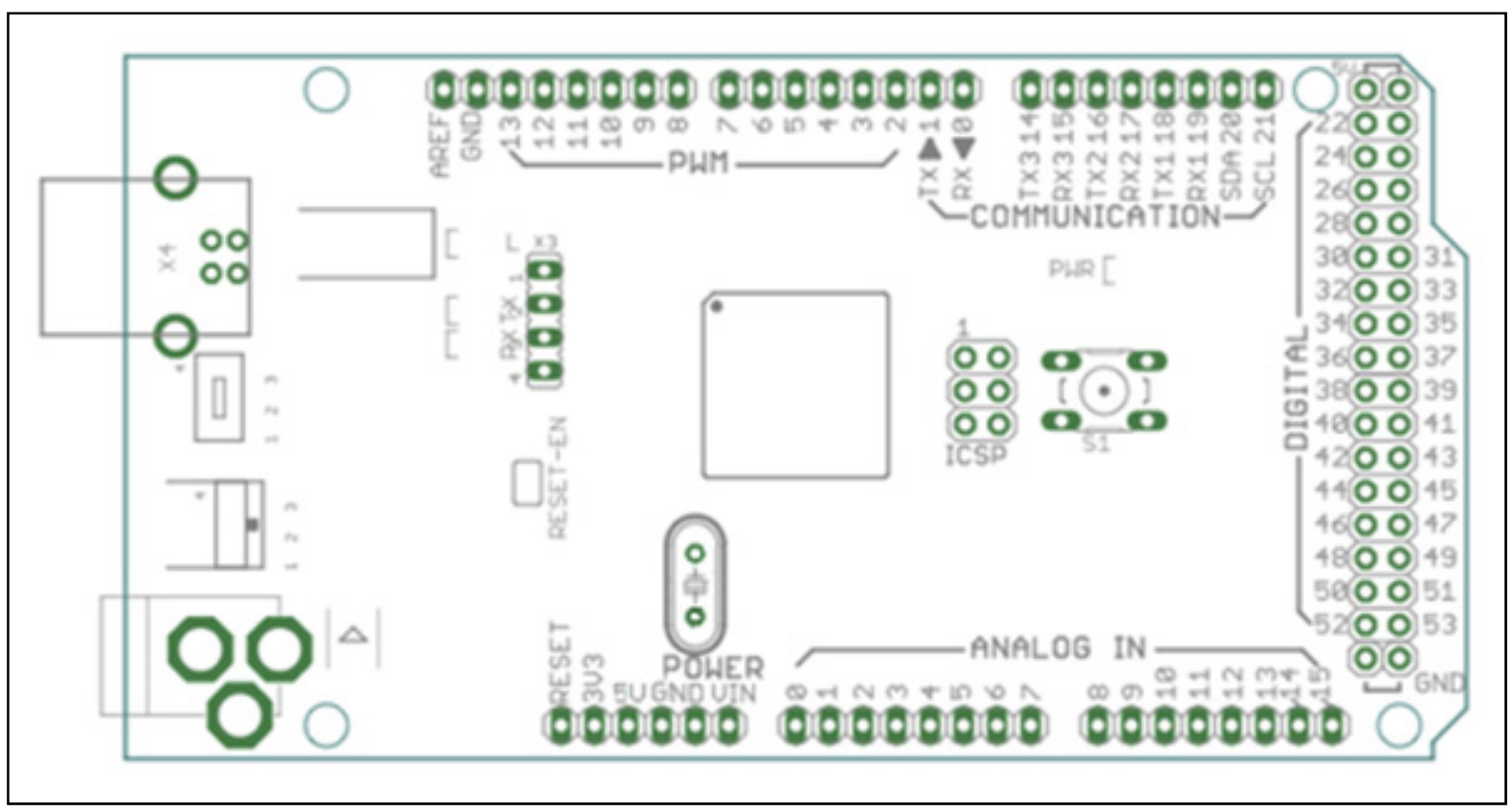

Figure-A III-5 Arduino Mega2560 rev3 pin layout 
As shown in Table-A III-7, there are many devices connected to the Arduino, but most of them use a digital signal. Therefore, circuit noise does not affect the accuracy of most measurements. The only analog signal comes from the thermistors. The wireless transmission of data does not affect accuracy either since a digital signal is used. Data packets can be lost, however, if radio reception is bad.

Table-A III-7 Type of signal used

by each device of the apparatus

\begin{tabular}{|l|l|}
\hline Device type & Signal type \\
\hline Anemometer & Digital signal (UART) \\
\hline Thermistor & Analog signal (3.3V) \\
\hline Humidity sensor & Digital signal (1-wire bus) \\
\hline $\mathrm{CO}_{2}$ sensor & Digital signal (UART) \\
\hline $\mathrm{XBee}$ radio & Digital signal (ZigBee protocol) \\
\hline
\end{tabular}

$\underline{\text { Anemometer }}$

YOUNG ultrasonic anemometer model 85000 is used to measure air velocities. An example of the device is shown in Figure-A III-6. The ultrasonic anemometer is preferred over the hot-wire anemometer because the latter is sensitive to dust accumulation, requiring frequent calibration. It is commonly used in weather stations. A unit calibration is made at the factory. It is the most expensive component of the system. The working principle is to measure the travel time variation of an ultrasonic impulse. An ultrasonic sound is emitted by an emitter on one branch and received by a receiver on the opposing branch. The travel time will vary depending on the air flow speed. If the air flow is in the same direction as the sound, then time of travel is reduced. If the flow is in the opposite direction, time of travel is increased. Measurement is done in both $\mathrm{x}$ and $\mathrm{y}$-axis. This allows the embedded electronic circuit to determine both the speed and orientation of the air flow. Data can be output in various formats. In the present case, the output is numerical ASCII, with x-y component format. The polled mode is used, meaning that the anemometer is only active for a second, each time the Arduino asks for a measurement. The rest of time, the anemometer is in sleep mode, not taking measurements and consuming a minimal amount of current $(<30 \mathrm{~mA})$. The data output of the anemometer corresponds to the median value of a sample of size 31. Speed measurement specifications are shown in Table-A III-8. 


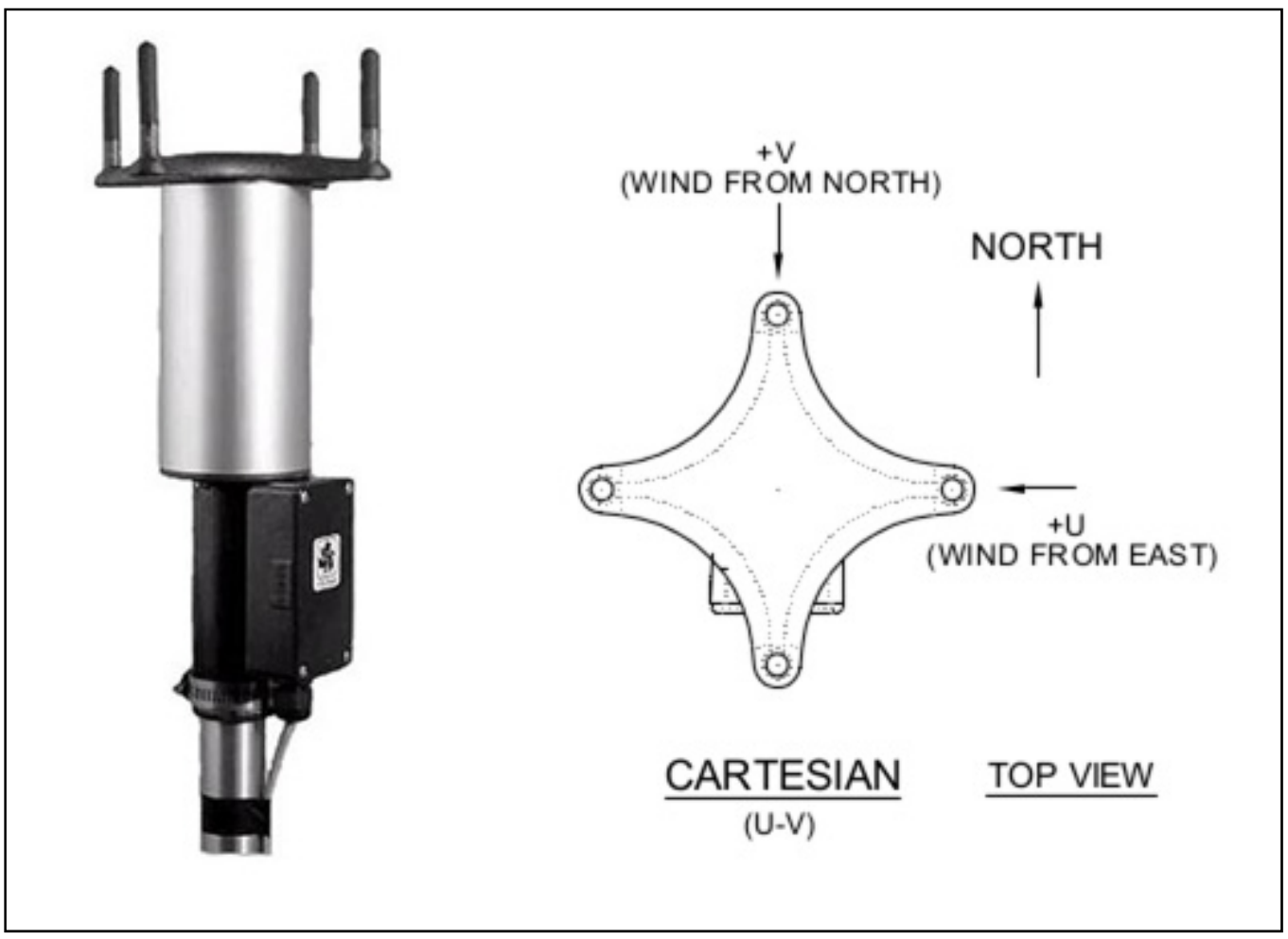

Figure-A III-6 Young 85000 Anemometer view with its sign convention

Table-A III-8 Young 85000

Anemometer wind speed characteristics

\begin{tabular}{|l|l|}
\hline Range & 0 to $40 \mathrm{~m} \mathrm{~s}^{-1}$ \\
\hline Resolution & $0.01 \mathrm{~m} \mathrm{~s}^{-1}$ \\
\hline Threshold & $0.01 \mathrm{~m} \mathrm{~s}^{-1}$ \\
\hline Accuracy & $\pm 1 \% \mathrm{rms}^{\prime} 0.05 \mathrm{~m} \mathrm{~s}^{-1}\left(0\right.$ to $\left.30 \mathrm{~m} \mathrm{~s}^{-1}\right)$ \\
\hline
\end{tabular}

The anemometer is configured to communicate in RS-232 signal so that the accuracy of the data does not depend on the Arduino Analog-to-Digital Converter (ADC) accuracy. The configuration of the anemometer is done through a modified cable. One end is a DB-9 male connection, while the other is a 5-pin DIN female connection with alligator clips to connect to the battery. The cable connections are shown in Table-A III-9. Configuration parameters values are shown in Table-A III-10. Anemometers are configured with the software provided by Young technical support. Each anemometer electrical box was also modified for RS-232 communication. 
Table-A III-9 Connection concordance for anemometer configuration with a computer

\begin{tabular}{|l|l|}
\hline Anemometer side (DIN 5-pin) & PC side \\
\hline Red (Positive) & Battery + \\
\hline Black (Negative) & Battery - \\
\hline White (Tx) & DB-9 pin 2 Tx (Red) \\
\hline Green (Rx) & DB-9 pin 3 Rx (Brown) \\
\hline Brown (Analogic voltage reference) & DB-9 pin 5 Ref (Yellow) \\
\hline
\end{tabular}

Table-A III-10 Anemometer configuration parameters

\begin{tabular}{|l|l|l|l|}
\hline Parameter & Value & Parameter & Value \\
\hline Serial output format & ASCII & Output Delay x8.192ms & 1 \\
\hline ASCII output format & Cartesian & Damping Factor & 0 \\
\hline Sensor Baud Rate & 9600 & Sample Count & 31 \\
\hline Poll Character & 0 & Wind Speed Multiplier & 10000 \\
\hline Signal type & RS-232 & Wind Direction Offset & 0 \\
\hline Voltage output & N/A & $\begin{array}{l}\text { Voltage Output Error } \\
\text { Reporting }\end{array}$ & None \\
\hline Threshold $(\mathrm{cm} / \mathrm{s})$ & 0 & Heater enabled & No \\
\hline
\end{tabular}

$12 \mathrm{~V}$ power is used to power the anemometers. Anemometers share a common $12 \mathrm{~V}$, common neutral, and common ground. The anemometers are positioned upright, abling measurements in the $x-y$ plane. The anemometer close to the ground is positioned upside down so that the ultrasonic sensors can measure velocities close to the ground. A 1.5 in NPT steel pipe is used to fix each anemometer on the iron angle. The holes in the iron angles reduce flow perturbation. Anemometers are installed far from the rest of the dolly for the same reason. The anemometer output in ASCII Cartesian is in the following format: "a uu.uu vv.vV $\mathrm{ss} * \mathrm{cc}<\mathrm{CR}>$ ". Velocity components are designated by "uu.uu" ad "vv.vv".

The MAX232 chip is used to convert the RS-232 anemometer signal to a transistor-totransistor (TTL) signal, which is receivable by the Arduino. The MAX4581 chip is a 12V digital/analog multiplexer. It allows the Arduino to communicate with multiple anemometers while only requiring one MAX232 chip and two I/O (Rx/Tx) on the Arduino. However, the MAX4581 is not ideal for multiplexing RS-232 signals. RS-232 signal varies between +12 and $-12 \mathrm{~V}$, while the MAX4581 can only operate between $0-12 \mathrm{~V}$. So the MAX4581 works in one direction (Arduino to Anemometer) but not the other (Anemometer to Arduino). An easy solution is to bypass the MAX4581 on the receiving side and use an array of diodes (1N4007) instead. Those diodes prevent anemometers from interfering with each other. In retrospect, by giving a different poll character to each anemometer, polling the devices might have been done without the use of a multiplexer. MAX232 and MAX4581 pin configurations are shown in Figure-A III-7. 


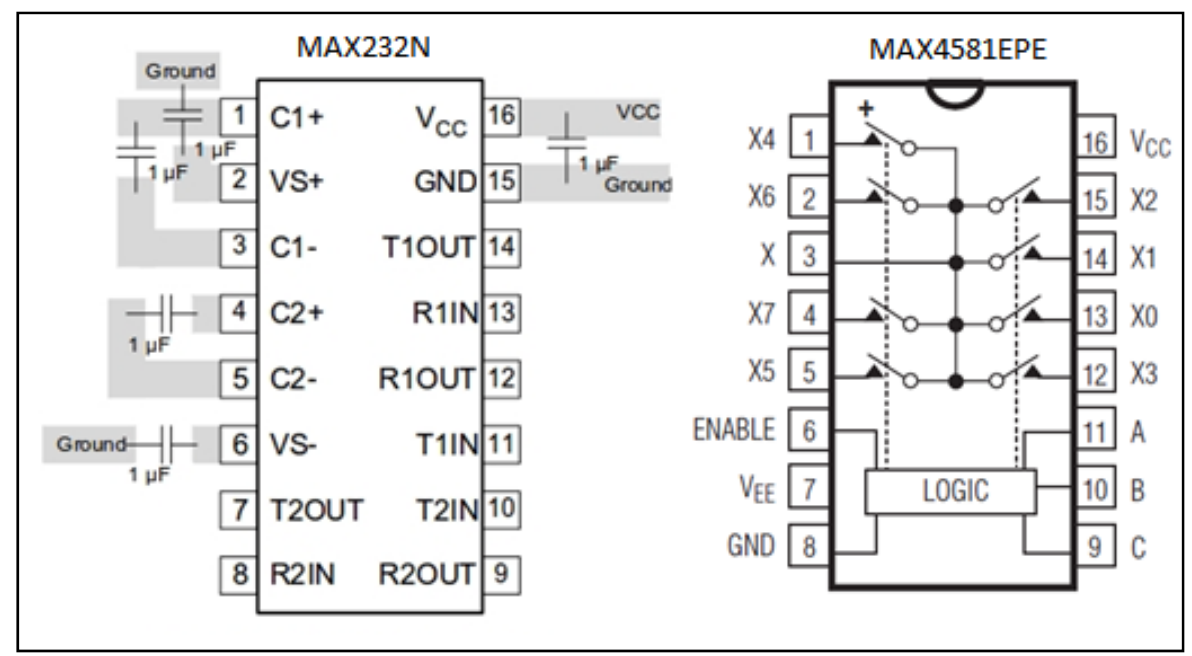

Figure-A III-7 MAX232N and MAX4581EPE pin configurations

\section{Temperature sensor}

Air temperature is measured with high-quality NTC thermistors ATH10K1R25, shown in Figure-A III-8. This sensor is intended for laser diodes, optical components, and industrial process control, where high-temperature sensitivity, long-term stability, and high sensing temperature are required. ATH10K1R25 specifications are shown in Table-A III-11.

The most common temperature sensor types are thermocouples, thermistors, RTD (Resistance Temperature Device) and IC (Integrated Circuit). The electrical resistance of thermistors change with temperature, and a voltage divider circuit is used to measure that resistance. There are many reasons why thermistors are the most adequate choice for this project. Thermistors have the highest sensitivity $\left(\Omega /{ }^{\circ} \mathrm{C}\right)$ of all types, allowing good reading accuracy with the 10-bit ADC integrated into the Arduino. No temperature reference or signal amplification is required. Response time is fast, due to the thermistor small size and thermal inertia. Thermistors produce a strong signal, making them less sensitive to signal noise issues. Wire resistance is negligible versus thermistor resistance, so the wire length can be modified without consequence. Finally, measurement is independent of voltage supply value. Thermistors do have some drawbacks. Temperature range is limited, but it is not a problem in the present project. Self-heating of the thermistor by Joule effect affects the reading accuracy (see Equation (A III-1)). This problem is eliminated by polling the thermistor $1 \%$ of the time, resulting in an average dissipated power of $10 \mu \mathrm{W}$. Thermistors have a non-linear response to temperature change. The Steinhart equation can be used, but experimental data chart from the manufacturer is used in this project. A lookup table is inserted in the Arduino memory, and data is interpolated for each reading. Thermistors are made of metal oxides inserted in a glass bead, so they are quite rugged, but they tend to be fragile where the lead wires are attached, so they must be manipulated with care.

$$
P=\frac{V^{2}}{R}=\frac{3.3 V^{2}}{10000 \Omega}=0.0011 \mathrm{~W} \square 1 \mathrm{~mW}
$$




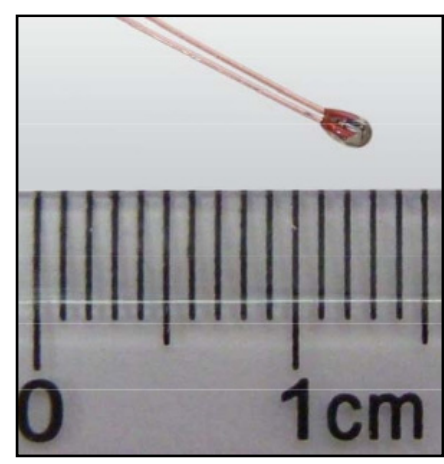

Figure-A III-8 Close-up view of thermistor ATH10K1R25

Table-A III-11 Thermistor ATH10K1R25 specifications

\begin{tabular}{|l|l|}
\hline Parameter Value & Value \\
\hline Nominal Resistance $@ 25^{\circ} \mathrm{C}$ & $10 \mathrm{~K} \Omega \pm 1 \%$ \\
\hline Temperature range (plastic wire) & -40 to $140^{\circ} \mathrm{C}$ \\
\hline Temperature range (thermistor) & -40 to $270^{\circ} \mathrm{C}$ \\
\hline$\beta$ Value $@ 25^{\circ} \mathrm{C} / 50^{\circ} \mathrm{C}$ & $3950 \mathrm{~K} \pm 1 \%$ \\
\hline$\beta$ Value $@ 25^{\circ} \mathrm{C} / 85^{\circ} \mathrm{C}$ & $3990 \mathrm{~K} \pm 1 \%$ \\
\hline $\mathrm{R} @ 25^{\circ} \mathrm{C} / \mathrm{R} @ 50^{\circ} \mathrm{C}$ & 2.771 \\
\hline $\mathrm{R} @ 25^{\circ} \mathrm{C} / \mathrm{R} @ 85^{\circ} \mathrm{C}$ & 9.271 \\
\hline Thermistor Diameter & $1.25 \pm 0.03 \mathrm{~mm}$ \\
\hline Thermistor Length & $2.0 \pm 0.5 \mathrm{~mm}$ \\
\hline Lead Diameter & $0.23 \mathrm{~mm}$ \\
\hline Lead Length & $70 \pm 1 \mathrm{~mm}$ \\
\hline Dissipation Factor & $\geq 1.0 \mathrm{~mW} \mathrm{C}^{-1}$ \\
\hline Insulation Resistance & $50 \mathrm{M} \Omega$ \\
\hline Thermal Time Constant & $2.39 \mathrm{~s}$ (in still air) \\
\cline { 2 - 2 } & $1 \mathrm{~s}$ (in water) \\
\hline
\end{tabular}

A voltage divider circuit allows measuring the thermistor resistance. A schematic of the voltage divider circuit is shown in Figure-A III-9. In Figure-A III-9 are seen R1, which is the series resistor, R_MUX, which is the internal resistance of the multiplexer, the thermistor itself, the $3.3 \mathrm{~V}$ power supply and $\mathrm{A} 0$, the analog input for the voltage measurement. This analog input makes a measurement between the multiplexer input and the digital ground. Although the multiplexer is supplied with $5 \mathrm{~V}$ (not shown), the measurement circuit is supplied with $3.3 \mathrm{~V}$ from the Arduino, and the analog input A0 is referenced to that value as well. The $3.3 \mathrm{~V}$ line supplies fewer components on the Arduino board than the $5 \mathrm{~V}$ line. 
Hence, the signal is less noisy, improving the measurement accuracy of the temperature sensing circuit. The $3.3 \mathrm{~V}$ line also benefits from a supplementary filter and a voltage regulator. A lower power supply tension also lowers the self-heating effect of the thermistor, as shown before. To lower noise level, five readings are taken in a row and averaged.

The ADC accuracy is not improved by lowering the voltage supply value from $5 \mathrm{~V}$ to $3.3 \mathrm{~V}$. The ADC accuracy [ADC/V] is improved by reducing the range, but the voltage divider circuit accuracy is worsened by reducing the sensitivity $[\mathrm{V} / \Omega]$. The two effects, in fact, cancel each other. The measurement accuracy could be truly improved by reducing the voltage range covered by the ADC while maintaining the voltage supply value (e.g. $3.3 \mathrm{~V}$ ). For example, to cover temperatures between 0 and $50^{\circ} \mathrm{C}$ with the present circuit, voltage values from 0.8 to $2.5 \mathrm{~V}$ must be covered. The 1024 values could be distributed over this narrower voltage range, increasing the overall accuracy $[\mathrm{ADC} / \Omega]$. This requires reprogramming the $\mathrm{ADC}$.

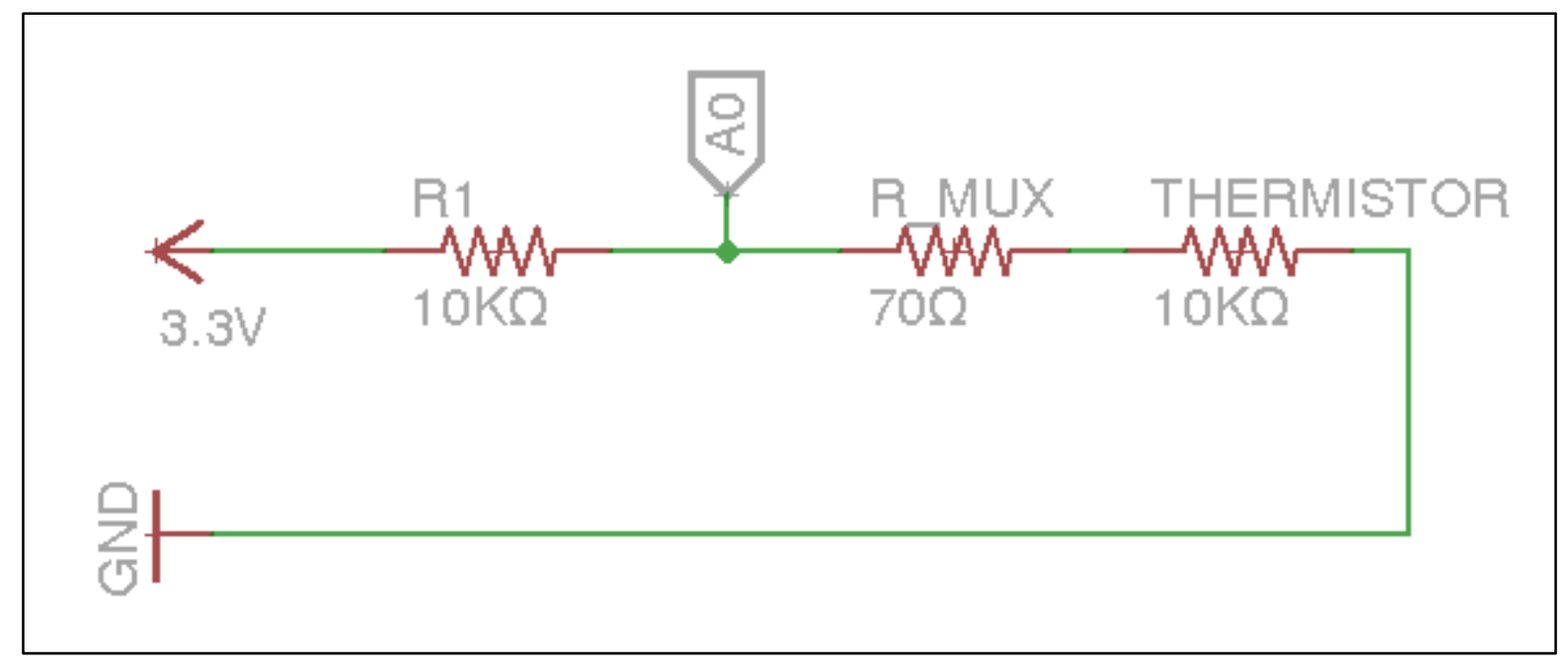

Figure-A III-9 Schematic view of the thermistor electric circuit (EAGLE software)

A precision resistance is usually recommended since the accuracy of the measurement depends on the series resistance. Instead, a resistance of $10 \mathrm{k} \Omega \pm 5 \%$ is used as a voltage divider. The resistance exact value is measured with a $1 \%$ accurate multimeter. The value taken into consideration is $9910 \pm 99 \Omega$. The following equation is the Steinhart simplified equation:

$$
\frac{1}{T}=\frac{1}{T_{0}}+\frac{1}{B} \ln \left(\frac{R}{R_{0}}\right)
$$

The manufacturer provides a chart that specifies the resistance as a function of temperature. This chart is used as an alternative to the Steinhart-Hart simplified equation. The two curves are compared in Figure-A III-10 over the range -10 to $50^{\circ} \mathrm{C}$. The error between the two curves at $30^{\circ} \mathrm{C}$ is $-0.1^{\circ} \mathrm{C}$. Linear interpolation is used between experimental data points. Based on the circuit properties, a chart is built that provides the temperature corresponding to 
a given ADC value. The resulting lookup table is implemented in the flash memory of the Arduino. The Arduino can quickly determine the temperature by accessing the lookup table.

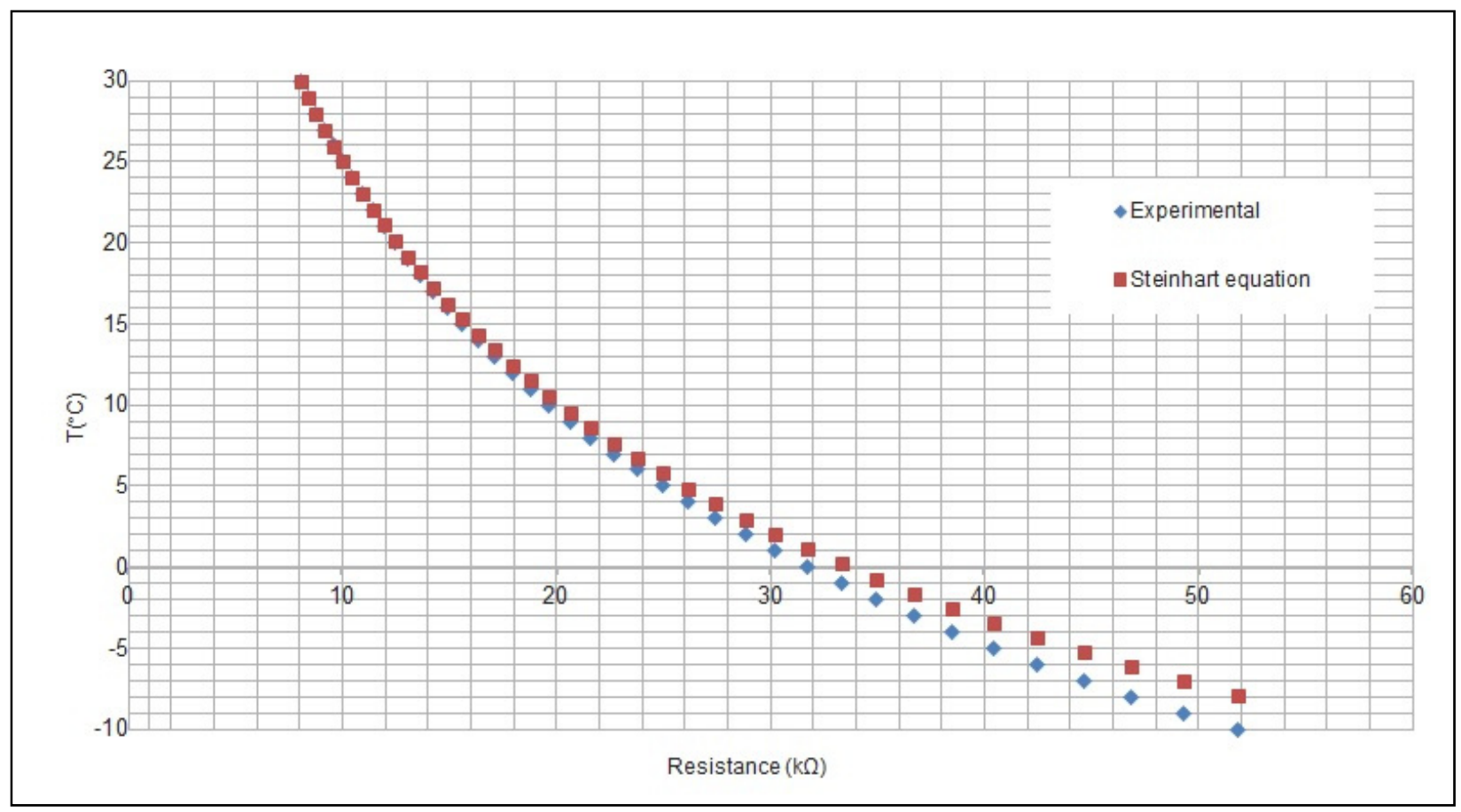

Figure-A III-10 Comparison between resistance values predicted by the Steinhart simplified equation and experimental values from the manufacturer

A multiplexer is used to control the eight thermistors. It allows taking multiple temperature measurements with only one Arduino analog input. The 16-channel analog multiplexer CD74HC4067 is used and can be seen at Figure-A III-11. Four digital outputs from the Arduino are used to control the multiplexer. According to specifications, the multiplexer has an average "on" resistance of $70 \Omega$ between input and output. A $70 \Omega$ resistance represents a non-negligible bias of $-0.2^{\circ} \mathrm{C}$ at $25^{\circ} \mathrm{C}$. This resistance is therefore taken into account in the conversion of $\mathrm{ADC}$ values to temperatures by adjusting the lookup table. In the broiler room, likely air temperatures range from $0^{\circ} \mathrm{C}$ to $50^{\circ} \mathrm{C}$. In the current configuration, the accuracy of the thermistor in the $0^{\circ} \mathrm{C}$ to $50^{\circ} \mathrm{C}$ range is $\pm 0.4^{\circ} \mathrm{C}$. Details about temperature accuracy calculations with propagation errors can be found in Annex IV. 


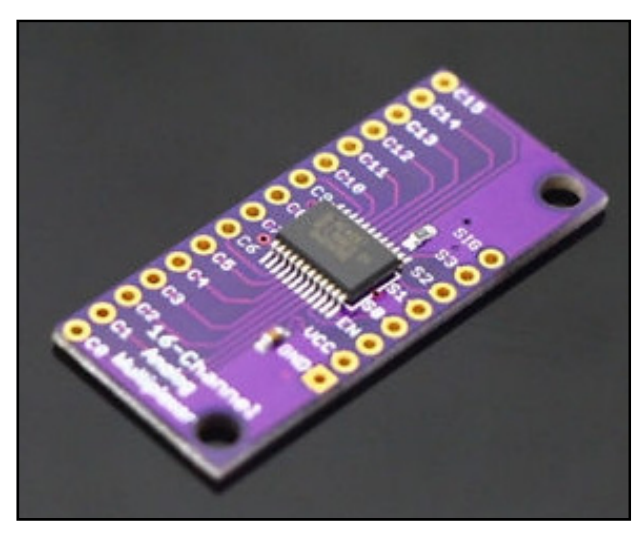

Figure-A III-11 Analog multiplexer CD74HC4067

$\underline{\text { Relative humidity sensor }}$

Humidity is measured near the ceiling, since humidity goes up, and close to the ground because this is where the chickens are. The DHT22 humidity sensor is used, as shown in Figure-A III-12. It is a capacitance humidity sensor. Arduino provides a library for this popular sensor (DHT.h). The data is communicated numerically with a single data line. A 4pin breadboard female cable is used to connect the sensor. The sensor acquisition rate is low $(0.5 \mathrm{~Hz}$ max $)$, but it is sufficient for this project. Users report a life expectancy of about 1-2 years for this sensor. (Smith, 2017) made extensive testing of this sensor, providing detailed methodology and results. The author noticed drifting effect over long periods of times. He also points out that the weakest point of the sensor is its temperature repeatability. The relative humidity value is highly dependent on temperature, and so the humidity value can only be as accurate as the temperature measurement accuracy.

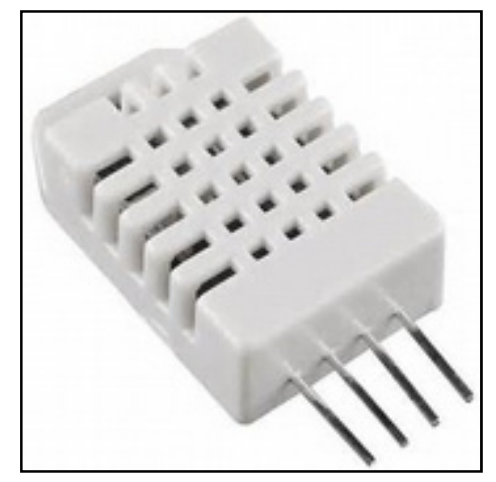

Figure-A III-12 Humidity sensor DHT22 
Table-A III-12 Manufacturer specifications for DHT22 sensor

\begin{tabular}{|l|l|}
\hline Parameter & Value \\
\hline Accuracy & $\pm 2 \%$ (middle range) to 5\% (extreme range) \\
\hline Repeatability & $\pm 1 \%$ \\
\hline Long term stability & $\pm 0.5 \%$ per year \\
\hline Relative humidity range & $0-100 \%$ \\
\hline Temperature range & $-40-80^{\circ} \mathrm{C}$ \\
\hline Maximum sampling rate & $0.5 \mathrm{~Hz}$ \\
\hline
\end{tabular}

\section{$\mathrm{CO}_{2}$ sensor}

The MHZ16 is a Non-Dispersive Infrared (NDIR) type of $\mathrm{CO}_{2}$ sensor. This type of sensor consumes lower power than a chemical sensor, which needs constant heating. Automatic recalibration is included in the device. By default, every $24 \mathrm{~h}$, the device recalibrates itself to prevent measurement drift. The procedure is based on the assumption that fresh air contains $400 \mathrm{ppm}$ of $\mathrm{CO}_{2}$ and that it is the lowest level of $\mathrm{CO}_{2}$ the sensor is exposed to. In this project, automatic recalibration must be avoided since the device is not exposed to fresh air. To prevent recalibration, power supply to the sensor is cut every $23 \mathrm{~h}$ with an NPN general purpose transistor $\mathrm{BC} 547 \mathrm{~B}$, therefore resetting the count. A manual calibration can be done with a dedicated button, when appropriate.

Table-A III-13 MH-Z16 $\mathrm{CO}_{2}$ sensor manufacturer specifications

\begin{tabular}{|l|l|}
\hline Accuracy & $\pm(50 \mathrm{ppm}+5 \%$ of reading value $)$ \\
\hline $\mathrm{CO}_{2}$ measurement range & $0-10000 \mathrm{ppm}$ \\
\hline Working voltage & $4.5-5.5 \mathrm{~V}$ DC \\
\hline Preheat time & $3 \mathrm{~min}$ \\
\hline Working temperature & $0-50^{\circ} \mathrm{C}$ \\
\hline Working relative humidity & $0-95 \%$ \\
\hline Lifespan & $>5$ years \\
\hline Output signal & UART or I2C \\
\hline
\end{tabular}

Wireless communication

Wireless communication is achieved with the XBee radio system. This includes two Xbee radio, an Arduino Xbee shield and a USB Explorer, as shown in Figure-A III-13 and FigureA III-14. A program from DIGI (XCTU_install_40003026_E.exe) allows the configuration of an XBee radio itself. A specific pilot driver is also needed (CDM_v2.12.00_WHQL_Certified.exe) on the PC used for the configuration process. Two XBee radios can often communicate with each other out-of-the-box, with default factory parameters. However, it is preferable to configure them so that they communicate specifically with one another. The USB Explorer is used to configure each Xbee radio, one after another. The parameters used are presented in Table-A III-14. Network ID is left to the default value (i.e. 3332). For more details about the configuration process, refer to one of the tutorials available like the one from the Sparkfun website. 


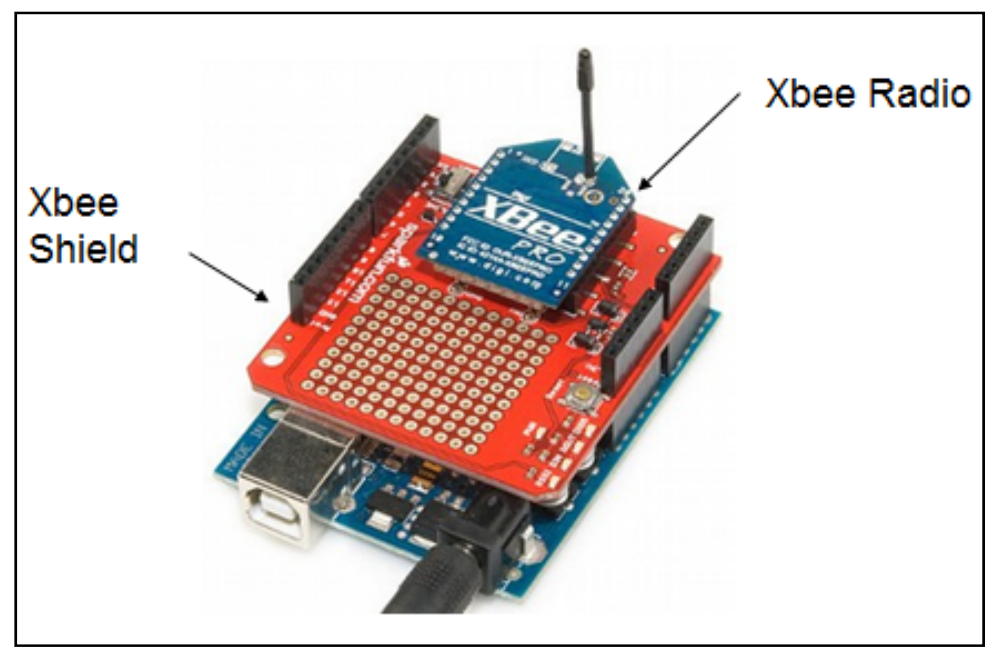

Figure-A III-13 Sparkfun XBee Shield and XBee Radio on an Arduino Uno

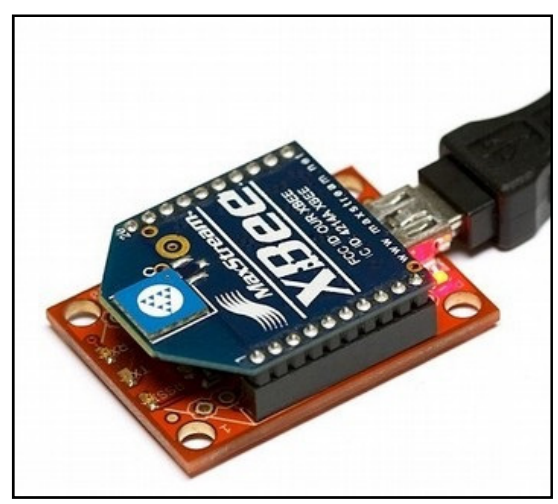

Figure-A III-14 Sparkfun XBee Explorer (red) with Xbee radio installed (blue)

Table-A III-14 Xbee Radios parameters

\begin{tabular}{|l|l|l|l|}
\hline & Acronym & $\begin{array}{l}\text { Radio } \\
1\end{array}$ & $\begin{array}{l}\text { Radio } \\
2\end{array}$ \\
\hline Channel & CH & C & C \\
\hline PAN ID (hex) & ID & 3332 & 3332 \\
\hline Destination Address High & DH & 0 & 0 \\
\hline Destination Address Low & DL & 1000 & 1001 \\
\hline 16-bit Source Address & MY & 1001 & 1000 \\
\hline
\end{tabular}




\section{APPENDIX IV}

\section{TEMPERATURE MEASUREMENT ACCURACY}

Temperature $\mathrm{T}$ is a function of $\mathrm{ADC}$, thermistor resistance $\mathrm{R}$ and series resistor $\mathrm{R}_{1}$.

$$
T=f\left(A D C, R, R_{1}\right)
$$

There are three independent errors: thermistor uncertainty ( $1 \%$ of the resistance value), series resistor uncertainty and the 10-bit ADC (Analog-to-Digital Converter) tension reading uncertainty (National Instruments, 2017). With error propagation, it is possible to calculate the uncertainty of dT:

$$
\begin{aligned}
& d T=\sqrt{\left[\frac{\partial T}{\partial x_{1}} \partial x_{1}\right]^{2}+\ldots+\left[\frac{\partial T}{\partial x_{n}} \partial x_{n}\right]^{2}} \\
& =\sqrt{\left[\frac{\partial T}{\partial A D C} \partial A D C\right]^{2}+\left[\frac{\partial T}{\partial R_{1}} \partial R_{1}\right]^{2}+\left[\frac{\partial T}{\partial R} \partial R\right]^{2}}
\end{aligned}
$$

ADC value depends on analogical input tension $\mathrm{V}_{\mathrm{i}}$, reference tension $\mathrm{V}_{0}$, and the total number of values possible with a 10 -bit $\operatorname{ADC}\left(2^{10}=1024\right.$ values, hence 0 to 1023$)$.

$$
A D C=\frac{V_{i}}{V_{c c}} 1023
$$

By using the Ohm law, applied to a standard voltage divider circuit, the voltage across the thermistor is

$$
V=\frac{R}{\left(R+R_{1}\right)} V_{c c}
$$

By isolating $\mathrm{R}$,

$$
R=\frac{R_{1} \cdot V}{V_{c c}-V}
$$

For later needs, the derivate of $\mathrm{R}$ with respect to $\mathrm{V}_{0}$, must be calculated :

$$
\frac{d R}{d V}=\frac{d}{d x}\left(\frac{R_{1} V}{V_{c c}-V}\right)
$$

As a reminder, quotient rule for derivatives is $\frac{d}{d x}\left(\frac{u}{v}\right)=\frac{u^{\prime} v-u v^{\prime}}{v^{2}}$ 


$$
\begin{gathered}
u^{\prime}=\frac{d}{d V}(u)=\frac{d}{d V}\left(R_{1} V\right)=R_{1} \\
v^{\prime}=\frac{d}{d V}(v)=\frac{d}{d V}\left(V_{c c}-V\right)=-1 \\
v^{2}=\left(V_{c c}-V\right)^{2} \\
\frac{d R}{d V}=\frac{u^{\prime} v-u v^{\prime}}{v^{2}}=\frac{R_{1}\left(V_{c c}-V\right)-R_{1} V(-1)}{\left(V_{c c}-V\right)^{2}}=\frac{R_{1} V_{c c}}{\left(V_{c c}-V\right)^{2}}
\end{gathered}
$$

$\frac{d T}{d A D C}$ is calculated with the chain rule:

$$
\frac{d T}{d A D C}=\frac{d T}{d R} \frac{d R}{d V} \frac{d V}{d A D C}
$$

Example for $\mathrm{T}=25^{\circ} \mathrm{C}$ : $\mathrm{R}=10000 \Omega, \mathrm{R}_{1}=9910 \Omega, \mathrm{V}=1.65 \mathrm{~V}$,

$$
\begin{gathered}
\left.\frac{d T}{d R}\right|_{T=25}=\frac{T_{2}-T_{1}}{R_{2}-R_{1}}=\frac{26-25}{9573-10000}=-0.00234 \frac{{ }^{\circ} \mathrm{C}}{\Omega} \\
\left.\frac{d R}{d V}\right|_{T=25}=\frac{R_{1} V_{c c}}{\left(V_{c c}-V\right)^{2}}=\frac{9910 \cdot 3.3}{(3.3-1.66)^{2}}=12159 \frac{\Omega}{V}
\end{gathered}
$$

$$
\text { where } \begin{gathered}
V=\frac{R}{\left(R+R_{1}\right)} V_{c c}=\frac{10000}{(10000+9910)} \cdot 3.3=1.66 \mathrm{~V} \\
\frac{d V}{d A D C}=\frac{3.3 \mathrm{~V}}{1023}=0.00323 \frac{\mathrm{V}}{\mathrm{ADC}}
\end{gathered}
$$

So for $\mathrm{T}=25^{\circ} \mathrm{C}$,

$$
\frac{d T}{d A D C}=\frac{d T}{d R} \frac{d R}{d V} \frac{d V}{d A D C}=(-0.00234) \cdot 12159 \cdot 0.00323=-0.09 \frac{{ }^{\circ} \mathrm{C}}{A D C}
$$

One can observe that the resulting value is negative, which is coherent with the fact that temperature decreases with increasing values of ADC. Measurement total accuracy also depends upon the series resistance $\mathrm{R}_{1}$ accuracy, which is part of the voltage divider circuit:

$$
\frac{d T}{d R_{1}}=\frac{d T}{d R} \frac{d R}{d V} \frac{d V}{d R_{1}}
$$


Again, by using the quotient rule for derivatives, it can be calculated that

$$
\frac{d V}{d R_{1}}=\frac{-R \cdot V_{c c}}{\left(R+R_{1}\right)^{2}}
$$

Therefore,

$$
\begin{gathered}
\left.\frac{d V}{d R_{1}}\right|_{T=25}=\frac{-R \cdot V_{c c}}{\left(R+R_{1}\right)^{2}}=\frac{-10000 \cdot 3.3}{(10000+9910)^{2}}=8.32 E-5 \frac{V}{\Omega} \\
\frac{d T}{d R_{1}}=\frac{d T}{d R} \frac{d R}{d V} \frac{d V}{d R_{1}}=(-0.00234) \cdot 12159 \cdot 0.0000832=-0.00237 \frac{{ }^{\circ} \mathrm{C}}{\Omega}
\end{gathered}
$$

For $\mathrm{T}=25^{\circ} \mathrm{C}$, a $1 \%$ accurate series resistance and a $1 \%$ accurate thermistor,

$$
\mathrm{dR}=\mathrm{dR}_{1}=0.01 \cdot 10000 \Omega=100 \Omega
$$

Finally, considering that the uncertainty for an $\mathrm{ADC}$ is \pm 1 scale unit (on 1023), the uncertainty dT can be calculated as:

$$
\begin{aligned}
& d T=\sqrt{\left[\frac{\partial T}{\partial A D C} \partial A D C\right]^{2}+\left[\frac{\partial T}{\partial R_{1}} \partial R_{1}\right]^{2}\left[\frac{\partial T}{\partial R} \partial R\right]^{2}} \\
& =\sqrt{(-0.09 \cdot 1)^{2}+(-0.00234 \cdot 100)^{2}+(-0.00234 \cdot 100)^{2}} \\
& =\sqrt{(-0.09)^{2}+(-0.234)^{2}+(-0.234)^{2}} \\
& =0.342 \\
& \mathbf{d T}=\mathbf{0 . 3 4}^{\circ} \mathbf{C}
\end{aligned}
$$

Table 1 Temperature measurement accuracy

\begin{tabular}{|c|c|c|c|c|}
\hline & $\mathrm{dT}_{\mathrm{ADC}}$ & $\mathrm{dT}_{\mathrm{R} 1}$ & $\mathrm{dT}_{\mathrm{R}}$ & $\mathrm{dT}$ \\
\hline $0^{\circ} \mathrm{C}$ & \pm 0.11 & \pm 0.20 & \pm 0.20 & \pm 0.30 \\
\hline $25^{\circ} \mathrm{C}$ & \pm 0.09 & \pm 0.23 & \pm 0.23 & \pm 0.34 \\
\hline $35^{\circ} \mathrm{C}$ & \pm 0.10 & \pm 0.25 & \pm 0.25 & \pm 0.37 \\
\hline $50^{\circ} \mathrm{C}$ & \pm 0.14 & \pm 0.27 & \pm 0.27 & \pm 0.41 \\
\hline
\end{tabular}

In conclusion, temperature measurement uncertainty in the range 0 to $50^{\circ} \mathrm{C}$ is $0.4^{\circ} \mathrm{C}$. 



\section{APPENDIX V}

\section{EXPERIMENTAL APPARATUS ARDUINO CODE}

/* Arduino Code for project PoulETS

Written by Frédéric Coulombe, 2018-07-04, filename 'Arduino_Global_8_propre.ino'

This code provides measurements for the following sensors:

- 4X YOUNG 85000 Ultrasonic anemometer (2D velocity measurement)

- 8X ANALOG TECHNOLOGIES ATH10K1R25 thermistor (temperature measurement)

- 2X AOSONG DHT22 sensor (polymer capacitor) (humidity sensor)

- 1X SANDBOX ELECTRONICS CO2 MHZ16 sensor 10,000 ppm (CO2 sensor)

Sketch uses 10580 bytes (34\%) of program storage space. Maximum is 30720 bytes.

Global variables use 435 bytes (21\%) of dynamic memory, leaving 1613 bytes for local variables. Maximum is 2048 bytes.

$* /$

\section{//////// DECLARATIONS $\quad / / / / / / / /$}

// initial declaration of variables and libraries

\#include $<$ math.h $>/ /$ library allows math functions such as isnan

\#include $<$ SoftwareSerial.h $>/ /$ library allows use of virtual series ports

// Not all pins on the Mega and Mega 2560 support change interrupts, so only the following can be used for RX: 10, 11, 12, 13, 14, 15, 50, 51, 52, 53, A8(62), A9(63), A10(64),

A11(65), A12(66), A13(67), A14(68), A15(69).

// Format: mySerial (Rx,Tx)

const int $\mathrm{CO} 2 \mathrm{Rx}=14$;

const int $\mathrm{CO} 2 \mathrm{Tx}=15$;

const int $\mathrm{CO} 2 \mathrm{TR}=2$; //Pin that controls transistor that periodically cuts power to $\mathrm{CO} 2$ sensor

const int $\mathrm{ANRx}=50$;

const int $\mathrm{ANTx}=52$;

SoftwareSerial mySerial1(ANRx,ANTx); //Anemometers

SoftwareSerial mySerial2(67,68); //CO2 sensor $67=\mathrm{A} 13,68=\mathrm{A} 14$

\#include $<$ avr/pgmspace.h $>/ /$ library pgmspace allows writing data tables to flash memory //\#define sigg 0 // Analog signals from all thermistors are multiplexed to Pin 0

\#define S0 13 // Digital Pin 13 // Multiplexer \#1 is controlled by 4 I/O pins

\#define S1 12 // Digital Pin 12

\#define S2 $11 / /$ Digital Pin 11

\#define S3 10 // Digital Pin 10 
\#define setRxA 53 //Define 3 canals that controls the multiplexer for the Rx signals of the anemometers ( $\mathrm{Rx}$ : signal from anemometer to Arduino)

\#define setRxB 51

\#define setRxC 49

\#define setTxA 44

\#define setTxB 42

\#define setTxC 40

// ADC/temperature conversion table is written once at startup in the flash memory (table takes into account the multiplexer resistance) (Data is stored in tenths of Celcius) const int temps[] PROGMEM = $(0,0,0,0,0,0,0,0,0,2484,2298,2163,2058,1973,1902,1841,1788,1740,1698,1660,1625,1593,15$ $64,1536,1511,1496,1474,1452,1432,1413,1395,1377,1361,1345,1330,1316,1302,1288,1275$, $1263,1251,1239,1228,1217,1206,1196,1186,1177,1167,1158,1149,1141,1132,1124,1116,110$ $8,1100,1089,1084,1078,1071,1065,1058,1051,1045,1038,1032,1026,1020,1013,1007,1001,9$ $96,991,986,980,975,970,965,960,955,950,945,941,936,931,927,922,918,914,909,905,901,89$ $7,893,889,885,881,877,873,869,866,862,858,855,851,847,844,840,837,834,830,827,824,820$, $817,814,811,808,804,801,798,795,792,789,786,783,780,778,775,772,769,766,764,761,758,7$ $56,753,750,748,745,742,740,737,735,732,730,727,725,722,720,718,715,713,710,708,706,70$ $4,701,699,697,694,692,690,688,686,683,681,679,677,675,673,671,669,667,665,662,660,658$, $656,654,652,650,648,646,645,643,641,639,637,635,633,631,629,628,626,624,622,620,618,6$ $17,615,613,611,609,608,606,604,603,601,599,597,596,594,592,591,589,587,586,584,582,58$ $1,579,577,576,574,573,571,569,568,566,565,563,562,560,559,557,555,554,552,551,549,548$, $546,545,543,542,540,539,538,536,535,533,532,530,529,527,526,525,523,522,520,519,518,5$ $16,515,514,512,511,509,508,507,505,504,503,501,500,499,497,496,495,493,492,491,489,48$ $8,487,486,484,483,482,480,479,478,477,475,474,473,472,470,469,468,467,466,464,463,462$, $461,459,458,457,456,455,453,452,451,450,449,447,446,445,444,443,441,440,439,438,437,4$ $36,434,433,432,431,430,429,428,426,425,424,423,422,421,420,419,417,416,415,414,413,41$ $2,411,410,409,407,406,405,404,403,402,401,400,399,398,397,396,395,393,392,391,390,389$, $388,387,386,385,384,383,382,381,380,379,378,377,376,375,373,372,371,370,369,368,367,3$ $66,365,364,363,362,361,360,359,358,357,356,355,354,353,352,351,350,349,348,347,346,34$ $5,344,343,342,341,340,339,338,337,336,335,334,333,332,331,330,329,329,328,327,326,325$, $324,323,322,321,320,319,318,317,316,315,314,313,312,311,310,309,308,308,307,306,305,3$ $04,303,302,301,300,299,298,297,296,295,294,293,293,292,291,290,289,288,287,286,285,28$ $4,283,282,281,281,280,279,278,277,276,275,274,273,272,271,270,270,269,268,267,266,265$, $264,263,262,261,260,260,259,258,257,256,255,254,253,252,251,251,250,249,248,247,246,2$ $45,244,243,243,242,241,240,239,238,237,236,235,235,234,233,232,231,230,229,228,227,22$ $6,226,225,224,223,222,221,220,219,218,218,217,216,215,214,213,212,211,211,210,209,208$, $207,206,205,204,203,203,202,201,200,199,198,197,196,196,195,194,193,192,191,190,189,1$ $88,188,187,186,185,184,183,182,181,181,180,179,178,177,176,175,174,174,173,172,171,17$ $0,169,168,167,166,166,165,164,163,162,161,160,159,158,158,157,156,155,154,153,152,151$, $150,150,149,148,147,146,145,144,143,142,142,141,140,139,138,137,136,135,134,134,133,1$ $32,131,130,129,128,127,126,125,125,124,123,122,121,120,119,118,117,116,116,115,114,11$ $3,112,111,110,109,108,107,106,106,105,104,103,102,101,100,99,98,97,96,95,94,94,93,92,91$ 
,90,89,88,87,86,85,84,83,82,81,80,79,78,78,77,76,75,74,73,72,71,70,69,68,67,66,65,64,63,62 ,61,60,59,59,58,57,56,55,54,53,52,51,50,49,48,47,46,45,44,43,42,41,40,39,38,37,36,35,34,33 ,32,31,30,29,28,27,26,25,24,23,22,21,20,19,18,17,16,15,13,12,11,10,9,8,7,6,5,4,3,2,1,0,-1,$3,-4,-5,-6,-7,-8,-9,-10,-11,-13,-14,-15,-16,-17,-18,-19,-20,-21,-22,-23,-25,-26,-27,-28,-29,-$ $30,-31,-33,-34,-35,-36,-37,-38,-40,-41,-42,-43,-44,-46,-47,-48,-49,-50,-52,-53,-54,-55,-56,-$ $58,-59,-60,-61,-63,-64,-65,-66,-68,-69,-70,-72,-73,-74,-75,-77,-78,-79,-81,-82,-83,-85,-86,-$ $87,-89,-90,-91,-93,-94,-96,-97,-98,-100,-101,-102,-104,-105,-107,-108,-110,-111,-112,-114,-$ $115,-117,-118,-120,-121,-123,-124,-126,-127,-129,-131,-132,-134,-135,-137,-138,-140,-141,-$ $143,-145,-146,-148,-150,-151,-153,-155,-156,-158,-160,-161,-163,-165,-167,-168,-170,-172,-$ $174,-176,-177,-179,-181,-183,-185,-187,-189,-191,-193,-194,-196,-198,-200,-202,-204,-206,-$ $209,-211,-213,-215,-217,-219,-221,-224,-226,-228,-230,-233,-235,-237,-240,-242,-244,-247,-$ $249,-252,-254,-257,-259,-262,-265,-267,-270,-273,-275,-278,-281,-284,-287,-290,-293,-296,-$ $299,-302,-305,-309,-312,-315,-319,-322,-326,-329,-333,-337,-341,-344,-348,-352,-357,-361,-$ $365,-370,-374,-379,-384,-388,-393,0,0,0,0,0,0,0,0,0,0,0,0,0,0,0,0,0,0,0,0,0,0,0,0,0,0,0,0,0,0)$;

\#include "DHT.h" //library for the humidity sensor DHT (provided by Arduino website) \#define DHTTYPE DHT22 // Selecting model 22 in the DHT library (AM2302 package contains a DHT22 sensor)

\#define DHTPIN $0 / /$ pin for the sensor

DHT dht(DHTPIN, DHTTYPE); //sensor initialization

\#include $<$ NDIRZ16.h $>$ //library for the $\mathrm{CO} 2$ sensor NDIRZ16 mySensor $=$ NDIRZ16(\&mySerial2); unsigned long previousMillis $=0$; // last time update long intervalReset $=43200000$; // interval time at which the sensor is reset $(43200000 \mathrm{~ms}=$ $12 \mathrm{~h})$

int iterations $=0 ; / /$ cycling initialization (count the number of measurements that were done)

\section{//I/I/// FUNCTIONS DECLARATIONS $/ / / / / / / /$}

// FONCTION: setMultiplexer_1 (thermistors)

// INPUT: mux channel as an integer, 0 - 15

// RETURN: none

int setMultiplexer_1(int channel)

\{

// use the first four bits of the channel number to set the channel select pins

digitalWrite(S0, bitRead(channel, 0));

digitalWrite(S1, bitRead(channel, 1));

digitalWrite(S2, bitRead(channel, 2));

digitalWrite(S3, bitRead(channel, 3));

\}

// FONCTION: setMultiplexer_Rx (anemometres_Rx)

// INPUT: mux channel as an integer, 0 - 15 


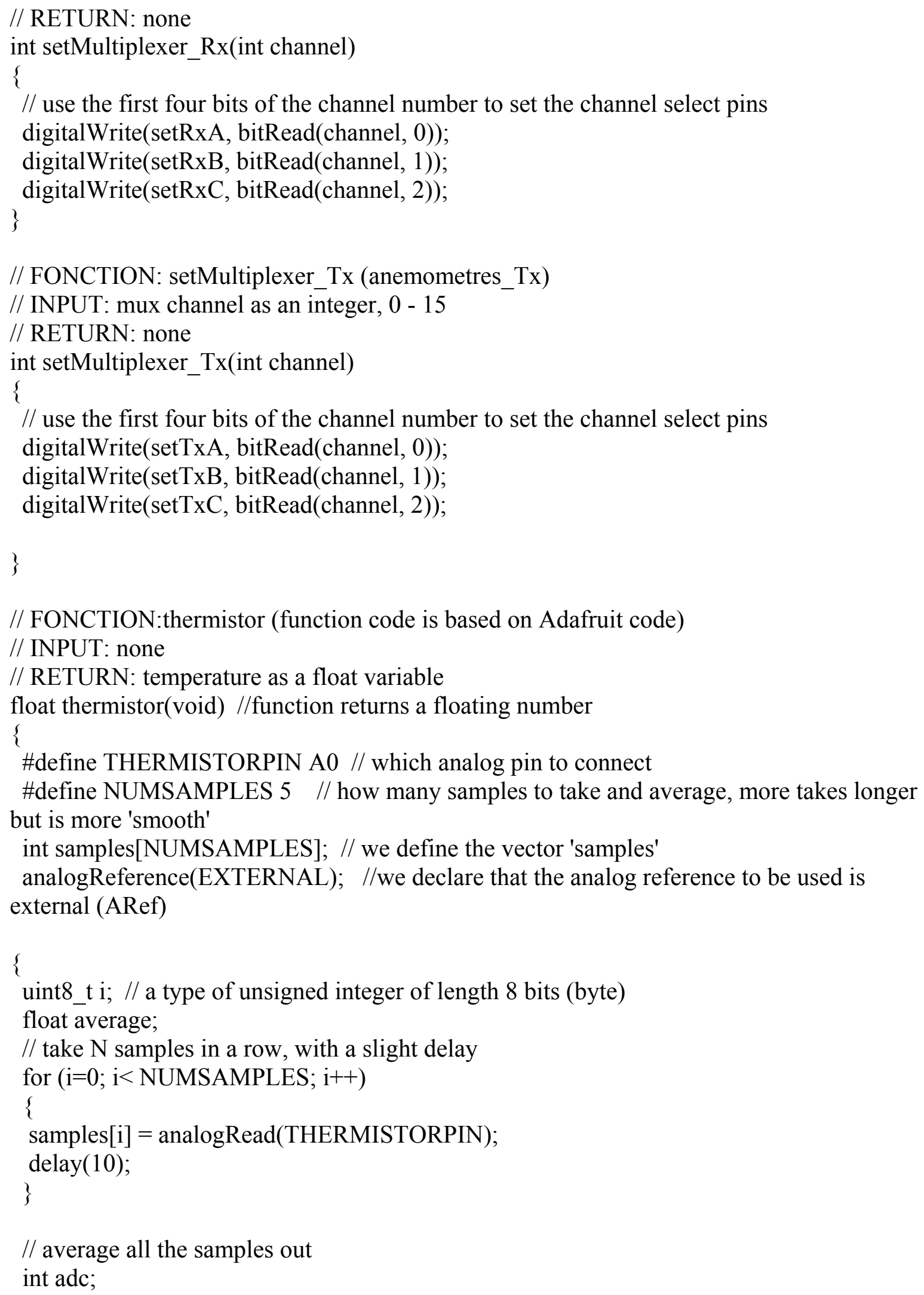


float temperature;

$\operatorname{adc}=0$

for $(\mathrm{i}=0 ; \mathrm{i}<$ NUMSAMPLES; $\mathrm{i}++)$

\{

adc $+=$ samples[i];

\}

adc /= NUMSAMPLES;

temperature=pgm_read_word(\&temps[adc]); //pgm_read_word looks into table "temps" at which temperature corresponds this "adc" value

temperature $=$ temperature $/ 10.0$; //convert tenths of celcius back into celcius

return temperature;

\}

\}

//////// SETUP ////////

//setup is run only once at Arduino startup

void $\operatorname{setup}()$

\{

Serial.begin(9600); // data is visualized through serial monitor at 9600 baud rate

mySeriall.begin(9600); //Anemometers data is transmitted through the virtual series port at 9600 baud rate

mySerial2.begin(9600); // CO2 sensor

//Serial.println("Startup");

pinMode(S0, OUTPUT); // Configure pins dedicated to thermistor multiplexor to 'output' mode (default mode is 'input')

pinMode(S1, OUTPUT);

pinMode(S2, OUTPUT);

pinMode(S3, OUTPUT);

pinMode(setRxA, OUTPUT);

pinMode(setRxB, OUTPUT);

pinMode(setRxC, OUTPUT);

pinMode(setTxA, OUTPUT);

pinMode(setTxB, OUTPUT);

pinMode( $\operatorname{set}$ TxC, OUTPUT);

dht.begin(); //humidity sensor startup

pinMode(CO2TR, OUTPUT);

digitalWrite(CO2TR, HIGH); // transistor that supplies $\mathrm{CO} 2$ sensor is $\mathrm{ON}$ by default 


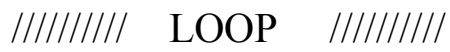

// loop runs as long as Arduino is on

void loop() \{

\section{//OVERALL MEASUREMENT CYCLE CONTROL}

// control measurement frequency with millis() function

long interval $=5000 ; / /$ interval at which to do something (milliseconds)

unsigned long currentMillis $=$ millis () ;

if(currentMillis - previousMillis $>=$ interval $)\{$

previousMillis $=$ currentMillis;

iterations $=$ iterations +1 ;

Serial.print("\# ");

delay (2000);

Serial.print(iterations);

Serial.print(" ");

\section{/// ANEMOMETERS //}

mySerial1.listen(); // selecting serial port to listen delay(1000);

for (int $\mathrm{i}=1 ; \mathrm{i}<=4 ; \mathrm{i}++) / / /$ "for loop" for all anemometers

\{

//Serial.print("ANEMOMETER ");

Serial.print(i);

Serial.print(" ");

//set the multiplexer to channel i (anemometer i)

setMultiplexer_Rx(i);

// sending polling command. the polling command is 'Ma!' where 'a' is the sensor adress.

The default adress is ' 0 ' for all anemometers in the present case.

// anemometer incoming data format: $<<$ uu.uu vv.vv ss*cc $>>$ setMultiplexer_Tx(i);

delay (500);

char sig1[ ] = \{"M0!" $\}$; // definition of signal to be sent to sensor

mySeriall.write(sig1); //arduino asks the aneometer for a velocity reading (polling mode)

delay(1000); //give reaction time to anemometer

while (mySerial1.available ()$>0)$ 
// look for the next valid integer in the incoming serial stream:

char data $=$ mySeriall $\cdot \operatorname{read}()$;

String str $=$ String(data); //convert data into string

str.replace('ไr',' '); //substitute "carriage return" by a space

Serial.print(str);

\}

$$
\text { \} }
$$

setMultiplexer_Rx(8);

setMultiplexer_Tx(8);

/// THERMISTORS ///

//Serial.print("THERMISTORS");

//Serial.print(" "); // TAB

for(int $\mathrm{i}=1 ; \mathrm{i}<=8 ; \mathrm{i}++) \quad / /$ for loop to cycle through all used multiplexer channels, $1-8$

\{

setMultiplexer_1(i); //set the multiplexer to channel i

float $\operatorname{sigValue}=$ thermistor(); //read value and convert to $\mathrm{C}$

Serial.print(sigValue,1); //prints only 1 decimal

Serial.print(" "); // TAB

\}

setMultiplexer_1(15); //set multiplexer to empty channel to avoid self-heating effect of the last thermistor called while waiting for next reading

//Serial.println(); // NEW LINE

\section{/// HUMIDITY SENSORS///}

//Serial.print("HUMIDITE ");

for(int $\mathrm{i}=3 ; \mathrm{i}<=4 ; \mathrm{i}++) / / \mathrm{i}$ represents $\mathrm{I} / \mathrm{O}$ canal \#

\{

DHT dht(i,DHTTYPE); //DHT dht(DHTPIN, DHTTYPE);

float $\mathrm{h}=$ dht.readHumidity () ;

// Read temperature as Celsius (the default)

float $\mathrm{t}=$ dht.readTemperature () ;

int test $\mathrm{H}=\mathrm{isnan}(\mathrm{h})$;

if $($ test $\mathrm{H}=1)\{$

$\mathrm{h}=100 ; \mathrm{t}=100 ;$ //avoid printing 'nan'

\}

//Serial.print(i);

Serial.print(" ");

Serial.print(h,1); //prints only first decimal

Serial.print(" "); // TAB

Serial.print(t,1); //prints only first decimal

//Serial.print(" C\t"); 


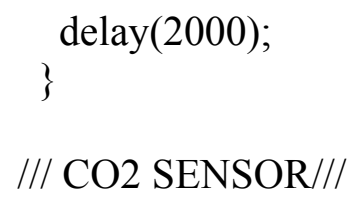




\section{REFERENCES}

AAFC. (2017). Canada's chicken industry - Agriculture and Agri-Food Canada (AAFC). Repéré le 2017-11-23 à http://www.agr.gc.ca/eng/industry-markets-and-trade/marketinformation-by-sector/poultry-and-eggs/poultry-and-egg-marketinformation/chicken/?id=1384971854392

Almuhanna, E., Ahmed, A., \& Al-Yousif, Y. (2011). Effect of air contaminants on poultry immunological and production performance. Int. J. Poult. Sci, 10(6), 461-470.

ANSYS. (2014a). ANSYS Fluent Theory Guide. 814.

ANSYS. (2014b). Ansys Fluent User's Guide.

ASHRAE. (2010). Standard 55-2010:"Thermal Environmental Conditions for Human Occupancy"; ASHRAE. Atlanta USA.

Baer, P., \& Mastrandrea, M. (2006). High stakes-designing emissions pathways to reduce the risk of dangerous climate change.

Bellache, O., Ouzzane, M., \& Galanis, N. (2005). Numerical prediction of ventilation patterns and thermal processes in ice rinks. Building and Environment, 40(3), 417426. doi: http://dx.doi.org/10.1016/j.buildenv.2004.08.004. Repéré à http://www.sciencedirect.com/science/article/pii/S0360132304002094

Bjerg, B., Svidt, K., Zhang, G., Morsing, S., \& Johnsen, J. O. (2002). Modeling of air inlets in CFD prediction of airflow in ventilated animal houses. Computers and Electronics in Agriculture, 34(1), 223-235.

Blanes-Vidal, V., Guijarro, E., Balasch, S., \& Torres, A. G. (2008). Application of computational fluid dynamics to the prediction of airflow in a mechanically ventilated commercial poultry building. Biosystems engineering, 100(1), 105-116. doi: http://dx.doi.org/10.1016/j.biosystemseng.2008.02.004. Repéré à http://www.sciencedirect.com/science/article/pii/S153751100800055X

Bokkers, E. A. M., van Zanten, H. H. E., \& van den Brand, H. (2010). Field study on effects of a heat exchanger on broiler performance, energy use, and calculated carbon dioxide emission at commercial broiler farms, and the experiences of farmers using a heat exchanger. Poultry Science, 89(12), 2743-2750. doi: 10.3382/ps.2010-00902. Repéré à http://dx.doi.org/10.3382/ps.2010-00902

Bustamante, E., García-Diego, F.-J., Calvet, S., Estellés, F., Beltrán, P., Hospitaler, A., \& Torres, G. A. (2013). Exploring Ventilation Efficiency in Poultry Buildings: The 
Validation of Computational Fluid Dynamics (CFD) in a Cross-Mechanically Ventilated Broiler Farm. Energies, 6(5). doi: 10.3390/en6052605

Bustamante, E., García-Diego, F.-J., Calvet, S., Torres, A. G., \& Hospitaler, A. (2015). Measurement and numerical simulation of air velocity in a tunnel-ventilated broiler house. Sustainability, 7(2), 2066-2085.

Campbell, J., Donald, J., Simpson, G., \& Macklin, K. (2008). Get ready for winter! The FiveStep Program. The Poultry Engineering, Economics and Management Newsletter, (55), 4.

Çengel, Y. A. (2007). Heat \& Mass Transfer: A Practical Approach. McGraw-Hill Education (India) Pvt Limited. à https://books.google.ca/books?id=nuQ7F81pBFAC

Coulombe, F., 2018. Design of a radiant sensor for broiler houses.

Council, C. A.-F. R. (2016). Recommended Code of Practice for the care and handling of farm animals. Chickens, Turkeys and Breeders from Hatchery to Processing.

Plant.

Dawkins, M. S., Donnelly, C. A., \& Jones, T. A. (2004). Chicken welfare is influenced more by housing conditions than by stocking density. Nature, 427(6972), 342.

de Vries, M., \& de Boer, I. J. M. (2010). Comparing environmental impacts for livestock products: A review of life cycle assessments. Livestock Science, 128(1), 1-11. doi: 10.1016/j.livsci.2009.11.007. Repéré à http://dx.doi.org/10.1016/j.livsci.2009.11.007

Donald, J. (2003). Principles of successful wintertime broiler house ventilation: Aviatech.

Dozier, W., \& Donald, J. (2001). Keys to successful brooding. Auburn: Auburn University/Poultry Engineering and Economics Department, 42.

EIA, U. S. (2017). Weekly Heating Oil and Propane Prices. Repéré à https://www.eia.gov/dnav/pet/pet_pri_wfr_a_EPLLPA_PRS_dpgal_w.htm

ESA. (2018a). Énergie Solutions Air. Repéré le 2018-04-27 à http://www.esair.ca/

ESA. (2018b). Smoke tests in a broiler house, ESA Internal Report.

Gouvernement du Québec. (2015). Inventaire québécois des émissions de gaz à effet de serre en 2012 et leur évolution depuis 1990. 
Government of Canada. (2017). Canadian Environmental Sustainability Indicators: Greenhouse Gas Emissions. Repéré à www.ec.gc.ca/indicateursindicators/default.asp?lang=En\&n=FBF8455E-1

Guerra-Galdo, E. H., Sanz, S. C., Barber, F. E., \& López-Jiménez, P. A. (2015). CFD model for ventilation assessment in poultry houses with different distribution of windows. International Journal of Energy and Environment, 6(5), 411.

Han, H., Kim, K., Jang, K.-J., Han, G.-S., \& Lee, I.-B. (2013). Energy Consumption and Indoor Environment of Broiler Houses with Energy Recovery Ventilators. Applied Engineering in Agriculture, 29(5), 751-759.

Henchion, M., McCarthy, M., Resconi, V. C., \& Troy, D. (2014). Meat consumption: Trends and quality matters. Meat Science, 98(3), 561-568. doi: http://dx.doi.org/10.1016/j.meatsci.2014.06.007. Repéré http://www.sciencedirect.com/science/article/pii/S0309174014001752

IEA. (2014). Key world energy statistics. Paris. International Energy Agency.

Kuznik, F., Rusaouën, G., \& Brau, J. (2007). Experimental and numerical study of a full scale ventilated enclosure: Comparison of four two equations closure turbulence models. Building and Environment, 42(3), 1043-1053. doi: http://dx.doi.org/10.1016/j.buildenv.2005.11.024. Repéré à http://www.sciencedirect.com/science/article/pii/S0360132305004841

Lee, I.-B., Sase, S., \& Sung, S.-H. (2007). Evaluation of CFD Accuracy for the Ventilation Study of a Naturally Ventilated Broiler House. Japan Agricultural Research Quarterly: JARQ, 41(1), 53-64. doi: 10.6090/jarq.41.53

Li, X., Li, D., Yang, X., \& Yang, J. (2003). Total air age: an extension of the air age concept. Building and Environment, 38(11), 1263-1269.

Limane, A., Fellouah, H., \& Galanis, N. (2015). Thermo-ventilation study by OpenFOAM of the airflow in a cavity with heated floor. Dans Building Simulation (Vol. 8, pp. 271283). Springer.

MacLeod, M., Gerber, P., Mottet, A., Tempio, G., Falcucci, A., Opio, C., . . . Steinfeld, H. (2013). Greenhouse gas emissions from pig and chicken supply chains-A global life cycle assessment. Food and Agriculture Organization of the United Nations (FAO), Rome.

Maric, T. (2014). The OpenFOAM Technology Primer.

Mohammadi, B., \& Pironneau, O. (1993). Analysis of the k-epsilon turbulence model. 
Mostafa, E., Lee, I.-B., Song, S.-H., Kwon, K.-S., Seo, I.-H., Hong, S.-W., . . . Han, H.-T. (2012). Computational fluid dynamics simulation of air temperature distribution inside broiler building fitted with duct ventilation system. Biosystems engineering, 112(4), 293-303. doi: http://dx.doi.org/10.1016/j.biosystemseng.2012.05.001. Repéré à http://www.sciencedirect.com/science/article/pii/S1537511012000797

National Instruments. (2017). Performing High-Accuracy Temperature Measurements Using a NI Digital Multimeter and Switch. Repéré le 2018-05-05 à http://www.ni.com/tutorial/3778/en/

NFACC. (2013). Code of practice for the care and handling of chickens, turkeys and breeders: review of scientific research on priority issues.

NFACC. (2016). Code of practice for the care and handling of hatching eggs, breeders, chickens, and turkeys. Repéré à http://www.nfacc.ca/pdfs/codes/poultry_code_EN.pdf

Nguyen, T. T. H., Bouvarel, I., Ponchant, P., \& van der Werf, H. M. (2012). Using environmental constraints to formulate low-impact poultry feeds. Journal of cleaner production, 28, 215-224.

Nielsen, P. V. (1976). Flow in air conditioned rooms.

NOAA. (2017). State of the Climate: Global Climate Report for Annual 2016. Repéré à https://www.ncdc.noaa.gov/sotc/global/201613

OpenFOAM. (2015). OpenFOAM User Guide 3.0.1.

Palmer, C. (2011). The demand for meat and patterns of consumption: An introductory guide. Nutrition and Climate Change: Major Issues Confronting the Meat Industry, $13,139$.

Patankar, S. (1980). Numerical heat transfer and fluid flow. CRC press.

Patankar, S. V. (1980). Numerical heat transfer and fluid flow. Taylor \& Francis.

Poultry Site. (2005). Basic Introduction to Broiler Housing Environmental Control. Repéré le 2018-06-26 à http://www.thepoultrysite.com/articles/386/basic-introduction-tobroiler-housing-environmental-control/

PoultryWateringU. (2018). How and why to manage your litter conditions very carefully. Repéré le 2018-06-13 à https://poultrywateringu.com/how-why-manage-litterconditions-carefully/ 
Purswell, J., Davis, J., Luck, B., Kim, E., Olanrewaju, H., Kiess, A., \& Branton, S. (2011). Effects of elevated carbon dioxide concentrations on broiler chicken performance from 28 to 49 days. International Journal of Poultry Science, 10(8), 597-602.

Reece, F., \& Lott, B. (1980). Effect of carbon dioxide on broiler chicken performance. Poultry science, 59(11), 2400-2402.

Rojano, F., Bournet, P.-E., Hassouna, M., Robin, P., Kacira, M., \& Choi, C. Y. (2015). Modelling heat and mass transfer of a broiler house using computational fluid dynamics. Biosystems engineering, 136, 25-38.

Ross. (2010). Environmental Management in the Broiler House. 48.

Seo, I.-h., Lee, I.-b., Moon, O.-k., Hong, S.-w., Hwang, H.-s., Bitog, J. P., . . L Lee, J.-w. (2012). Modelling of internal environmental conditions in a full-scale commercial pig house containing animals. Biosystems engineering, 111(1), 91-106. doi: http://dx.doi.org/10.1016/j.biosystemseng.2011.10.012. Repéré à http://www.sciencedirect.com/science/article/pii/S1537511011001966

Seo, I. H., Lee, I. B., Moon, O. K., Kim, H. T., Hwang, H. S., Hong, S. W., . . Han, J. W. (2009). Improvement of the ventilation system of a naturally ventilated broiler house in the cold season using computational simulations. Biosystems engineering, 104(1), 106-117. doi: http://dx.doi.org/10.1016/j.biosystemseng.2009.05.007. Repéré à http://www.sciencedirect.com/science/article/pii/S1537511009001561

Smith, R. J. (2017). Test and Calibrate DHT22 Hygrometers. Repéré le 2017-05-05 à https://www.kandrsmith.org/RJS/Misc/Hygrometers/calib_dht22.html

Tabler, G. T. (2003). Brooding Chicks and Poults: Environmental Critical Control Points. Avian Advice, 5(1), 5.

Tabler, T., Wells, J. B., \& Zhai, W. (2012). Broiler house ventilation during cold weather. Mississippi State University Extension Service.

UKAG. (2009). Poultry Production Manual of the University of Arkansas, chapter 8. Repéré à http://www2.ca.uky.edu/poultryprofitability/production_manual.html

Versteeg, H. (1995). W., Malalasekera. An Introduction to Computational Fluid Dynamics: The Finite Volume Method Approach.

Wellesley, L., Happer, C., \& Froggatt, A. (2015). Changing Climate, Changing Diets: Pathways to Lower Meat Consumption.

Wheeler, E. F., Casey, K. D., Zajaczkowski, J., Topper, P. A., Gates, R. S., Xin, H., . . . Tanaka, A. (2003). Ammonia emissions from US poultry houses: part III-broiler 
houses. Dans Air Pollution from Agricultural Operations-III (pp. 159). American Society of Agricultural and Biological Engineers.

World Resources Institute. (2015). CAIT Climate Data Explorer (n 2018-05-10). Repéré à http://cait.wri.org

Yakhot, V., Orszag, S., Thangam, S., Gatski, T., \& Speziale, C. (1992). Development of turbulence models for shear flows by a double expansion technique. Physics of Fluids A: Fluid Dynamics, 4(7), 1510-1520. 